Pontifícia Universidade Católica $_{\text {mand }}$

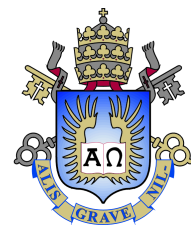

Bruno Vinícius Sanches Perdigão

\title{
Essays on Monetary Economics and Banking
}

\section{Tese de Doutorado}

Thesis presented to the Programa de Pós-graduação em Economia of PUC-Rio in partial fulfillment of the requirements for the degree of Doutor em Economia.

Advisor: Prof. Carlos Viana de Carvalho 


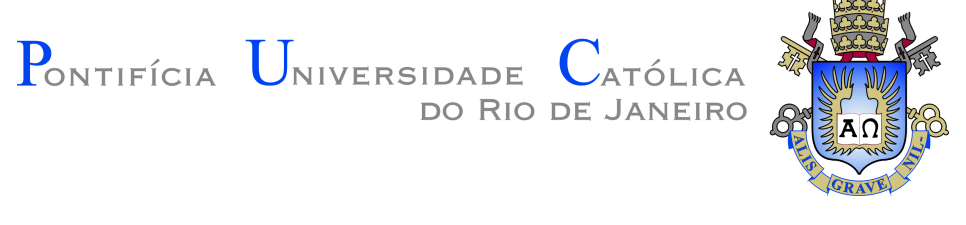

\section{Bruno Vinícius Sanches Perdigão}

\section{Essays on Monetary Economics and Banking}

Thesis presented to the Programa de Pós-graduação em Economia of PUC-Rio in partial fulfillment of the requirements for the degree of Doutor em Economia. Approved by the undersigned Examination Committee.

Prof. Carlos Viana de Carvalho

Advisor

Departamento de Economia - PUC-Rio

Prof. Marcelo Medeiros

Departamento de Economia - PUC-Rio

Prof. Diogo Guillen

Departamento de Economia - PUC-Rio

Prof. Marco Bonomo

Instituto de Ensino e Pesquisa - Insper

Prof. João Manoel Pinho de Mello

Instituto de Ensino e Pesquisa - Insper

Prof. Augusto Cesar Pinheiro da Silva

Vice Dean of the Centro de Ciências Sociais - PUC-Rio

Rio de Janeiro, July the 27th, 2018 
All rights reserved.

\section{Bruno Vinícius Sanches Perdigão}

Majored in Public Administration by the Escola de Governo Paulo Neves de Carvalho - Fundação João Pinheiro, majored in Economics by Universidade Federal de Minas Gerais, now holds a PhD degree in Economics from PUC-Rio.

Bibliographic data

Sanches Perdigão, Bruno Vinícius

Essays on Monetary Economics and Banking / Bruno Vinícius Sanches Perdigão; advisor: Carlos Viana de Carvalho. - Rio de janeiro: PUC-Rio, Departamento de Economia, 2018.

v., 120 f: il. color. ; $30 \mathrm{~cm}$

Tese (doutorado) - Pontifícia Universidade Católica do Rio de Janeiro, Departamento de Economia.

Inclui bibliografia

1. Economia - Teses. 2. Crédito subsidiado;. 3. Política monetária;. 4. Mecanismos de transmissão;. 5. Choque monetário;. 6. Identificação;. 7. SVAR;. 8. Restrições de sinal;. 9. Bancos estrangeiros;. 10. Empréstimos bancários;. 11. Firmas pequenas e médias.. I. Viana de Carvalho, Carlos. II. Pontifícia Universidade Católica do Rio de Janeiro. Departamento de Economia. III. Título. 


\section{Acknowledgments}

To my advisor Carlos, for stimulating me and being my partner in this work.

To my family that, unconditionally, always supported me.

To the Central Bank of Brazil, for allowing my enrollment in the $\mathrm{PhD}$ through the post graduation program.

To my fiance and future wife, for being my friend at all times.

To my colleagues at PUC-Rio. To the the professors that participated in the examination committee.

To all professors and employees in the Economics Department at PUC-Rio, my deeply gratitude for the lessons learned and the time spent in this special place. 


\section{Abstract}

Sanches Perdigão, Bruno Vinícius; Viana de Carvalho, Carlos (Advisor). Essays on Monetary Economics and Banking. Rio de Janeiro, 2018. 120p. Tese de doutorado - Departamento de Economia, Pontifícia Universidade Católica do Rio de Janeiro.

This thesis is composed of three papers. The first one studies the relation between monetary policy power and the availability of earmarked loans. To that end, we estimate the responses of sectoral macroeconomic variables to monetary policy shocks identified through sign and equality restrictions in a factor-augmented VAR (FAVAR). We find that monetary policy loses power in sectors with a larger share of earmarked loans among its bank debt. The second paper proposes the introduction of new restrictions to identify monetary policy shocks in SVARs. In particular, besides standard sign restrictions on interest rates and inflation, we propose to add as an identification restriction the inability of monetary policy to have real effects ten years after the shock. This paper presents evidence of the model consistency of this neutrality restriction both for the canonical 3equation new keynesian model and the Smets and Wouters (2007) model. In a simple empirical application, this paper shows that this restriction may be important to recover real effects of monetary policy. The third paper shows that foreign banks can mitigate informational barriers vis-a-vis private domestic banks by observing their peers' behavior. Conditional on a loan application being filed by a SME firm, we find that the existence of past loans of this firm with private domestic banks constitute a more important predictor that a loan will be granted by foreign banks in comparison to private domestic banks. Our results are compatible with the view that the higher ability of private domestic banks to access informationally opaque business credit risks makes past loans with these banks a more valuable signal for foreign lenders.

\section{Keywords}

Subsidized credit; Monetary policy; Transmission mechanisms; Monetary shock; Identification; SVAR; Sign restrictions; Foreign banks; Information asymmetry; Bank loans; SME firms. 


\section{Resumo}

Sanches Perdigão, Bruno Vinícius; Viana de Carvalho, Carlos. Ensaios sobre Economia Monetária e Bancária. Rio de Janeiro, 2018. 120p. Tese de Doutorado - Departamento de Economia, Pontifícia Universidade Católica do Rio de Janeiro.

Essa tese é composta por 3 artigos. O primeiro estuda a relação entre política monetária e a disponibilidade de crédito direcionado. Com esse propósito, estimamos as respostas de variáveis macroeconômicas setoriais a choques de política monetária identificados com restrições de sinal e restrições de igualdade em um factor-augmented VAR (FAVAR). Nossos resultados mostram que a política monetária perde potência em setores com maior proporção de crédito direcionado. O segundo artigo propõe a introdução de novas restrições para identificação de choques de política monetária. Em particular, além das restrições de sinal usuais sobre taxas de juros e inflação, nós propomos como restrição de identificação que a política monetária não tenha efeitos reais dez anos após o choque. Esse artigo apresenta evidências de que essa restrição é consistente com o modelo novo-keynesiano canônico de 3 equações e com o modelo proposto por Smets and Wouters (2007). Em uma aplicação empírica simples, esse artigo mostra que essa restrição pode ser importante para recuperar efeitos reais de política monetária. O terceiro artigo mostra que bancos estrangeiros podem mitigar barreiras informacionais vis-à-vis bancos privados nacionais a partir da observação do comportamento de seus pares. Dado um pedido de empréstimo por parte de uma firma pequena ou média, a existência de empréstimos bancários passados desta firma com bancos privados nacionais constitui um preditor mais importante da probabilidade de que o empréstimo seja concedido para bancos estrangeiros, em comparação a bancos privados nacionais. Nossos resultados são compatíveis com a visão de que a maior habilidade de bancos privados nacionais em aferir o risco de crédito de firmas pouco transparentes torna os empréstimos anteriores com esses bancos um sinal mais valioso para bancos estrangeiros.

\section{Palavras-chave}

Crédito subsidiado; Política monetária; Mecanismos de transmissão; Choque monetário; Identificação; SVAR; Restrições de sinal; Bancos estrangeiros; Empréstimos bancários; Firmas pequenas e médias. 


\section{Table of contents}

1 Do earmarked loans affect the transmission of monetary policy? Sectoral evidence from Brazil $\quad 15$

$\begin{array}{ll}1.1 \text { Introduction } & 15\end{array}$

1.2 Related literature 20

1.3 Econometric framework: FAVAR, monetary shock identification and cross-section regressions 22

$\begin{array}{lll}\text { 1.3.1 FAVAR } & 22\end{array}$

1.3.2 Monetary shock identification 24

1.3.2.1 Identification problem and set identification 24

1.3.2.2 Giacomini \& Kitagawa (5) algorithm to compute IRF's identified set 26

$\begin{array}{ll}1.3 .3 \text { Cross-section regressions } & 27\end{array}$

$\begin{array}{lll}1.4 & \text { Data } & 28\end{array}$

$\begin{array}{lll}1.5 & \text { Results } & 30\end{array}$

1.5.1 Estimation setup 30

1.5.2 Sector effects of a contractionary monetary shock 31

1.5.3 Earmarked loan effects on monetary policy power 36

$\begin{array}{lll}1.6 & \text { Discussion } & 41\end{array}$

$\begin{array}{lll}1.7 & \text { Conclusion } & 42\end{array}$

2 "Still" an agnostic procedure to identify monetary policy shocks with sign restrictions 43

2.1 Introduction 43

2.2 Related literature 46

2.3 Overview of main identification issues with sign restrictions and importance of the 10-year monetary neutrality restrictions 48

2.3.1 Uhlig's "pure sign restriction" approach 48

2.3.2 Monetary neutrality restrictions in the medium-run 50

2.3.3 3-equation model example 52

2.4 Smets and Wouters (2007) model 54

$\begin{array}{lll}2.5 & \text { Empirical application } & 62\end{array}$

$\begin{array}{lll}2.6 \text { Conclusion } & 65\end{array}$

3 Do foreign banks overcome borrower informational asymmetries by relying on their peer's behavior? $\quad 66$

$\begin{array}{lll}3.1 & \text { Introduction } & 66\end{array}$

$\begin{array}{lll}3.2 \text { Data } & 70\end{array}$

3.2.1 Data description 70

3.2.2 Loan market share and firm size distribution by bank ownership 72

$\begin{array}{lll}3.3 & \text { Empirical strategy } & 76\end{array}$

$\begin{array}{lll}\text { 3.3.1 Econometric specification } & 76\end{array}$

$\begin{array}{ll}\text { 3.3.2 Identification concerns } & 80\end{array}$

$\begin{array}{lll}3.4 & \text { Results } & 81\end{array}$

3.4.1 Unidentified bank ownership of potential borrowers previous lenders 81

3.4.2 Identified bank ownership of potential borrowers previous lenders 84 
3.4.3 Heterogeneities in the signal given by loans with domestic banks 86

3.4.4 Possible complementarities among loan types 88

$\begin{array}{lll}3.5 & \text { Robustness } & 89\end{array}$

$\begin{array}{lll}3.6 & \text { Discussion } & 92\end{array}$

$\begin{array}{lll}3.7 & \text { Conclusion } & 93\end{array}$

$\begin{array}{lr}\text { Bibliography } & 94\end{array}$

$\begin{array}{lll}\text { A Appendix to Chapter } 1 & 102\end{array}$

$\begin{array}{lll}\text { A.1 } & \text { Figures } & 102\end{array}$

$\begin{array}{lll}\text { A.2 Control estimates in OLS regressions } & 104\end{array}$

$\begin{array}{lll}\text { A.3 Robust } \beta \text { estimates } & 108\end{array}$

B Appendix to Chapter 2 110

B.1 3-equation model 110

B.2 Smets and Wouters (2007) model 111

B.3 Empirical application with US data 113

C Appendix to Chapter 3 $\quad 115$

$\begin{array}{ll}\text { C.1 Placebo regressions } & 115\end{array}$

C.2 Investigating the importance of loan type complementarities with $\begin{array}{ll}\text { simulated data } & 117\end{array}$ 


\section{List of figures}

Figure 1.1 Credit expansion in Brazil between 2004M04 and 2017M04. Credit to GDP ratio (black line) and earmarked credit to total credit ratio (red line). The vertical dashed line indicate the month of Lehman Brothers bankruptcy, what marks the worsening of the financial crisis effects in Brazil.

Figure 1.2 Evolution of average annualized earmarked, market and policy rates (Selic). Loan rates are restricted to corporations. Correlation between earmarked rate and policy rate $=0.55$. Correlation between policy rate and market rates $=0.96$.

Figure 1.3 Posterior mean bounds interval (black lines) and 68\% credibility region (blue shaded region) for real rate responses after a 50bps contractionary monetary shock. Real rates are defined according to a consumer price index (left panel) and a producer price index (right panel). Values are in percent and defined on level variables.

Figure 1.4 Sector scatter plots of the mean of the posterior mean bounds intervals for 2, 4, 6 and 8 periods after the shock. This negative correlation is statically significant for 4,6 and 8 periods after the shock.

Figure 1.5 Mean of the posterior mean bounds interval for six different sector variables: industrial production (IP), producer prices (IPA), new loans, employment admissions, loan rates and real wages. The sector lines are represented in light gray while the black lines show the corresponding aggregate variable response. Responses are in percent and on level variables.

Figure $1.6 \quad \beta$ histograms estimated in equation 1-11 on 650 draws of (5) algorithm. Every column denote a different dependent variable: industrial production (IP), producer price index (IPA), new loans, loan rates, employment admissions and real wages. Every row corresponds to a different IRF horizon. Dashed blue lines represent 16 th and 84 th percentis. The black vertical line represent the median. Responses are in percent and on level variables (part A).

Figure $1.7 \quad \beta$ histograms estimated in equation 1-11 on 650 draws of (5) algorithm. Every column denote a different dependent variable: industrial production (IP), producer price index (IPA), new loans, loan rates, employment admissions and real wages. Every row corresponds to a different IRF horizon. Dashed blue lines represent 16th and 84th percentiles. The black vertical line represent the median. Responses are in percent and on level variables (part B).

Figure 2.1 IRF's of a $\sigma_{i}$ contractionary monetary policy shock identified with only sign restrictions (3-equation model) 
Figure 2.2 IRF's of a $\sigma_{i}$ contractionary monetary policy shock identified with sign restrictions and monetary neutrality restrictions (3-equation model)

Figure 2.3 Structural shocks weights versus output impact responses for identified IRFs (3-equation model)

Figure 2.4 IRF's of a $\sigma_{i}$ contractionary monetary policy shock identified with only sign restrictions - SW(2007) model

Figure 2.5 IRF's of a $\sigma_{i}$ contractionary monetary policy shock identified with sign and zero restrictions - SW(2007) model

Figure 2.6 Accepted impulse weights of identified monetary shocks - SW(2007) model

Figure 2.7 Identified IRF's of a $\sigma_{i}$ contractionary monetary shock for the "sign restriction only" approach (first row) and the identification setup incorporating the neutrality restrictions (second row). Estimated 3-variable VAR with US data. Sample: 1956Q1 - 2004Q4

Figure 3.1 Distribution of the total amount of loans by ownership type by four different measures of firm size: total loans, maximum outstanding debt, number of credit relationships and gross revenues. All loans granted by private banks to firms located in Sao Paulo from 2012M01 to 2017M06 are considered. Vertical axis are in percent.

Figure 3.2 Frequency of loans by ownership type for four different measures of firm size: total loans, maximum outstanding debt, number of credit relationships and gross revenues. All loans granted by private banks to firms located in Sao Paulo from 2012M01 to 2017M06 are considered. Vertical axis are in percent. 75

Figure A.1.1Correlation between 3-month ahead moving averages of changes in loans rates and changes in the Selic rate against the time average share of earmarked loans among bank debt for each manufacturing industry sector. Slope is statistically significant at $5 \%$.

Figure A.1.2Posterior mean bounds interval (black lines) and 68\% credibility region (blue shaded region) for macro variables responses after a 50bps contractionary monetary shock. The gray vertical region indicates sign restricted variables and the restricted horizon. IRF values are in percent and defined on level variables.

Figure B.3.1Identified output responses of a $\sigma_{i}$ contractionary monetary shock imposing the neutrality restrictions in different time lengths. Estimated 3-variable VAR with US data. Sample: 1956Q1 - 2004Q4. 
Figure B.3.2Identified IRF's of a $\sigma_{i}$ contractionary monetary shock for the "sign restriction only" approach (first row) and the identification setup incorporating the neutrality restrictions (second row). Estimated 3-variable VAR with US data. Sample: 1978Q1 - 2004 Q4.

Figure C.2.1Schematic representation of DGP. 


\section{List of tables}

Table 1.1 FAVAR information set.

Table 1.2 Restrictions on the identified set of IRF's to identify a contractionary policy shock.

Table 1.3 Average sector IRF's.

Table 1.4 Proportion of negative sector IRF's. 35

Table 1.5 $\beta$ percentiles for OLS regressions in equation 1-11. 38

Table 2.1 Agnostic restrictions on impulse response functions $\quad 52$

Table 2.2 Proportion of negative responses for different IRF horizons - sign restrictions only

Table 2.3 Proportion of negative responses for different IRF horizons - sign and zero restrictions

Table 2.4 Proportion of negative responses for different IRF horizons - Arias et al. (31)

Table 2.5 Proportion of negative responses for different IRF horizons - Wolf (49)

Table 2.6 Mean identified shock weights for different identification strategies

Table 2.7 Mean absolute IRFs after 40 quarters (in percent) for different identification strategies

Table 2.8 Mean half lives of identified monetary shocks (in time periods) for different identification strategies

Table 3.1 Bank loan market share by ownership

Table 3.2 Description and sample statistics of the regression variables 78

Table 3.3 Linear probability model estimates of equation (3-1). Dependent variable: LoanGranted fbt $_{\text {}}$

Table 3.3 Linear probability model estimates of equation (3-1). Dependent variable: LoanGranted ${ }_{f b t}$ (continued)

Table 3.4 Linear probability model estimates of equation (3-2). Dependent variable: LoanGranted ${ }_{f b t}$

Table 3.5 Linear probability model estimates. Dependent variable: LoanGranted $_{f b t}$

Table 3.5 Linear probability model estimates. Dependent variable: LoanGranted $_{f b t}$ (continued)

Table 3.6 Transition matrices across loan types calculated for loans granted by foreign banks up to 3 months after information requests to SME firms that borrowed previously from other lenders. Matrix entry $(i, j)$ identifies the share of firms that took loans of type $i$ in $[t-1, t-3]$ that moved to loan type $j$ in $[t, t+3] .89$

Table 3.7 Robustness exercises. Dependent variable: LoanGranted $_{f b t} 90$

Table $\quad 3.7$ Robustness exercises. Dependent variable: LoanGranted $_{f b t}$ (continued). 
Table A.2.1Percentiles on the parameter associated to working capital share on OLS regressions in equation 1-11.

Table A.2.2Percentiles on the parameter associated to the $\log$ of campaign contributions in 2014 on OLS regressions in equation 1-11.

Table A.2.3Percentiles on the parameter associated to the average firm size on OLS regressions in equation 1-11.

Table A.3.1 $\beta$ percentiles for OLS regressions in equation 1-11. Robust parameters estimates for different points in the identified set of IRF's.

Table B.1.1Calibrated parameters: 3-equation model

Table B.2.1Proportion of negative responses for different IRF horizons - monetary neutrality in 8 years

Table B.2.2Proportion of negative responses for different IRF horizons - monetary neutrality in 9 years

Table B.2.3Proportion of negative responses for different IRF horizons - monetary neutrality in $\mathbf{1 1}$ years

Table B.2.4Proportion of negative responses for different IRF horizons - monetary neutrality in 12 years

Table B.2.5Mean identified shock weights for sign and zero restrictions identification

Table C.1.1Linear probability model estimates of equation 3-1. Dependent variable: LoanGranted fbt $_{\text {. Bank ownership randomly }}$ assigned.

Table C.1.2Linear probability model estimates of equation 3-2. Dependent variable: LoanGranted ${ }_{f b t}$. Bank ownership randomly assigned.

Table C.2.3Loan application share by bank ownership

Table C.2.4Transition matrices across loan types calculated for all loans granted up to 3 months after information requests for firms that borrowed previously from other lenders. Matrix entry $(i, j)$ identifies the share of firms that took loans of type $i$ in $[t-1, t-3]$ that moved to loan type $j$ in $[t, t+3]$.

Table C.2.5Market share of operations by bank ownership and loan type

Table C.2.6Regression estimates with real and artificial data. Dependent variable: LoanGranted fbt $_{\text {f }}$ 


\section{List of Abreviations}

EPM - Empresas Pequenas e Médias

SME - Small and Medium Enterprises 


\section{1 \\ Do earmarked loans affect the transmission of monetary policy? Sectoral evidence from Brazil}

Brazil features a large share of earmarked credit, extended at subsidized rates that are little sensitive to monetary policy. We study if this kind of loans interferes with the transmission of monetary policy. To that end, we estimate the responses of sectoral macroeconomic variables to monetary policy shocks identified through sign and equality restrictions in a factor-augmented VAR (FAVAR). We find that cross-sectional heterogeneity in sectoral responses to monetary shocks is correlated with sectoral shares of earmarked loans. In summary, monetary policy loses power in sectors with a larger share of earmarked loans among its bank debt.

JEL Classification: E50, E51, E52

Keywords: Subsidized credit, earmarked loans, monetary policy, transmission mechanism, credit channel

\section{1 \\ Introduction}

Is the Brazilian economy little sensitive to movements in the basic interest rate? Economists usually give an affirmative answer to this question in magazines and newspapers. ${ }^{1}$ This subject is often debated when they try to explain why we have seen great inflation level and persistence in the last fifteen years, despite the high swings in the policy rate. Usually, the large amount of earmarked loans is considered a candidate to explain such behavior. Since these loan rates are both below market rates and unresponsive to the policy rate, some economists claim its availability limit the proper functioning of monetary transmission channels. ${ }^{2}$ Given the importance of this debate, our aim in this

\footnotetext{
${ }^{1}$ For example: brasileconomico.ig.com.br/financas/2015-05-19/alta-da-selic-afeta-poucoa-inflacao.html.

${ }^{2}$ For example: economia.estadao.com.br/noticias/geral,credito-direcionado-afeta-apolitica-monetaria,10000023042, exame.abril.com.br/economia/alta-do-credito-direcionadoreduz-efeitos-de-politicas.
} 
paper is to assess empirically the relation between monetary policy power and the availability of earmarked loans.

Earmarked loans are bank loans granted under a specific regulation that defines its sources of funding and the loan conditions, such as interest rates, loan maturity, eligible individuals or firms and the goods that can be financed through these loans. The earmarked loan rates are considerably below market rates, what makes them popularly known as "subsidized loans". ${ }^{3}$ Its motivation ranges from financing projects that generate spillovers, and would otherwise not be financed by the private sector alone, to social concerns regarding cheaper housing financing and microfinance. Since part of their funding sources comes from regular bank deposits, earmarked loans may be granted by all commercial banks, including private banks. Additionally, a large share of earmarked loans comes from the Brazilian Development Bank (BNDES), either directly or channeled through commercial banks. As of 2017, agricultural, housing and loans granted by BNDES corresponded to roughly $95 \%$ of all earmarked loans. Government owned banks are responsible for the largest part of this share.

Figure 2.1 shows the rise in credit the Brazilian economy experienced over the last years. We can see the overall credit, as a proportion to GDP, jumped from $23 \%$ in 2002 to nearly $50 \%$ in 2017. Since the Lehman Brothers bankruptcy in the financial crisis, when credit markets froze, earmarked loans boomed as a government response to the crisis. However, even when the economy started a recovery earmarked loans continued increasing, what explains the steady increase in the credit to GDP ratio until late 2015.

The upsurge in earmarked loans raised questions about its efficacy as a policy instrument, specially because it's high levels, it's different availability across sectors and it's bellow market interest rates translate into cross-subsidies and high government expenditures to sustain this policy. Questions regarding misallocation of resources, for example, were studied by Bonomo et al. (1). The authors found that larger, older and less risky firms benefited most from the earmarked credit expansion since the financial crisis.

Another dimension of the increase in earmarked loans concerns its implications for monetary policy, since the regulated rates are smaller and less responsive to the policy rate than market rates. Figure 2.2 presents these features of interest rates, where Selic is the policy rate. ${ }^{4}$ The figure makes

\footnotetext{
${ }^{3}$ The average annual loan rates between 2011M01 and 2017M01, weighted by loan amount, was $39.8 \%$ for market rates and $8.9 \%$ for earmarked loan rates.

${ }^{4}$ Comprehensive loan rates data are only available for this short period of time. The congress approved in 2017 a law that substituted the TJLP, a reference rate for a large part of earmarked loans, for a rate called TLP, which is strictly linked to the yields on 5-year treasury bonds. This change will make the new rate to closely follow the policy rate. The implication of earmarked loans to monetary policy was explicitly part of the motivation
} 


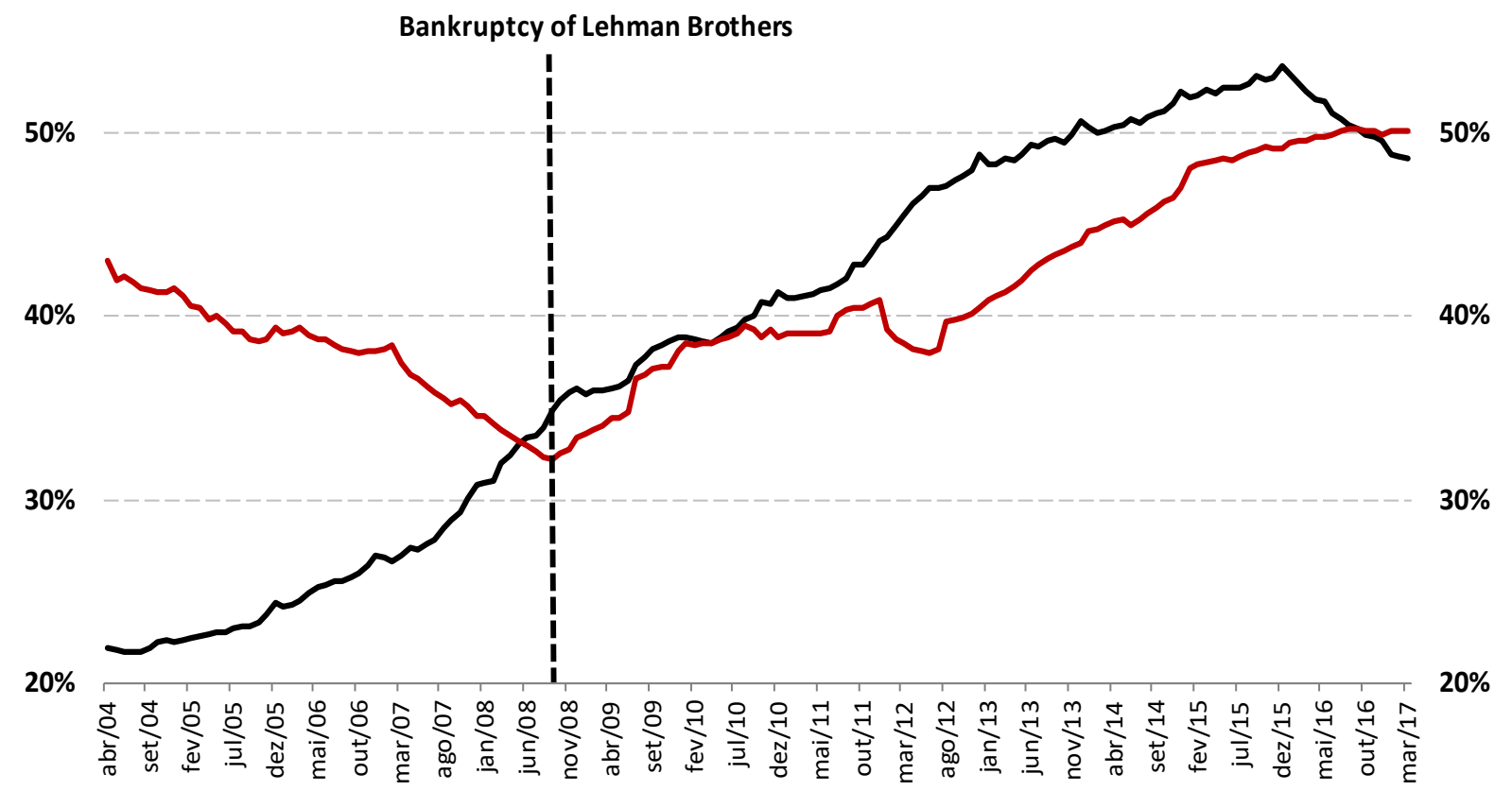

-\% total credit to GDP _ _\% earmarked credit to total credit

Figure 1.1: Credit expansion in Brazil between 2004M04 and 2017M04. Credit to GDP ratio (black line) and earmarked credit to total credit ratio (red line). The vertical dashed line indicate the month of Lehman Brothers bankruptcy, what marks the worsening of the financial crisis effects in Brazil.

clear that the average earmarked loans rate doesn't fully follow the swings in the policy rate. This correlation is 0.55 , which is substantially lower than the correlation between the policy rate and the average market rate, $0.96 .^{5}$ For that reason, there is a chance the consumption and investment decisions of individuals and firms who have access to earmarked loans won't be affected by short term movements in the policy rate. Or, at least, will be less affected than decisions of individuals and firms who are not eligible for this kind of loans. Since there are large differences in the access to these loans across sectors, we use this heterogeneity in this paper to analyze if they can explain different sector variables responses following monetary policy shocks.

To compute sector variables responses to a policy shock, we estimate a to introduce the new law. This replacement, however, will take place gradually, since a transition rate (a combination of the old and new rate) will prevail in the first 5 years of the new rule.

${ }^{5}$ In appendix A.1, we present in figure A.1.1 a more elaborated way to make this point. We plot the correlation between 3-month ahead moving averages of changes in loans rates and changes in the Selic rate against the time average share of earmarked loans among bank debt for each sector in the manufacturing industry. We can see this correlation is lower (ie: loan rates change less due to a change in the policy rate) in sectors where the share of earmarked loans is higher. The slope in the figure is statistically significant at $5 \%$. 


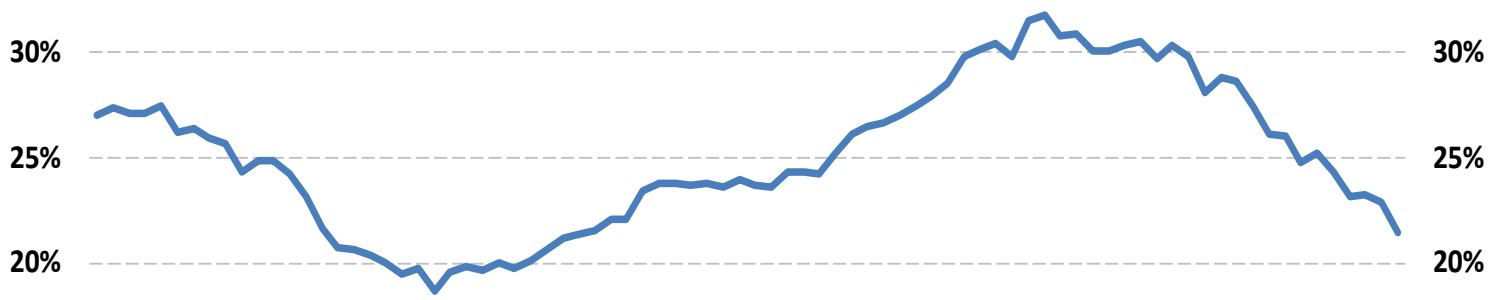

$15 \%$

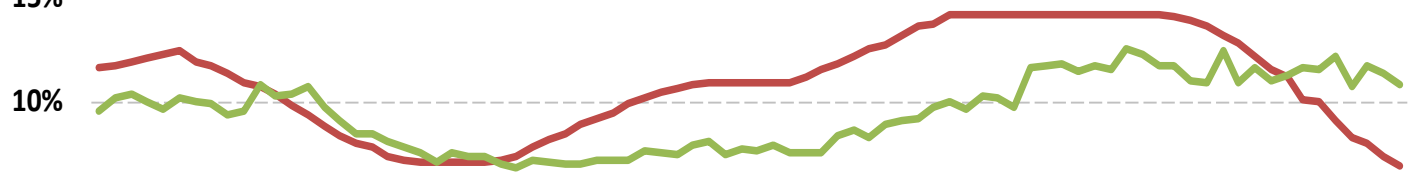

$0 \%$

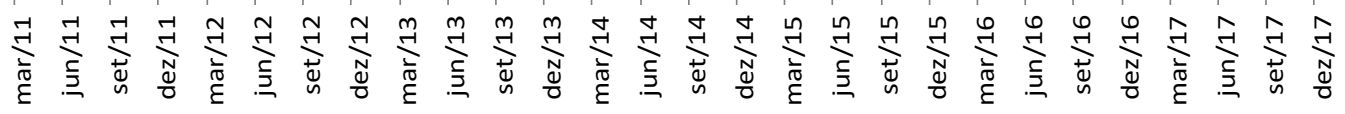

-Market loan rates - Selic rate $\quad$ Earmarked loan rates

Figure 1.2: Evolution of average annualized earmarked, market and policy rates (Selic). Loan rates are restricted to corporations. Correlation between earmarked rate and policy rate $=0.55$. Correlation between policy rate and market rates $=0.96$.

factor-augmented VAR (FAVAR), as in Bernanke et al. (2). The estimation of a FAVAR is appropriate in the sense that: (i) it allows us to compute impulse response functions (IRF) for a large number of sector variables; (ii) it can be estimated with a rich information set, what mitigates possible omitted variable bias. We separate the problem in two steps. First, we estimate the factors by principal components. Then, we use standard bayesian VAR procedures to draw reduced form parameters from their posterior distributions.

As usual, the identification of a shock in a VAR comes with a set of restrictions that (if properly imposed) enable us to derive some economic content from the VAR residuals. With that purpose in mind, we impose only a limited group of equality and inequality restrictions that we believe have a strong theoretical background to identify monetary shocks. Since these restrictions aren't enough to create a one-to-one map between the VAR and its underlying structural parameters, we adopt set identification techniques that allow us to characterize the identified set of IRF's for a class of models compatible with the imposed restrictions. ${ }^{6}$ This agnostic approach is useful in

${ }^{6}$ In this case there is a many-to-one map between the structural VAR and its associated reduced form. That is, after imposing the identification restrictions, there still might be more 
the sense that it enables us to avoid imposing unreliable structure in the data. As a downside, we lose precision in our estimates.

The bayesian framework turns out to be the standard choice when dealing with set identified VARs, since it is computationally convenient and it allows us to introduce prior information on the non-identified rotation matrices that maps VAR residuals in structural shocks. But, as is known in this literature, the prior for these matrices may influence the inference based on IRF posteriors in a nonstandard way, even the ones claimed to be flat $[(3),(4)]$. Given the non-informativeness of the data to identify the rotation matrices, this feature remains even asymptotically, what represents a serious potential problem. For that reason, we use in this paper the Giacomini \& Kitagawa (5) method to conduct posterior inference of IRF's. Their approach is appropriate to avoid the mentioned problems because it is robust to the choice of priors for the rotation matrix. Basically, their procedure delivers upper and lower bounds of the identified set of IRF's that is consistent both with the imposed restrictions and all potential priors for the rotation matrices.

Once we obtain lower and upped bounds for the IRFs of each sector variable to a monetary shock, we analyze if the heterogeneity in sector variables IRFs can be explained by the availability of earmarked loans in each sector. Specifically, for each sector variable and each IRF horizon (ie: the number of periods after a shock) we perform cross-section regressions of the mean values of these IRF bounds on the sectors share of earmarked loans among bank debt, our measure of earmarked funds availability. We test six different sector IRFs as dependent variables: new loans, loan rates, prices, industrial production, new employment admissions and real wages. This procedure turns out to be rich enough to test not only the importance of earmarked loans for different variables IRFs, but also the timing when earmarked loans possibly interfere on monetary policy transmission. In summary, after a contractionary policy rate shock, we find the majority of sector new loans, new employment admissions, prices, industrial production and real wages fall, in tandem with theory. Also, sector loan rates rise. Overall, we provide evidence that earmarked loans reduce monetary policy power. Given a 50bps contractionary monetary shock, a $10 \%$ rise in the share of earmarked loans among bank debt for a given sector:

- weakens this sector loan rate response between $0.22 \%$ and $0.38 \%$ after 2 to 12 months;

- weakens this sector price level response between $0.11 \%$ and $0.18 \%$ after 2 to 12 months;

than one matrix of contemporaneous effects in the SVAR associated to the same covariance matrix of VAR residuals. 
- weakens this sector industrial production level response between $0.34 \%$ and $0.47 \%$ after 2 to 8 months;

- weakens this sector new employment admissions level response between $0.56 \%$ and $1.13 \%$ until 2 months after the shock.

Different mechanisms may lie behind our results. We believe our history fits better in the traditional interest rate channel of monetary policy, in which movements in the policy rate are perceived to affect the cost of capital for firms. In this case, different availability of earmarked loans across sectors mechanically produces heterogeneous real loan rates responses following a monetary shock. Thus, there are heterogeneous firm investment decisions and, so, different responses of sector real variables. Nevertheless, we don't rule out the possibility of other mechanisms being consistent with our reduced form results, including the ones related to the supply side of credit.

Next section relates our question to the existing literature. Section 1.3 explains our econometric framework. To make this paper self-contained, we include a brief overview of the set identification approach and the Giacomini \& Kitagawa (5) algorithm to compute bounds for the identified set of IRF's. Section 1.5 introduces the estimation setup, including the imposed equality and inequality restrictions to identify the monetary shock and presents the main results of the paper. Section 1.6 discusses possible mechanisms and the implications of our results. The last section concludes.

\section{2}

\section{Related literature}

The literature that concerns public policy interventions on financial markets is large in scope. A part of this literature focus on the presence of the government on credit markets, generally directly through government owned banks. In this sense, some papers compared different aspects of government owned banks on credit markets, including the possibility of politically motivated loans $[(6),(7)]$, their lending behavior over the business cycle $[(8,9)]$, their loan conditions (10) and the performance of government owned banks vis-a-vis private banks $[(11,12)]$. Overall, available cross-section data between countries reveal large heterogeneity in the presence of public banks on credit markets (13). La Porta et al. (14) document the negative correlation between the development level of countries and the share of bank assets held by government owned banks.

A tiny part of this literature studies the consequences of credit subsidies as a public policy. The motivation behind this instrument is diverse. It might 
be related to the need to improve credit allocation, for example channeling credit to sectors that generate spillovers or to credit markets that present large information asymmetries (15). Or it may also be a government response to financial crisis in order to soften credit market crunches. Gale (16) studies the impact of large credit subsidies in the United States between 1980 and 1987. He found substantial effect on credit allocation, but little effect on aggregate investment. Efficiency costs of this policy were shown to be large. Bonomo et al. (1) used a rich data set to study the credit allocation and the consequences of government-driven credit in Brazil. Despite the importance of earmarked loans in sectors that present spillovers, they found that the larger part of governmentdriven credit was granted to big, old and less risky firms. The authors didn't find evidence of investment increases for publicly traded firms that borrowed in the earmarked loan market. Podpiera (17) documented how credit subsidies were used as an anti-crisis instrument in Serbia during the 2008 financial crisis. In a theoretical model with financial accelerator mechanisms calibrated for the Serbian economy, he found that this instrument helped mitigate the downturn in GDP during the crisis.

An even smaller group of papers examined the relation between monetary policy power and availability of earmarked loans in Brazil, precisely our question in this work. Castro (18) and Silva et al. (19) address this question theoretically, in both cases with DSGE models featuring cost-channels of monetary policy. In the first paper, following a monetary contractionary shock the availability of earmarked loans weakens output responses, but strengthens prices responses. In the later, earmarked loans weaken both responses. Additionally, Castro (18) points to the fact that aggregate and micro implications of earmarked funds availability on responses following a shock may be quiet different due to the presence of general equilibrium effects in the former. The author found both effects in the same direction, but considerably smaller aggregate effects.

The work closest to ours is Bonomo \& Martins (20), who also try to answer this question empirically. ${ }^{7}$ Using a rich database with micro information at the loan level, comprehending roughly 300,000 firms, they use the share of earmarked loans among bank debt and variations in the policy rate to explain different firm-level variables. ${ }^{8}$ In summary, they regress firms loan growth, number of employees growth and loan rates growth on the share of earmarked loans and its interaction with changes in the policy rate, among other controls, including firm fixed effects. Their results show the availability

${ }^{7}$ We didn't know about that until the end of 2016, when our work was under way.

${ }^{8}$ They also present results using a more comprehensive measure of government-driven credit that includes all government loans. 
Chapter 1. Do earmarked loans affect the transmission of monetary policy? Sectoral evidence from Brazil

of earmarked loans weakens monetary policy effects. Our approach, when compared to Bonomo \& Martins (20), has pros and cons. Their rich database with more than 2 million firm-year observations gives them the benefits a large sample usually does. Besides that, their estimations don't rely on identifying assumptions to characterize variations in monetary policy. ${ }^{9}$ But, given the large information set of the monetary authority, separating the effects of changes in the policy rate from other macroeconomic conditions might be an issue, despite their inclusion of some macro variables as regression controls. This problem may be further aggravated in large time intervals, like a year, when economic conditions may have varied substantially. Thus, we believe the identification of monetary shocks may be important to characterize the effects of an exogenous variation in the policy rate.

We add further to Bonomo \& Martins (20) in two different ways. First, we provide evidence of the importance of earmarked loans in explaining heterogeneous sector price and industrial production responses to monetary policy. These data are not available at the firm level. Second, following a monetary shock, we shed light on the timing when earmarked credit interfere on the transmission of monetary policy shocks. Overall, we view our results as an important complimentary evidence that earmarked loans interfere on monetary transmission mechanisms. Since our cross-section variables are defined on a more aggregate level than the firm level, we believe our findings might be closer to the macro effects of earmarked credit on monetary policy power.

\section{3}

\section{Econometric framework: FAVAR, monetary shock identification and cross- section regressions}

In this section we discuss all the methodological steps we go through. We begin estimating a factor-augmented VAR (FAVAR) and them proceed to identify a monetary shock, as usual in the VAR literature. Once we have estimated the IRF identified set for all variables of interest, we test whether different sector variables responses to a monetary shock can be explained by the availability of earmarked funds.

\subsection{1}

\section{FAVAR}

To estimate the sector IRF's we departure from a FAVAR, as in Bernanke et al. (2). Three key features of this approach perfectly fit to our needs: (i) utilization of a rich information set to identify monetary policy shocks

\footnotetext{
${ }^{9}$ Reverse causality is not an issue when regressing firm-level variables on macro variables.
} 
without estimating a prohibitively number of parameters; (ii) possibility to compute IRF's for a large number of variables; (iii) the existence of a large menu of possible restrictions to identify a monetary shock. First, a rich information set allows us to control for almost all variables that may affect the common component of monetary policy, mitigating the omitted variable bias in the IRF's estimation. In this sense, we reduce the probability of being in information disadvantage regarding the monetary authority. ${ }^{10}$ Second, the possibility to compute a large number of IRF's is crucial to our analysis, since we are most interested in exploring cross-section differences in sector responses to a monetary shock. Finally, this rich information set and the estimated IRF's form a large menu of possible restrictions at our disposal to identify a monetary shock. Thus, we are able to avoid imposing unreliable structure in the data and focus only on restrictions with strong theoretical support.

Equations (2-1) and (2-2) characterize the FAVAR:

$$
\begin{aligned}
F_{t} & =B(L) F_{t-1}+u_{t} \\
X_{t} & =\Lambda F_{t}+e_{t} .
\end{aligned}
$$

The first equation is a transition equation that describes the law of motion in the economy in terms of $F_{t}$, a $k \times 1$ vector of common factors that have pervasive effects to all macroeconomic variables. Some of these factors may represent latent variables corresponding to broad economic concepts, like economic activity or inflation, not precisely characterized by one or two time series. In equation $(2-1), B(L)$ is a lag polynomial and $u_{t}$ is a one-step ahead prediction error. The second equation, the observation equation, maps the $n \times 1$ vector of macroeconomic observable variables, $X_{t}$, into the factors through a loading matrix $\Lambda . X_{t}$ summarizes the large information set of the monetary authority $(n>>k)$ and, so, is the information available for estimation of the non-observable factors. In this equation, $e_{t}$ is a vector of idiosyncratic errors, assumed not correlated to $u_{t}$, but allowed to be serially correlated and weakly correlated across variables.

Since we are interested in a monetary shock, we follow Bernanke et al. (2) and include the Selic rate among the factors, so we increase the chance of the monetary shock being spanned by a combination of reduced form errors. Thus, we consider $F_{t}=\left(f_{t}^{\prime}, R_{t}^{\prime}\right)^{\prime}$, where $R_{t}$ is the Selic rate and $f_{t}$ is a vector of latent factors. ${ }^{11}$ We estimate equations (2-1) and (2-2) in a two-step procedure.

\footnotetext{
${ }^{10}$ This gap of information between the econometrician and the monetary authority was claimed to be the most likely cause of counterintuitive results (e.g.: price puzzle) that some papers have found in the literature (21).

${ }^{11}$ To impose $R_{t}$ as a factor, we adopt Boivin et al. (22) iterative procedure to assure the
} 
Chapter 1. Do earmarked loans affect the transmission of monetary policy?

First, we estimate the latent factors with principal components. ${ }^{12}$ As shown in Stock \& Watson (23), given the above idiosyncratic error conditions and some regularity conditions, the principal components will consistently estimate the space spanned by the factors. ${ }^{13}$ Second, we use standard bayesian VAR procedures to draw posterior parameters of both equations. ${ }^{14}$

\subsection{2}

\section{Monetary shock identification}

\subsubsection{1}

\section{Identification problem and set identification}

We suppose there is an underlying structural model associated to equation 2-1, so that our reduced form specification is correct. Thus, $u_{t}$ spans the space of structural disturbances that affects the economy (i.e.: we assume the invertibility condition is satisfied):

$$
A u_{t}=\epsilon_{t}
$$

where $A$ is a square matrix and $\epsilon_{t}$ is a mean zero $k \times 1$ vector of structural disturbances. We assume these shocks are not correlated with each other and impose unit variance as a normalization condition, $E \epsilon_{t} \epsilon_{t}^{\prime}=I$. The variance of the reduced form errors is given by:

$$
\Sigma \equiv E u_{t} u_{t}^{\prime}=A^{-1} A^{-1^{\prime}} .
$$

If we express our transition equation as:

$$
F_{t}=C(L) u_{t}, \text { where } C(L)=\left(I+C_{1} L+C_{2} L^{2}+C_{3} L^{3}+C_{4} L^{4}+\ldots\right)
$$

the matrix of factor IRF's on horizon $h$ may be expressed as:

$$
I R_{F}^{h}=C_{h} A^{-1}
$$

which gives the IRF matrix of variables in the vector $X_{t}$ on horizon $h$ :

$$
I R_{X}^{h}=\Lambda C_{h} A^{-1}
$$

where the element $(i, j)$ of the above matrix informs the impact on variable $i$ of a standard deviation shock in variable $j, h$ periods after the shock. We will represent this scalar by $r_{i j}^{h}$.

latent factors and $R_{t}$ span different dimensions of the data.

${ }^{12}$ For this purpose, we normalized $X_{t}$ to have mean zero and unit variance.

${ }^{13}$ Since only the space spanned by the factors is identified, the principal components estimation also provide a mathematically convenient identification for the factors and its associated loadings (24).

${ }^{14} \mathrm{~A}$ similar estimation procedure was carried out in Mumtaz \& Surico (25). 
To move on to the partially identified components of the model, is convenient to characterize the set of matrices $A$ as $\left\{A: A=Q^{\prime} \Sigma_{t r}^{-1}, Q \in \mathcal{O}(n)\right\}$, where $\Sigma_{t r}$ is the lower triangular Cholesky decomposition of $\Sigma, \Sigma=\Sigma_{t r} \Sigma_{t r}^{\prime}$, and $\mathcal{O}(n)$ represents the space of orthogonal matrices (proposition A.1 of Uhlig (26)). ${ }^{15}$ With this result, we can express the IRF matrix for vector $X_{t}$ as a linear function of $\mathrm{Q}$ :

$$
I R_{X}^{h}=\Lambda C_{h} \Sigma_{t r} Q
$$

with individual IRF's expressed as $r_{i j}^{h}=e_{i}^{\prime} \Lambda C_{h} \Sigma_{t r} q_{j}$, where $e_{i}$ is the canonical vector and $q_{j}$ is the $j$ column of $Q$. This format makes explicit that most of the identifying restrictions generally imposed on $A$ may be instead imposed on Q.

As standard in the SVAR literature, the IRF identification problem rests on matrix $Q$, since $\Lambda, C_{h}$ and $\Sigma$ can be estimated from equations (2-1) and (2-2). The estimated $\Sigma$ does not pin down a unique $Q$, what creates a lack of identification for this matrix. Traditionally, point-identified methods impose enough restrictions on $Q$ until there is a one-to-one map between $\Sigma$ and $Q$. Thus, these methods create a one-to-one map between the reduced form VAR and its underlying structural linear model. The recursive identification strategy of Sims (27) is probably the most known case of point-identification strategy.

In this paper, however, we adopt a set-identification strategy, which means that we will place less restrictions on $Q$ than necessary for pointidentification. Instead, we will identify a set of $Q$ matrices that satisfy these restrictions, so we get a many-to-one map between $Q$ and $\Sigma$. The advantage of this approach is that it allows us to impose only the restrictions we have strong theoretical background a monetary policy shock satisfies. On the downside, the set identification strategy creates a sort of model uncertainty underlying our FAVAR (27), thus we lose precision on IRF estimates.

The numerically convenience and possibility to impose a prior for $Q$ make the bayesian approach the standard choice for papers that deal with set identification in VARs. Nevertheless, it should be noted that the data are completely uninformative about $Q$, so the uncertainty regarding the true matrix $Q$ remains even in large samples, what makes the choice of prior for this matrix a crucial decision for the econometrician. ${ }^{16}$ Since the seminal works of Canova (28) and Uhlig (26), most applied papers that employ set identification techniques in VARs define noninformative priors for the matrix $Q$. However,

\footnotetext{
${ }^{15}$ This transformation is necessary because most of the algorithms in the bayesian set identification literature involves drawing matrices $Q$ from $\mathcal{O}(n)$, a procedure not directly feasible with the matrix $A$.

${ }^{16}$ Considering Gaussian errors in equation (2-1), data distribution will be the same for two different matrices $Q$ that satisfy the imposed restrictions.
} 
Baumeister \& Hamilton (4) have shown commonly used noninformative priors turn out to be very informative about the shape of IRF's distributions, an undesirable feature of these priors. In an attempt to avoid these unintended consequences, we employ in this paper Giacomini \& Kitagawa (5) robust approach to compute IRF identified sets, since it does not rely on a prior choice for $Q$. Their method is robust in the way that it considers all possible priors for $\mathrm{Q}$ that satisfy the imposed restrictions. At the same time, their approach is sufficiently flexible to allow the imposition of all standard identification restrictions widely used in the SVAR literature. In what follows, to make this paper self contained, I give a summarized description of Giacomini \& Kitagawa (5) algorithm to compute the IRF identified sets. I refer the interested reader to their paper for a complete understanding of their method.

\subsubsection{2}

\section{Giacomini \& Kitagawa (5) algorithm to compute IRF's identified set}

Consider $\phi=(\Lambda, \Sigma, B)$ the vector of reduced-form parameters in equations (2-1) and (2-2). ${ }^{17}$ With some abuse of notation, define $F(\phi, Q)=0$ as the set of equality restrictions imposed to identify the monetary shock, which may include short-run restrictions $[(27),(2)]$, long-run restrictions [(29), (30)], as well as restrictions imposed directly on $A(31)$. Accordingly, let $S(\phi, Q) \geq 0$ represent the sign restrictions. Given both sets of restrictions, we can summarize the set of admissible Q's as:

$$
\mathcal{Q}(\phi \mid F, S)=\{Q \in \mathcal{O}(n): S(\phi, Q) \geq 0, F(\phi, Q)=0\}
$$

Given the set of admissible Q's, we can represent the identified set of impulse responses:

$$
I S_{r}(\phi \mid F, S)=\{r(\phi, Q): Q \in \mathcal{Q}(\phi \mid F, S)\} .
$$

That is, for a given $\phi$, the identified set presents the range of IRF's such that $Q$ has support in $\mathcal{Q}(\phi \mid F, S)$. The identified set bounds can be obtained with the following algorithm proposed by Giacomini \& Kitagawa (5):

1. Specify a prior $\pi_{\phi}$ for $\phi$. In this step, we define conjugate priors for $\phi$ in the same lines as Bernanke et al. (2), so the posterior is available in closed form. ${ }^{18}$

2. Draw $\phi$ from the marginal posterior, $\pi_{\phi \mid Y}$.

${ }^{17}$ Throughout the paper I follow Giacomini \& Kitagawa (5) notation in order to keep track with their paper.

${ }^{18}$ The details can be seen in the appendix of the working paper version of their paper. 
3. Draw $Q$ conditional on zero restrictions and test if sign restrictions are satisfied. ${ }^{19}$ If a great number of draws don't satisfy the sign restrictions, return to step $2 .^{20}$ Otherwise, for a given $Q$ satisfying all imposed restrictions, move on to step 4.

4. Solve the following nonlinear constrained optimization problem to compute maximum and minimum values of $r(\phi, Q)$, using $Q$ found in step 3 as initial point:

$$
\begin{array}{ll} 
& \mathcal{L}(\phi)=\min _{Q} e_{i}^{\prime} \Lambda C_{h} \Sigma_{t r} q_{j} \\
\text { s.t. } & Q^{\prime} Q=I_{n}, F(\phi, Q)=0, \\
& S(\phi, Q) \geq 0 .
\end{array}
$$

The fourth step of the above algorithm delivers bounds for $I S_{r}(\phi \mid Q)$. The interval represented by the means of the lower and upper bounds across many draws of $\phi$ correspond to be the posterior mean bounds interval (proposition 4.1 of Giacomini and Kitagawa (5)). In section 4, we report results based on the mean point of this interval.

\subsection{3}

\section{Cross-section regressions}

Given the bounds of the identified set of IRF's for all sector variables in the vector $X_{t}$, we check if the heterogeneity in sector responses following a monetary shock can be explained by the availability of earmarked loans in each sector. Our cross-section exercise on the sector level works as follows. We run OLS regressions of the mean identified set of IRF's, $h$ periods after the shock, on the share of earmarked loans among bank debt and other regression controls. In order to account for variation in $\phi$, we run these regressions every draw of the algorithm and report corresponding parameter distributions. In summary, we include the following step on the previous algorithm:

5. Run the following cross-section regressions on the sector level:

$$
I R F_{j}^{i, h}=\alpha^{i, h}+\beta^{i, h} e m l_{j}+\theta^{\mathbf{i}, \mathbf{h}} \mathbf{Z}_{\mathbf{j}}+v_{j}^{i, h},
$$

where $j$ indexes the sector, $h$ indexes the number of periods after the shock and $i$ denotes the sector variable, $i=\{$ new loans, loan rates,

\footnotetext{
${ }^{19}$ Steps 2.1 and 2.2 of Giacomini \& Kitagawa (5) algorithm show precisely how this can be done. Another option is to use Arias et al. (32) algorithm to draw $Q$ conditional on zero restrictions.

${ }^{20}$ We tried the maximum of 10,000 draws of $Q$ in this step.
} 
industrial production, new employment admissions, real wages, prices\}. IRF stands for the mean identified set of IRF's, eml is the monthly median fraction of earmarked loans share among bank debt and $\mathbf{Z}$ is a vector of sector controls. Thus, each pair $(i, h)$ defines a different regression for every draw of the algorithm.

The parameter of interest is $\beta^{i, h}$, which measures how the sector responses to a monetary shock vary with the share of earmarked loans, our measure of earmarked funds availability. According to the view that earmarked loans weaken monetary policy power, and considering that a monetary shock has the expected effects on the sector variables, our hypothesis is that $\beta^{i, h}$ is negative when $i=\{$ loan rates $\}$ and positive otherwise.

We include three different sector controls that might be correlated both to the mean identified set of IRF's and the share of earmarked loans. First, we include the $\log$ of the average number of firms employees per sector. This variable is expected to reflect the average size of firms in a given sector, which is positively correlated to the chance of accessing earmarked loans (1). ${ }^{21}$ On the other hand, large firms may react differently in the business cycle and/or represent more concentrated sectors, what imply heterogeneous sector responses to monetary policy shocks. Since a small part of earmarked loans aim at financing working capital needs, we also include the share of working capital among bank debt to control for an operating cost channel of monetary policy (33). Finally, we include the log of campaign contributions to federal elections in 2014. ${ }^{22}$ This variable controls for the possibility of politically motivated earmarked loans and other government benefits. In a recession, for example, sectors that contribute more to campaigns might receive tax exemptions or other benefits, creating a link between campaign contributions and monetary policy responses.

\section{4}

Data

The FAVAR information set consists of 632 monthly time-series ranging from 2002M01 to 2017M04. From these, we used 161 series to estimate the factors, including disaggregate series by economic sector for prices and

${ }^{21}$ This issue can be clearly seen in a recent BNDES program, called "National Champions", with the purpose of promoting (i.e.: financing with subsidized loans) big firms in Brazil.

${ }^{22}$ We consider contributions for candidacies of deputies, senators and presidents. We didn't average this variable over time because it is not available for previous campaigns. Since earmarked loans regulation occurs at the federal level, we ignore contributions to state and municipalities campaigns. 
Chapter 1. Do earmarked loans affect the transmission of monetary policy? Sectoral evidence from Brazil

industrial production. ${ }^{23}$ These series were picked to represent the current state of the economy and, so, approximate the information set of the monetary authority. Thus, almost all of them are shown in the Inflation Report, the most important disclosed document of Central Bank of Brazil. Table 2.1 presents the number of series by category.

Table 1.1: FAVAR information set.

\begin{tabular}{|c|c|c|}
\hline Series category & $\begin{array}{c}\text { Total number of } \\
\text { series }\end{array}$ & $\begin{array}{l}\text { Number of series used } \\
\text { to extract factors }\end{array}$ \\
\hline Employment and labor earnings & 224 & 5 \\
\hline Prices & 107 & 78 \\
\hline Money and Credit & 107 & 6 \\
\hline Interest rates and equity & 98 & 7 \\
\hline Industrial production & 78 & 56 \\
\hline Trade sales & 6 & 1 \\
\hline External sector & 6 & 4 \\
\hline $\begin{array}{l}\text { Confidence index and market } \\
\text { surveys }\end{array}$ & 3 & 3 \\
\hline Other & 3 & 1 \\
\hline Total & 632 & 161 \\
\hline \multicolumn{3}{|c|}{$\begin{array}{l}\text { Different data sources were used to build our information set and the } \\
\text { regression controls. Aggregate macroeconomic data were mainly taken from } \\
\text { the Central Bank of Brazil website. Sector employment admissions and wages } \\
\text { data come from two widely known labor market databases in Brazil, Caged and } \\
\text { RAIS. Prices were taken from the Brazilian Institute of Economics (IBRE). } \\
\text { Campaign contribution from the Superior Electoral Tribunal website. Indus- } \\
\text { trial production data were downloaded in the Brazilian Institute of Geography } \\
\text { and Statistics (IBGE) website. The information on sector availability of ear- } \\
\text { marked funds, as well as on sector bank loans and loan rates, were taken from } \\
\text { a credit registry managed by the Central Bank of Brazil. New loans data were } \\
\text { transformed to real values through a deflation by the consumer price index } \\
\text { (IPCA). }\end{array}$} \\
\hline $\begin{array}{l}\text { Sectors correspond to } \\
\text { these sectors in order to get } \\
{ }^{23} \text { Disaggregate series for new } \\
\text { available only after } 2005 \text {. In order } \\
\text { to use these series for estimation o } \\
\text { advice and do not include aggree } \\
\text { since this can induce large correla } \\
\text { and a weighted average of idiosyn }\end{array}$ & $\begin{array}{l}\text { manufacturing indus } \\
\text { aggregate informatio } \\
\text { s, loan rates, employme } \\
\text { naximize the time dimer } \\
\text { latent factors. Besides, } \\
\text { series along with all th } \\
\text { between idiosyncratic c } \\
\text { ic components of the di }\end{array}$ & $\begin{array}{l}\text { al groups. We focus on } \\
\text { of prices and industrial } \\
\text { admissions and wages are } \\
\text { n of the data, we chose not } \\
\text { follow Stock \& Watson }(24) \\
\text { disaggregate counterparts, } \\
\text { ponents of aggregate series } \\
\text { gregate series. }\end{array}$ \\
\hline
\end{tabular}


production, not available for other sectors. To properly match industrial sectors across different variables, we employed the classification established by CNAE 2.2 , a taxonomy defined by IBGE to categorize different economic activities. It is important to note, however, that the number of observations in cross-section regressions varies with the number of disaggregate sectors available for each dependent variable, ranging from 74 to 99 observations.

Finally, data were deseasonalized and transformed to ensure stationarity. For consistency, data in the same category were transformed in the same way. We also treated outliers following standard practices.

\section{5}

\section{Results}

In this section we present results based on 650 iterations of Giacomini \& Kitagawa(5) algorithm. First, we present the estimation setup, including the restrictions imposed to find bounds for the identified set of IRF's to a monetary contractionary shock. We move on to show disaggregate effects on the sector level. We argue our identification looks reasonable, since most of these effects have the expected direction. Finally, we show the heterogeneity on IRF responses can be partially explained by the availability of earmarked loans in each sector.

\subsection{1}

\section{Estimation setup}

Our benchmark specification has 8 factors (7 latent factors + Selic rate) and 3 lags. ${ }^{24}$ Table 2.2 presents restrictions imposed on the identified set of IRF's to identify a monetary policy contractionary shock. Instead of imposing a rise in nominal rates as the policy movement, a usual feature in the literature that uses sign restrictions to identify monetary shocks [(26), (35), (36), (31)], we impose a rise in the real rate, measured both in relation to a producer price index inflation $(\triangle I P A)$ and to a consumer price index inflation $(\triangle I P C A)$. We proceed this way to rule out theoretical possible (and empirically implausible) situations where nominal rates fall in the same period of a contractionary shock. ${ }^{25}$ Besides, a contractionary shock must be defined in relation to the real rate, since it is the rate that affects investment and consumption decisions. For

\footnotetext{
${ }^{24}$ We selected the number of factors both using Bai \& Ng (34) information criteria and making sure there were reduced form parameters in the FAVAR estimation compatible with the identification restrictions. Overall, factors explain, on average, $23 \%$ of the 632 time series. For sector variables, these numbers are: industrial production (37\%), prices (32\%), new employment admissions (27\%), new loans (12\%), loan rates (8\%), real wages (12\%).

${ }^{25}$ This feature is present in new keynesian DSGE models when the monetary shock persistence is very high.
} 
both measures of real rates the sign restriction is binding only on impact. We normalize the shock to $50 \mathrm{bps}$ for the real rate measured in relation to IPCA. ${ }^{26}$

We also impose sign restrictions on a group of aggregate variables: monthly interpolated GDP, industrial production, new employment admissions, real wages, producer price index, consumer price index and loan rates. ${ }^{27}$ Restrictions on prices and economic activity indexes have standard direction according to economic theory. Restrictions on loan rates are less common in this literature, but simply reflect a pass-through from the policy rate to market rates. These sign restrictions are binding until 2 periods after the shock on level variables. Importantly, we don't restrict in any way disaggregate IRF's used latter on cross-section regressions.

There is almost a consensus that monetary shock identification becomes very loose when it is performed only with sign restrictions $[(27),(5)]$, what made us search for reasonable equality restrictions. Thus, as a short run restriction, we impose that the consumer price index does not change on impact. We don't do the same for the producer price index because it generally moves faster following a monetary shock. Additionally, for GDP and industrial production we impose monetary neutrality 15 years after the shock, what we call medium run restrictions in table 2.2. We chose these two real variables because they account for different dimensions of economic activity. In another paper of ours, we show these medium-run (and not long-run) neutrality restrictions might be important to identify monetary shocks because they remove confounding combinations of supply and demand shocks (37).

\section{5 .2}

\section{Sector effects of a contractionary monetary shock}

Figure 1.3 presents real rate responses to a monetary contractionary shock, both in relation to a consumer and a producer inflation. We set the rise of the real rate to 50bps (computed for the consumer price inflation). Black bars represent the posterior mean bounds interval while the blue shaded region corresponds to a $68 \%$ credibility region, calculated according to Giacomini \& Kitagawa (5). ${ }^{28}$ In appendix A.1, figure A.1.2 presents similar results for macro variables typically shown in empirical papers. IRF values are in percent and defined on level variables. Despite the large uncertainty regarding estimates, a feature accentuated by the set identification strategy, identification looks

\footnotetext{
${ }^{26}$ To account for the uncertainty regarding the matrix of contemporaneous effects, $A$, we do this normalization every iteration of the algorithm.

${ }^{27}$ We impose sign restrictions on four different categories of loan rates: working capital, vendor operations, vehicle acquisition and personal credit.

${ }^{28}$ For all possible priors of the matrix $Q$, the IRF's lie in the blue shaded region with at least $68 \%$ posterior probability.
} 
Table 1.2: Restrictions on the identified set of IRF's to identify a contractionary policy shock.

\begin{tabular}{|c|c|c|c|}
\hline Variables & Short run & $\begin{array}{l}\text { Medium } \\
\text { run }\end{array}$ & Sign rest. \\
\hline Selic $_{t}-\Delta I P C A_{t+1}$ & & & $>0$ \\
\hline Selic $_{t}-\Delta I P A_{t+1}$ & & & $>0$ \\
\hline$G D P$ & & $=0$ & $\leq 0$ \\
\hline$I P$ & & $=0$ & $\leq 0$ \\
\hline $\operatorname{Emp} a d m$ & & & $\leq 0$ \\
\hline Real wage & & & $\leq 0$ \\
\hline$I P C A$ & $=0$ & & $\leq 0$ \\
\hline$I P A$ & & & $\leq 0$ \\
\hline Loan rates & & & $\geq 0$ \\
\hline
\end{tabular}

Notes: sign restrictions on real rates are imposed only on impact. Other sign restrictions are binding until 2 periods after the shock on level variables. Medium run equality restrictions are imposed on level variables 160 months after the shock.

reasonable for a contractionary shock, since unrestricted responses have the expected sign: stock index (IBOV), monetary aggregate (M1) and new loans fall after the shock.

Nevertheless, our focus is on sector responses. Thus, as another check on how well identified is the monetary policy shock, we can look at sector prices versus quantities responses in a given IRF horizon after the shock, an exercise analogous to Boivin et al. (22). Interpreting the monetary shock as a demand shock, we would expect that sectors in which prices fall most (what can be interpreted as greater price flexibility), quantities fall less. Figure 1.4 displays sector scatter plots of the mean of the posterior mean bounds interval (the analogous to the black dots in figures 1.3 and A.1.2) of prices and quantities. Results are shown for different IRF horizons. ${ }^{29}$

We move on to present in figure 1.5 the mean of the posterior mean bounds interval for six different sector variables: industrial production (IP), producer prices (IPA), new loans, employment admissions, loan rates and real wages. Individual sector IRF's are represented in dotted gray lines, while the thick black line shows the corresponding aggregate variable response. Although this is just an informal visual check, there seems to be large heterogeneity in responses across sectors for all six variables presented. ${ }^{30}$ We also notice most

\footnotetext{
${ }^{29}$ The negative correlation between prices and quantities responses is statically significant at $5 \%$ for 4,6 and 8 periods after the shock.

${ }^{30}$ Sector responses may appear larger than expected for a monetary shock. We attribute
} 

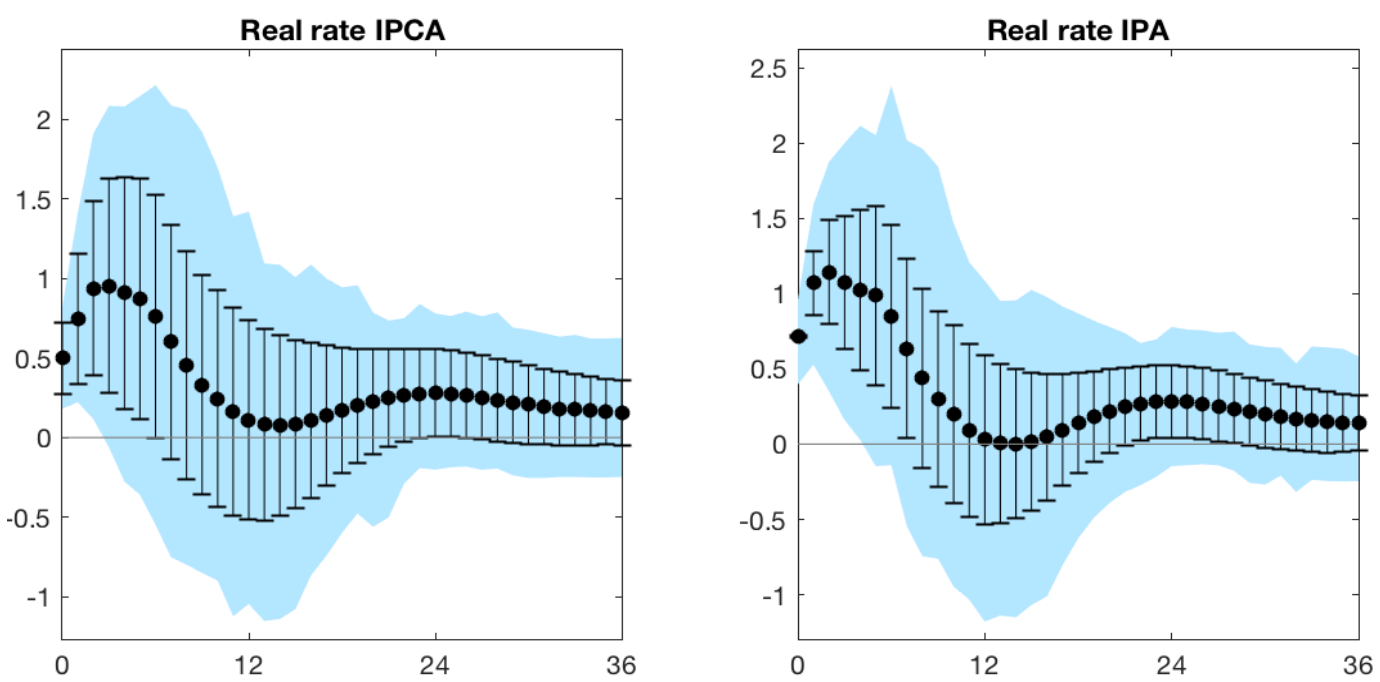

Figure 1.3: Posterior mean bounds interval (black lines) and 68\% credibility region (blue shaded region) for real rate responses after a 50bps contractionary monetary shock. Real rates are defined according to a consumer price index (left panel) and a producer price index (right panel). Values are in percent and defined on level variables.
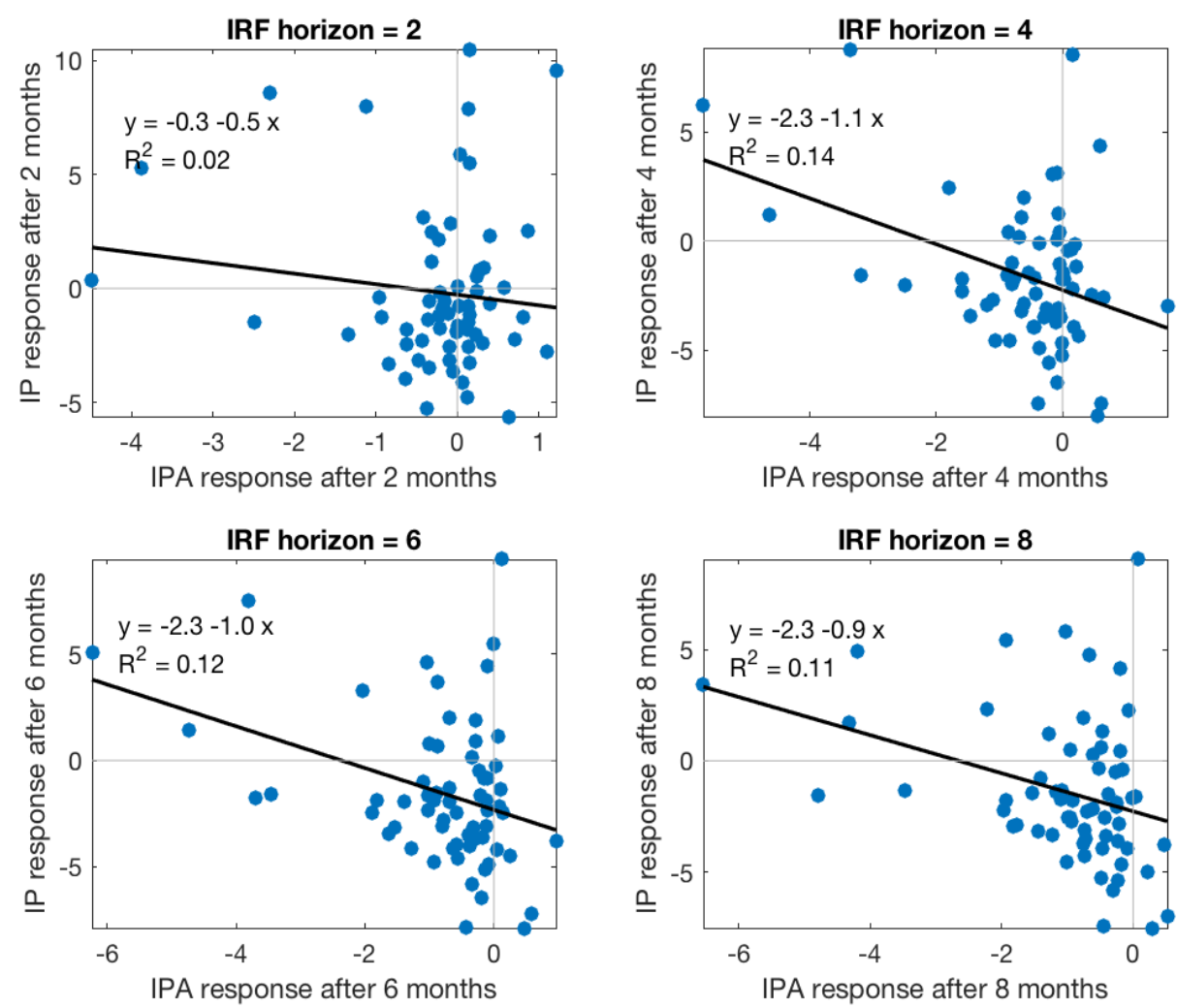

Figure 1.4: Sector scatter plots of the mean of the posterior mean bounds intervals for 2, 4, 6 and 8 periods after the shock. This negative correlation is statically significant for 4,6 and 8 periods after the shock.

this finding to the super volatile nature of sector variables time series. Mean standard deviations of transformed sector variables are (in percent): IPA (1.71), IP (9.49), new loans 
of the responses have the expected direction. To clearly see this, tables 2.3 and 2.4 show the average sector responses and the proportion of negative sector responses for different IRF horizons. That is, we draw a vertical line on a specified point on the $\mathrm{x}$ axis in figure 1.5 and take the average and proportion of negative values.
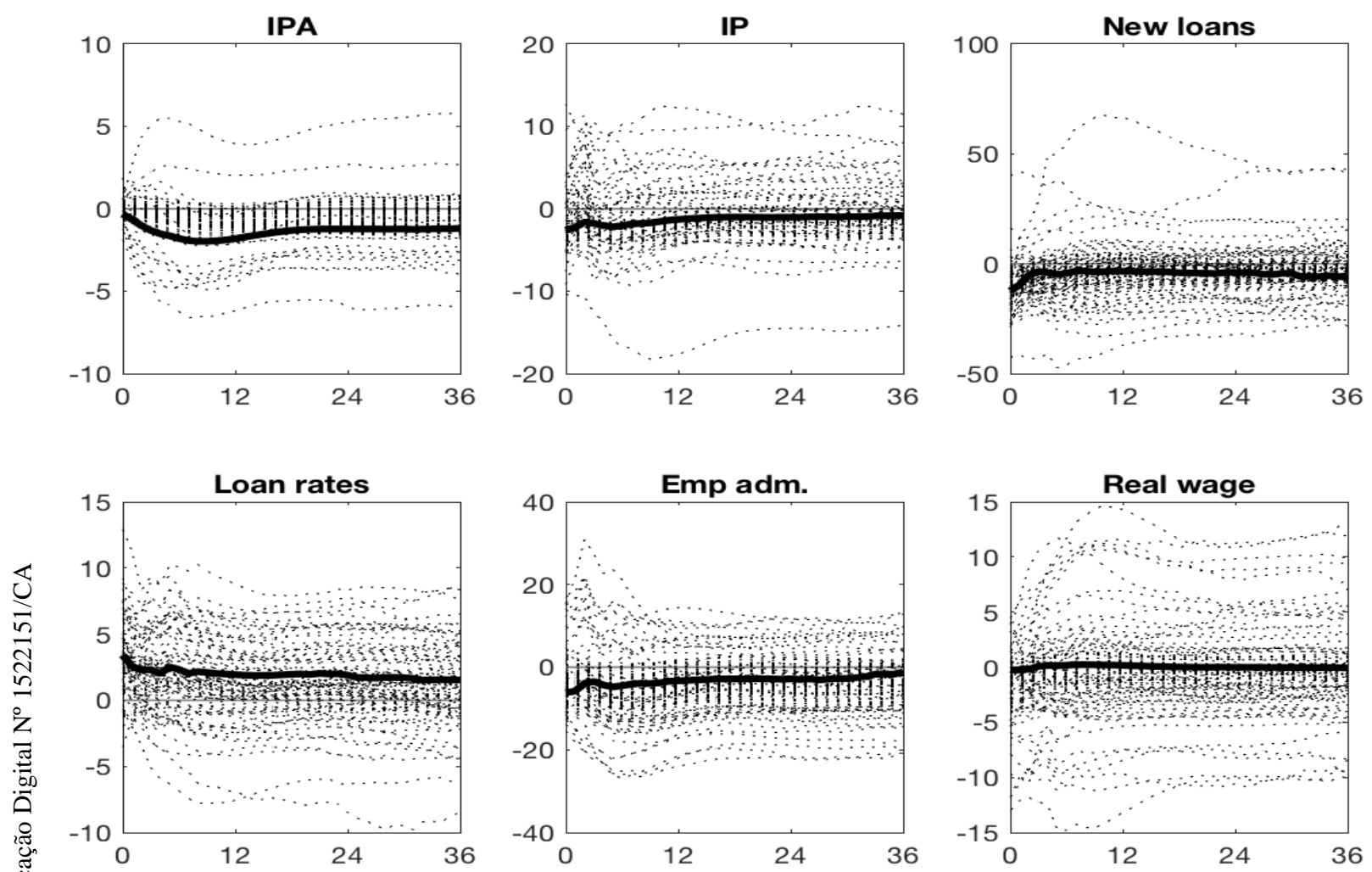

Figure 1.5: Mean of the posterior mean bounds interval for six different sector variables: industrial production (IP), producer prices (IPA), new loans, employment admissions, loan rates and real wages. The sector lines are represented in light gray while the black lines show the corresponding aggregate variable response. Responses are in percent and on level variables.

Table 2.4 shows a widespread pass-through from the policy rate hike to sector loan rates, since $88 \%$ of them rise within a month. Also, $94 \%$ of sector new loans fall. Together, these evidences point out to a contraction in the supply of funds (rise in prices and fall in quantity), a pattern that might be explained by an operating credit channel of monetary policy. For other real variables, most responses have the expected negative sign. Also, we note real activity variables, new loans and loan rates effects occur shortly after the shock, while prices react more sluggish, with an average negative peak of $-1.03 \%$ ten months after the shock.

(44.10), loan rates (10.36), employment admissions (18.57) and real wages (9.15). We can also notice that aggregate series responses have reasonable magnitudes. 
Chapter 1. Do earmarked loans affect the transmission of monetary policy?

Table 1.3: Average sector IRF's.

\begin{tabular}{lcccccc}
\hline \hline $\begin{array}{l}\text { IRF } \\
\text { horizon }\end{array}$ & IPA & IP & $\begin{array}{c}\text { New } \\
\text { loans }\end{array}$ & $\begin{array}{c}\text { Loan } \\
\text { rates }\end{array}$ & $\begin{array}{c}\text { Emp. } \\
\text { adm. }\end{array}$ & $\begin{array}{c}\text { Real } \\
\text { wages }\end{array}$ \\
\hline $\mathrm{h}=0$ & 0.00 & -1.91 & -11.30 & 3.07 & -3.53 & -1.91 \\
$\mathrm{~h}=1$ & -0.11 & -0.95 & -7.65 & 2.31 & -3.26 & -1.60 \\
$\mathrm{~h}=2$ & -0.25 & -0.13 & -6.33 & 2.03 & -2.55 & -1.36 \\
$\mathrm{~h}=3$ & -0.42 & -1.38 & -6.61 & 2.20 & -4.10 & -0.82 \\
$\mathrm{~h}=4$ & -0.57 & -1.66 & -5.05 & 1.89 & -5.20 & -0.54 \\
$\mathrm{~h}=6$ & -0.79 & -1.53 & -5.67 & 2.04 & -5.60 & -0.63 \\
$\mathrm{~h}=8$ & -0.98 & -1.41 & -4.51 & 1.73 & -5.64 & -0.37 \\
$\mathrm{~h}=10$ & -1.03 & -1.05 & -3.63 & 1.45 & -5.21 & -0.34 \\
$\mathrm{~h}=12$ & -0.99 & -0.88 & -3.12 & 1.29 & -4.68 & -0.29 \\
\hline \hline
\end{tabular}

Note: mean of the posterior mean bounds intervals, averaged across sectors, for six different variables: industrial production (IP), producer prices (IPA), new loans, new employment admissions, loan rates and real wages. Values for different IRF horizons. Responses are in percent and on level variables.

\begin{tabular}{|c|c|c|c|c|c|c|}
\hline $\begin{array}{l}\text { IRF } \\
\text { horizon }\end{array}$ & IPA & IP & $\begin{array}{l}\text { New } \\
\text { loans }\end{array}$ & $\begin{array}{l}\text { Loan } \\
\text { rates }\end{array}$ & $\begin{array}{l}\text { Emp. } \\
\text { adm. }\end{array}$ & $\begin{array}{c}\text { Real } \\
\text { wages }\end{array}$ \\
\hline $\mathrm{h}=0$ & 0.49 & 0.77 & 0.94 & 0.12 & 0.80 & 0.80 \\
\hline $\mathrm{h}=1$ & 0.51 & 0.73 & 0.91 & 0.17 & 0.80 & 0.76 \\
\hline $\mathrm{h}=2$ & 0.54 & 0.65 & 0.88 & 0.18 & 0.79 & 0.74 \\
\hline $\mathrm{h}=3$ & 0.58 & 0.74 & 0.87 & 0.21 & 0.82 & 0.66 \\
\hline $\mathrm{h}=4$ & 0.72 & 0.74 & 0.80 & 0.25 & 0.83 & 0.62 \\
\hline $\mathrm{h}=6$ & 0.80 & 0.72 & 0.78 & 0.26 & 0.81 & 0.63 \\
\hline $\mathrm{h}=8$ & 0.88 & 0.70 & 0.75 & 0.25 & 0.80 & 0.58 \\
\hline $\mathrm{h}=10$ & 0.89 & 0.70 & 0.71 & 0.25 & 0.81 & 0.61 \\
\hline $\mathrm{h}=12$ & 0.89 & 0.72 & 0.70 & 0.24 & 0.81 & 0.60 \\
\hline
\end{tabular}

Note: mean negative proportion across sectors of the means of the posterior mean bounds intervals for six different variables: industrial production (IP), producer prices (IPA), new loans, employment admissions, loan rates and real wages. Values for different IRF horizons.

Overall, figure 1.5 and tables 2.3 and 2.4 document sector responses that reveal a widespread economic downturn following the monetary contractionary shock. It can also be noticed a large sector heterogeneity in responses following a monetary shock. The next subsection shows this heterogeneity may be partially explained by the availability of earmarked funds in each sector. 
Chapter 1. Do earmarked loans affect the transmission of monetary policy?

\subsection{3}

\section{Earmarked loan effects on monetary policy power}

In this subsection we check whether the availability of earmarked loans is informative about the responses to a monetary shock for six different disaggregated variables: industrial production (IP), producer prices (IPA), new loans, loan rates, employment admissions and real wages. Specifically, we run cross-section regressions, on the sector level, of the mean identified set of IRF's on the share of earmarked loans and other regression controls. To account for parameter variability in $\phi$ and construct a distribution for regression parameters, we run these regressions in each iteration of Giacomini \& Kitagawa (5) algorithm, according to equation 1-11. We run separate regressions for each IRF horizon presented on tables 2.3 and 2.4.

Table 2.5 summarizes the main results of this paper. For each dependent variable and IRF horizon, it presents the estimated median of $\beta$ in equation 1-11, along percentiles 16th and 84th. ${ }^{31}$ Figures 1.6 and 1.7 show the corresponding histograms. Besides new loan responses, median estimates for all other dependent variables point to a weakening of monetary policy power: given a contractionary shock, industrial production, employment admissions, prices and real wages fall less, while loan rates $\underline{\text { rise less, }}$, for sectors with larger availability of earmarked loans. Parameter estimates that are different from zero with high probability were marked in red to facilitate visualization of results. Overall, a $10 \%$ rise in the share of earmarked loans for a given sector weakens this sector loan rate response between $0.22 \%$ and $0.38 \%$ after 3 to 12 months. It also weakens this sector industrial production response between $0.34 \%$ and $0.47 \%$ after 2 to 8 months and its employment admissions responses between $0.56 \%$ and $1.13 \%$ until 2 months after the shock. The timing of earmarked loans availability impact on price responses follow those of industrial production and manifest itself when the drop in prices begins to unfold for most of the sectors. In this case, a $10 \%$ rise in the share of earmarked loans weakens the sector price response between $0.11 \%$ and $0.18 \%$ after 2 to 12 months.

Similar tables for control variables coefficients are presented in Appendix A.2. We notice that prices fall less and employment admissions fall more in sectors with a higher share of working capital loans among bank debt (table A.2.1). This finding is theoretically consistent with an operating cost channel of monetary policy in these sectors [(33), (18)]. We also find in table A.2.2 that prices, new loans and employment admissions fall less in

\footnotetext{
${ }^{31} \mathrm{It}$ is a common practice in the bayesian VAR literature to present $68 \%$ credibility regions $[(26),(35),(31)]$.
} 
sectors that contributed more to federal campaigns in $2014 .^{32}$ We believe this result might be related to political links between campaign contributing firms and the government. In a recession, for example, sectors that contributed more to campaigns might receive additional benefits of the government (e.g.: tax exemptions), thus mitigating the negative effects of the contractionary monetary shock. Lastly, the average size of firms in a sector relates ambiguously to monetary policy power, as shown in table A.2.3. While this variable is related to a lower rise in loan rates, it is also contributing to a sharper decline in prices.

As a robustness exercise, we try as dependent variables points in the identified set of IRF's other than the mean. We have chosen the mean so far, since it is the standard representative element of an interval. However, different points in the identified set of IRF's are observationally equivalent for the set identification strategy and we have no a priori reasons to choose a specific one. Thus, in Appendix A.3 we present $\beta$ estimates when the dependent variable is defined for points on the identified set of IRF's other than the mean. ${ }^{33}$ Median parameter estimates point to similar effects of earmarked loans availability on monetary policy power mentioned before. But the additional layer of uncertainty introduces some imprecision in the estimates. With high probability, the effects of earmarked loans share on prices and employment admissions remain, but not for industrial production and loan rates.

Overall, we interpret the results as showing interference of earmarked loans availability on the transmission of monetary policy at the sector level. Monetary policy loses power at the sector level not only for loan rates, what may be mechanically explained, but also for producer prices, industrial production and employment admissions. In this sense, our results are a complementary evidence on a more aggregate level of what Bonomo \& Martins (1) have shown for the firm level. Additionally, it gives evidence of monetary policy power loss for prices and industrial production, a novel contribution of this paper.

\footnotetext{
${ }^{32}$ Industrial production falls more within 3 months after the shock, but we see this as an isolated finding.

${ }^{33}$ We give details on how we do this in Appendix A.3. It is important to note the restrictions we impose to identify a monetary shock satisfy Giacomini \& Kitagawa (5) Lemma 5.2 conditions for $I S_{r}(\phi \mid Q)$ to be a convex set. Thus, every point in the identified set of IRF's is attainable for a specific $Q$ matrix.
} 
Chapter 1. Do earmarked loans affect the transmission of monetary policy?

Table 1.5: $\beta$ percentiles for OLS regressions in equation 1-11.

\begin{tabular}{|c|c|c|c|c|c|c|c|}
\hline $\begin{array}{l}\text { IRF } \\
\text { horizon }\end{array}$ & $\begin{array}{c}\text { Per- } \\
\text { centile }\end{array}$ & IPA & IP & $\begin{array}{l}\text { New } \\
\text { loans }\end{array}$ & $\begin{array}{l}\text { Loan } \\
\text { rates }\end{array}$ & $\begin{array}{l}\text { Emp } \\
\text { adm. }\end{array}$ & $\begin{array}{l}\text { Real } \\
\text { wage }\end{array}$ \\
\hline \multirow[t]{3}{*}{$\mathrm{h}=\mathbf{0}$} & $\mathrm{p} 16$ & -0.41 & -0.83 & -24.47 & -4.36 & 0.93 & -1.16 \\
\hline & $\mathrm{p} 50$ & 0.15 & 0.94 & -10.55 & -0.37 & 5.56 & 0.26 \\
\hline & p84 & 1.03 & 5.83 & 5.92 & 2.25 & 14.61 & 1.64 \\
\hline \multirow[t]{3}{*}{$h=1$} & p16 & -0.28 & -0.08 & -19.79 & -4.66 & 1.27 & -1.97 \\
\hline & $\mathrm{p} 50$ & 0.54 & 2.32 & -8.18 & -0.03 & 10.03 & 0.47 \\
\hline & $\mathrm{p} 84$ & 1.93 & 7.65 & 10.48 & 1.92 & 17.80 & 2.41 \\
\hline \multirow[t]{3}{*}{$\mathrm{h}=\mathbf{2}$} & p16 & 0.07 & 0.32 & -21.01 & -7.67 & 0.83 & -1.68 \\
\hline & $\mathrm{p} 50$ & 1.14 & 3.42 & -6.65 & -1.70 & 11.30 & 0.52 \\
\hline & p84 & 3.35 & 9.24 & 9.65 & 1.91 & 20.03 & 3.60 \\
\hline \multirow[t]{3}{*}{ ᄂ $=3$} & p16 & 0.43 & 0.66 & -20.11 & -8.62 & -1.06 & -1.96 \\
\hline & $\mathrm{p} 50$ & 1.50 & 4.68 & -5.27 & -2.27 & 10.44 & 1.43 \\
\hline & p84 & 3.69 & 11.89 & 19.80 & -0.31 & 21.64 & 5.23 \\
\hline \multirow{3}{*}{$\frac{n}{2}=4$} & p16 & 0.68 & 0.53 & -17.19 & -9.80 & -2.68 & -1.94 \\
\hline & $\mathrm{p} 50$ & 1.48 & 4.17 & -3.90 & -2.65 & 11.32 & 1.15 \\
\hline & p84 & 3.85 & 13.08 & 29.64 & -0.80 & 20.93 & 6.84 \\
\hline \multirow{3}{*}{ 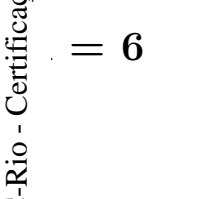 } & p16 & 0.81 & 0.24 & -20.22 & -12.69 & -4.43 & -2.37 \\
\hline & p50 & 1.55 & 4.18 & -3.42 & -3.78 & 12.70 & 2.03 \\
\hline & p84 & 3.58 & 13.03 & 24.13 & -0.28 & 23.12 & 6.16 \\
\hline \multirow[t]{3}{*}{$h=8$} & p16 & 0.88 & 0.11 & -20.98 & -13.88 & -5.68 & -2.19 \\
\hline & $\mathrm{p} 50$ & 1.76 & 3.77 & -1.17 & -3.89 & 12.36 & 2.46 \\
\hline & p84 & 3.50 & 11.72 & 17.94 & -0.84 & 24.04 & 8.31 \\
\hline \multirow[t]{3}{*}{$\mathrm{h}=10$} & p16 & 0.74 & -1.40 & -22.93 & -14.39 & -5.02 & -1.28 \\
\hline & $\mathrm{p} 50$ & 1.49 & 3.22 & 2.06 & -3.76 & 12.52 & 2.33 \\
\hline & p84 & 3.32 & 10.32 & 17.27 & -0.95 & 26.39 & 6.83 \\
\hline \multirow[t]{3}{*}{$\mathrm{h}=12$} & p16 & 0.36 & -2.27 & -20.98 & -15.03 & -5.09 & -4.11 \\
\hline & $\mathrm{p} 50$ & 1.47 & 2.97 & 0.42 & -3.47 & 13.36 & 2.43 \\
\hline & $\mathrm{p} 84$ & 3.35 & 9.56 & 22.38 & -0.99 & 25.90 & 6.46 \\
\hline $\begin{array}{l}\text { observa- } \\
\text { tions }\end{array}$ & & 74 & 74 & 99 & 89 & 99 & 99 \\
\hline
\end{tabular}

Note: dependent variables are the mean of the identified set for industrial production (IP), producer price index (IPA), new loans, loan rates, new employment admissions, real wages. Distribution is calculated across iterations of the algorithm (ie: for different values of $\phi$ ). 

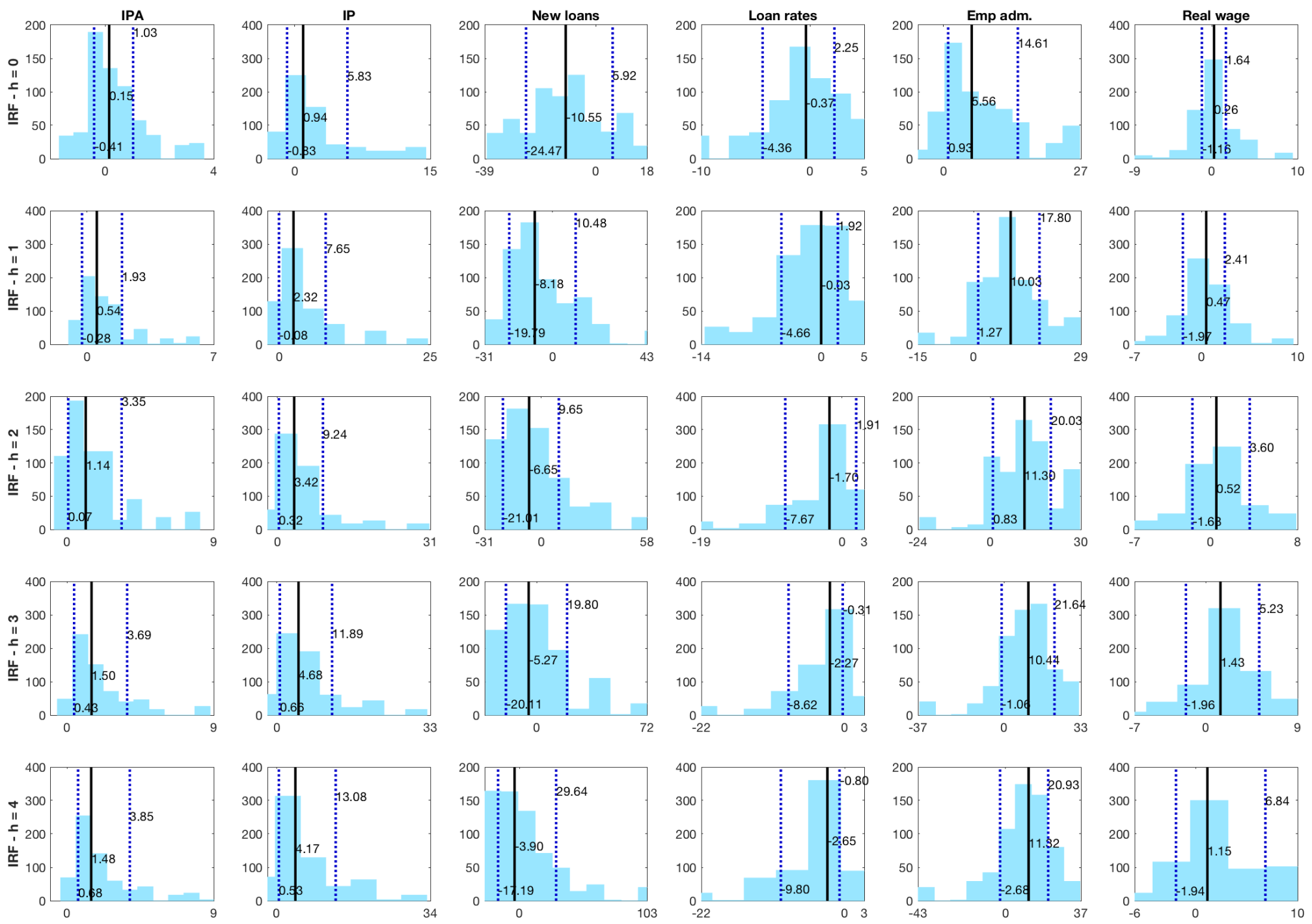

- Median $\cdots \cdots \cdots \cdot 16$ th and 84 th percentiles

Figure 1.6: $\beta$ histograms estimated in equation 1-11 on 650 draws of (5) algorithm. Every column denote a different dependent variable: industrial production (IP), producer price index (IPA), new loans, loan rates, employment admissions and real wages. Every row corresponds to a different IRF horizon. Dashed blue lines represent 16th and 84th percentis. The black vertical line represent the median. Responses are in percent and on level variables (part A). 

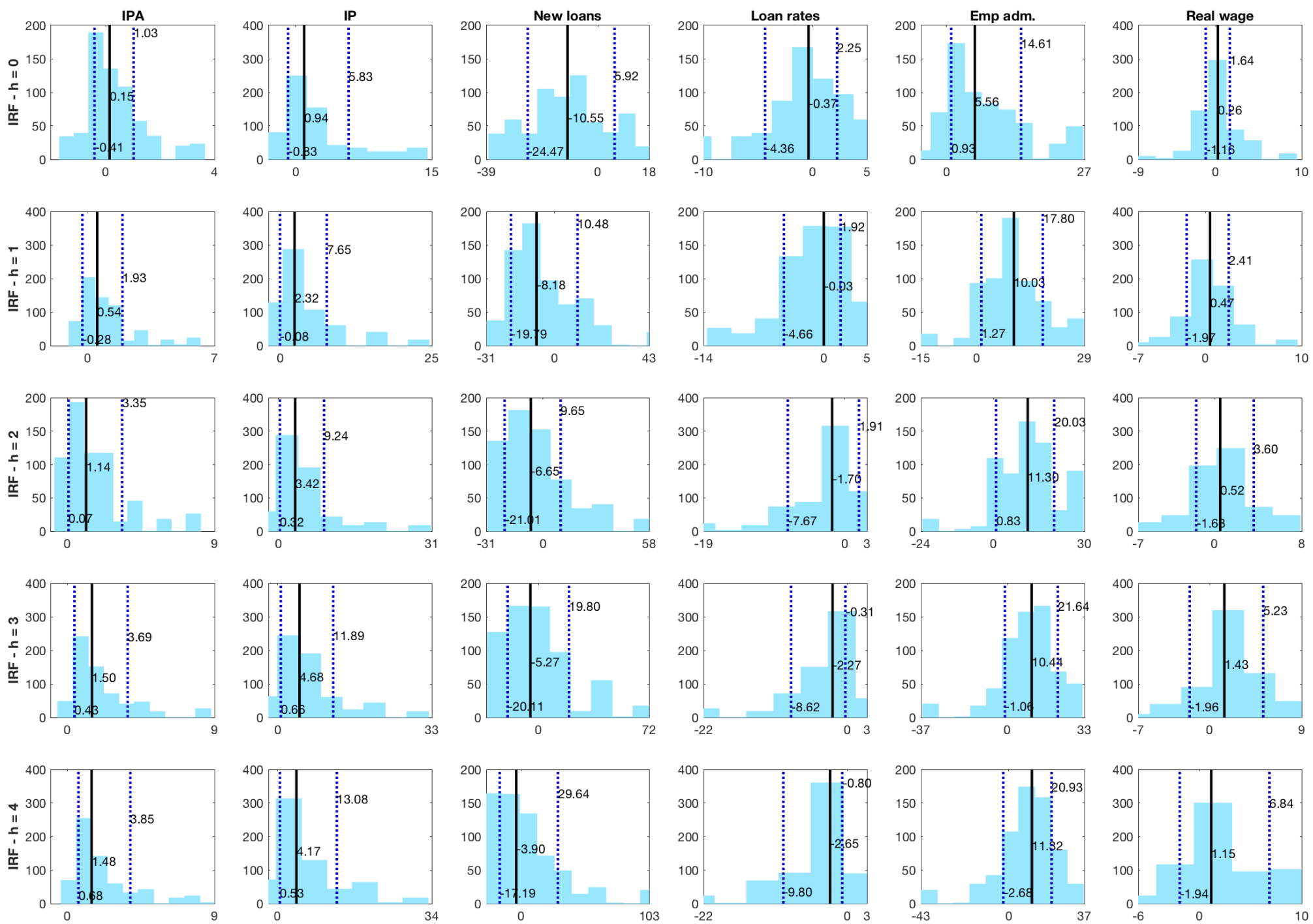

Figure 1.7: $\beta$ histograms estimated in equation 1-11 on 650 draws of (5) algorithm. Every column denote a different dependent variable: industrial production (IP), producer price index (IPA), new loans, loan rates, employment admissions and real wages. Every row corresponds to a different IRF horizon. Dashed blue lines represent 16th and 84th percentiles. The black vertical line represent the median.Responses are in percent and on level variables (part B). 


\section{6 \\ Discussion}

Monetary policy channels. We haven't mentioned so far which monetary policy channels are possibly being partially blocked by the availability of earmarked loans. We believe our results fit more clearly in the usual interest rate channel (or cost of capital channel) in which monetary policy affects firms/consumers decisions through movements in interest rates. In this case, the different availability of earmarked funds with below market interest rates across sectors will mechanically produce heterogeneous real loan rates responses to monetary shocks. ${ }^{34}$ Thus, investment and consumption decisions will be different across sectors, leading to heterogeneous responses in employment, prices and production.

Although our results are more easily interpreted with usual demand-side mechanisms, other more elaborated stories on the supply-side of credit that rely on credit market imperfections (e.g.: credit channel) are possible. If monetary policy is able to affect the cost of funds for some banks on top of the rise in interest rates, ${ }^{35}$ the loan supply schedule for these banks will be affected (38). Assuming these credit imperfections are more intense on lenders that cannot provide earmarked loans, there might be a link between the existence of a credit channel and the availability of earmarked funds. A reasonable example would be if the credit channel operates for regular private banks, but not for public banks and BNDES, a fair hypothesis since the government usually borrows at a rate close to the policy rate. But this link is not dependent on a policy invariant and below market loan rate for earmarked funds. It only implies two different credit markets, earmarked and non-earmarked, one in which the credit channel is operational and the other where it is not. Thus, it would not be an evidence that earmarked loans affect monetary policy power through the credit channel, only that this channel is not operational on the market for earmarked loans. Nevertheless, we believe this evidence would have to be supported with information on the supply side of credit, as done in papers that presented evidence of the credit channel of monetary policy [(39), (40), (41), (42)].

Aggregate effects of earmarked loans availability. So far, our results presented the loss of monetary policy power on sectors with larger

\footnotetext{
${ }^{34}$ We don't even need some form of nominal rigidity to justify the ability of monetary policy to change real rates in this case. The existence of a policy invariant below market loan rate for some economic sectors will mechanically produce heterogeneous real rate responses.

${ }^{35}$ This may occur either through a partial replacement of deposits for more expensive forms of financing (a bank lending channel), or through a deterioration of bank's balance sheets that lead to a fall in bank's creditworthiness (a balance sheet channel).
} 
availability of earmarked loans, but little can be said about earmarked loans aggregate consequences, since we are not capturing general equilibrium effects. In a discussion of firm-level implications of earmarked loans to monetary policy, Castro (18) pointed out that Bonomo \& Martins (20) findings that firms with more access to these funds react less to monetary policy don't necessarily translate in the same order of magnitude for aggregate effects of earmarked loans on monetary policy. As a theoretical example, the author showed in a simple DSGE model that firm and aggregate effects of earmarked funds on monetary policy power can be considerably different. While the same critic applies to this paper, our results contribute to the discussion giving novel evidence that monetary policy loses power due to earmarked loans in a more aggregate level than firm-level. Thus, we are capturing "intra-sector" general equilibrium effects and, so, might be closer to the true aggregate effects.

\section{7}

\section{Conclusion}

We provided evidence that monetary policy loses power in sectors with greater availability of earmarked loans. As long as our findings carry out to aggregate effects, they endorse the view that the big swings in the policy rate seen in the last years should have had greater effects on prices and production in the absence of earmarked loans. In this regard, our findings have policy implications. We believe the evidence presented, along those of Bonomo \& Martins (20), provide valuable information to evaluate the granting of earmarked loans as a public policy. 


\section{"Still" an agnostic procedure to identify monetary policy shocks with sign restrictions}

In this paper we use prominent models as a laboratory to analyze the performance of different identification strategies and propose the introduction of new model consistent restrictions to identify monetary policy shocks in SVARs. In particular, besides standard sign restrictions on interest rates and inflation, we propose to add as an identification restriction the inability of monetary policy to have real effects ten years after the shock. We present evidence of the model consistency of this neutrality restriction both for the canonical 3-equation new keynesian model and the Smets and Wouters (2007) model. In a simple empirical application, we show that this restriction may be important to recover real effects of monetary policy.

JEL Classification: C32, E52

Keywords: Monetary shock, identification, SVAR, sign restrictions

\section{1}

\section{Introduction}

What is the effect of monetary policy on the economy? This question has been addressed empirically at least in the last 30 years, most often using structural vector autoregression (SVAR) techniques. But results are far for conclusive and some of them point to responses of different directions than theory suggests, even for key macroeconomic variables, such as inflation and output. ${ }^{1}$ The reason for the lack of convergence in responses for such an old question lies in the difficulty of estimating causal effects in macroeconomics. Since most macro variables are endogenously determined in dynamic systems, identifying the effects of an exogenous variation in the desired variable (the monetary policy rate, for example) requires the introduction of identification restrictions the data are typically silent about.

Since the data are most often not informative about the imposed restrictions, a validation exercise would be to test these restrictions against a class

\footnotetext{
${ }^{1}$ Recent surveys of the literature include Nakamura \& Steinsson (43) and Ramey (44).
} 
of models considered adherent to the data by the macro community. In this case, the reasonableness of the proposed restrictions will depend on the group of models that comply with them. The larger this class of models, the more robust are considered the restrictions. But how do traditionally used SVAR identification techniques perform in these controlled environments? The most common approach, Cholesky identification, does not hold in new keynesian models, so it can imply severely biased impulse response functions (IRF) when the shock of interest is identified with this procedure [(45), (46)]. Even for other approaches, the identification of all parameters in a SVAR may require an amount of exclusion restrictions not compatible with a large class of models. On the other hand, agnostic techniques that rely on the imposition of fewer restrictions than required to assure point identification, ${ }^{2}$ such as Canova (28) and Uhlig (26) sign restrictions approach, may represent insufficient structure to identify the shock of interest [(47), (48), (49)].

In this paper we use prominent models as a laboratory to analyze the performance of different identification strategies and propose the introduction of new restrictions to identify monetary policy shocks in SVARs. In particular, we propose to add to the standard sign restrictions used in the literature (i.e.: restrictions on interest rates and inflation responses) a novel set of equality restrictions: the inability of monetary policy to have real effects 10 years after the monetary shock. When only sign restrictions are imposed, the identification of monetary policy shocks is confounded by combinations of demand and supply shocks, as shown by Wolf (49). Since these confounding shocks are usually very persistent, the introduction of neutrality restrictions in the medium-run does a good job trying to eliminate them, approximating the identified IRFs to it's true effects.

While the introduction of neutrality restrictions shrink the identified set of IRFs, mitigating the problem that sign restrictions alone are considered "too loose" to properly identify the desired effect, we believe it keeps the agnostic spirit of the set identification approach adopted in Uhlig (26), in the sense that it constitute a small set of restrictions with large theoretical background. Our challenge with these restrictions is to improve the identification of monetary policy shocks without imposing much structure, so we can be adherent to a large class of models. With this minimalist approach, we avoid "throwing the baby out with bathwater", that is, imposing unreliable structure in the data so it can forcefully produce precise estimates. As a downside, we lose precision

${ }^{2}$ In the context of identification of shocks in SVARs, we consider point identification the case in which the imposed restrictions allow the existence of a one-to-one map between the SVAR and its associated VAR representation. We call set identification the case in which this map is many-to-one. 
in our results.

Our first contribution is to show the introduction of model consistent neutrality restrictions improves identification substantially. As measures of identification performance, we present the identified IRF bounds together with the underlying model IRF and the fraction of real variables negative responses following a contractionary monetary shock, both widely used in this literature $[(27),(50)]$. For almost all real variables and IRF horizons, the identified set of IRFs is substantially tightened with the introduction of neutrality restrictions. It also comprises the underlying model responses or at least become very close to it. We also show that identified real variables responses following a contractionary shock are strictly negative few periods after the shock, so an empirical macroeconomist employing our identification strategy in this controlled environment would undoubtedly find real effects of monetary policy. For comparison, we present the identification performance when only sign restrictions are used to identify monetary shocks, an identification setup closer to Uhlig's (26) agnostic procedure. This comparison makes clear that the good performance of our identification proposal is entirely due to the inclusion of medium-run neutrality restrictions, since monetary shocks are poorly identified when only sign restrictions are imposed, even when the DGP is given by a model in which only monetary policy shocks satisfy these sign restrictions.

Second, we use the Smets \& Wouters (51) model as the underlying DGP to compare the performance of our identification approach with recent identification strategies proposed by Arias et al. (31) and Wolf (49) to identify monetary policy shocks. Both of these papers employ theoretical reasonable restrictions in a set identification SVAR context, what makes them perfectly comparable to our proposed identification setup. For the specific DGP used in this comparison, we argue our approach is more model consistent and effective them theirs. Finally, we provide a simple empirical application that shows the introduction of monetary neutrality restrictions in 10 years is sufficient to recover real effects of monetary policy, a result in contrast with Uhlig's (26) previous findings.

In the next section, we relate our paper to others in this literature. Then, we closely follow Wolf (49) in describing the problem with Uhlig's (26) "sign restriction only" approach to identify monetary policy shocks. Based on empirical and theoretical papers, we also argue why the neutrality restrictions make sense. We close the section with a clear example of how important the additional restriction may be in a standard textbook new-keynesian model. We repeat the exercise for a more reasonable DGP in section 2.4, the Smets \& Wouters (51) model, and compare the performance of our proposed restrictions 
with recent model-consistent restrictions suggested by Arias et al. (31) and Wolf (49). The fifth section presents a simple empirical application based on a VAR estimated with US data that shows the 10-year horizon neutrality restrictions may be important to identify real effects of monetary policy. The last section concludes.

\section{2}

\section{Related literature}

The use of SVAR to identify monetary policy shocks is observed since the 80's. Early methods of identification include short-run (27) and longrun restrictions (29). Evolution in data availability and computation capacity over the years made possible the introduction of new and modern methods, such as Uhli'g (26) sign restriction approach and high frequency identification $[(52),(53)]$. Recent techniques include the possibility of mixing sign and zero restrictions (32), the identification of VARs with instrumental variables [(54), (55)] and the robust computation of lower and upper bounds of IRFs through optimization procedures (?).

The empirical macro literature that made use of these techniques is large in scope. The causal effects of almost all thinkable aggregate disturbances have been studied, including monetary shocks $[(2),(56)]$, productivity shocks $[(57)$, (58)], government spending shocks (59), government taxation shocks [(59), (55)], oil price shocks (60), etc. Despite the great effort spent to answer these classical questions, a great variety of results can be found due to the difficulty in identifying causal effects in macroeconomics.

For this reason, a subgroup of this SVAR literature aims to validate these identification techniques in controlled environments. Some authors have showed the performance of recursive identification and sign restrictions in cases where the DGP is given by a specified model. Carlstrom et al. (45) documented the harsh implications a recursive approach may have on the responses of monetary shocks when the DGP is given by a standard new-kewnesian model. Castelnuovo (46) showed the Choleky identification underestimates the effects of monetary policy on financial variables in a medium scale new-kewnesian model with financial frictions. Even when the DGP satisfies the imposed restrictions, the truncation of the number of lags in a VAR can distort results when long run restrictions are imposed, as Chari et al. (57) point out in the discussion of the response of hours to productivity shocks in a businesscycle model. In the context of identifying monetary policy shocks with sign restrictions, Paustian (47), Castelnuovo (48) and Wolf (49) point to fact that Uhlig's (26) inequality restrictions on inflation and interest rate are not enough 
to recover real effects of monetary policy, even when the DGP is given by a model in which only monetary policy shocks satisfy the imposed restrictions. In this case, Paustian (47) documented that identification of multiple shocks and higher values for the variance of the shock of interest improve identification. However, Wolf (49) emphasized that even implausibly large variances of the shock of interest can't rule out the existence of confounding shocks in most common cases.

Another branch of this literature suggested the use of sign restrictions to choose between competing models that predict divergent causal effects of a specific shock on a variable of interest. The exercise work as follows: depart from a broad class of models with different frictions and uncertainty regarding parameter estimates. Derive the signs of variables responses to this shock that are robust to all possible models. Use these robust restrictions to partially identify a VAR with sign restrictions, leaving the variable of interest unrestricted. Dedola \& Neri (61) used this approach to identify how productivity shocks affect hours worked. They used a broad class of models that encompassed Real Business-Cycle (RBC) models and models with nominal rigidities, as well as different parameterizations for them, to derive the robust sign responses. The estimated VAR with US data and identified through these sign restrictions predicted that hours are more likely to rise following a productivity shock, an evidence in favor of RBC models. In a similar exercise, Canova \& Paustian (50) proposed this approach to investigate the compatibility of real data with wage and price rigidities, since different degrees of these frictions may result in divergent responses of wages to a monetary shock. The authors defended the importance of this method since the model likelihood may be flat for different degrees of these nominal rigidities, what undermines the use of traditional likelihood-ratio tests.

We are most connected to papers that argue for the introduction of model consistent restrictions as a way to improve identification. In this regard, Arias et al. (31) proposed the use of sign and zero restrictions on the monetary equation of the SVAR, what constitutes a novel approach to identification. Specifically, they impose that monetary policy contemporaneous reaction to inflation and output must be positive and also that monetary policy doesn't react to total and nonborrowed reserves on impact. ${ }^{3}$ Arias et al. (31) claim model consistency of their approach, since most new keynesian models include a Taylor rule with these features. With these new restrictions, the authors find that contractionary monetary shocks are most likely to have negative effects

\footnotetext{
${ }^{3}$ Although they introduce new sign and zero restrictions, their principal conclusions are driven mostly from their sign restrictions.
} 
Chapter 2. "Still" an agnostic procedure to identify monetary policy shocks with sign restrictions

on output, in contrast with Uhlig's previous findings. In the same spirit, Wolf (49) departs from Uhlig's approach to draw candidate impulse vectors, but proposes, in addition to sign restrictions on interest rates and inflation, the exclusion of candidate draws that have implausibly large effects on output. ${ }^{4}$

Our paper is similar to those two, in the sense of trying to bring to SVAR identification new model consistent restrictions. In section 2.4, we compare the model consistency of our approach with those of Wolf (49) and Arias et al. (31). We argue through comparisons based on the Smets \& Wouters (51) model that our proposed restrictions are more likely to shrink the identified set of impulse responses in the direction of the effects caused by true monetary policy shocks. For that, we claim our approach is more effective then theirs. To our knowledge, this paper is the first to analyze in a controlled environment how the combination of equality and inequality restrictions can improve identification. Much has been done with sign restrictions alone to test weather Uhlig's seminal sign restrictions recover the true effects of monetary policy [(47), (48), (49)]. But none of these papers have shown how the introduction of model consistent equality restrictions can improve identification.

\section{3}

Overview of main identification issues with sign restrictions and importance of the 10-year monetary neutrality restrictions

In this section we briefly present Uhlig's sign restriction approach to compute IRFs and point the possible identification problems with the identified set of impulse responses, closely following Wolf (49). We introduce and motivate why the additional 10-year neutrality restrictions make sense and help identify monetary policy shocks. Then, we show the implications of these additional restrictions when the DGP is given by a canonical 3-equation new-keynesian model, taken from Gali's (62) textbook.

\subsection{1}

\section{Uhlig's "pure sign restriction" approach}

To identify the shock of interest, we depart from the infinite SVAR representation of our model generated data:

$$
A^{-1} y_{t}=B+\sum_{j=1}^{\infty} B_{j} y_{t-j}+\epsilon_{t},
$$

where $y_{t}$ is a $n \times 1$ vector of observed macroeconomic variables and $\epsilon_{t}$ is a mean zero vector of structural disturbances. We assume these shocks are

${ }^{4} \mathrm{He}$ proposes the exclusion of impulse vectors with absolute value of (output response/monetary response) larger than 1.2 , on impact. 
not correlated with each other and impose unit variance as a normalization condition, $E\left(\epsilon_{t} \epsilon_{t}^{\prime}\right)=I_{n}$. As is standard in simultaneous equations models, the contemporaneous impact matrix, $A$, is not identified. For that reason, empirical macroeconomists usually try to recover structural content from this model departing from the associated VAR form of (2-1), given by:

$$
y_{t}=C+\sum_{j=1}^{\infty} C_{j} y_{t-j}+u_{t},
$$

where $u_{t}=A \epsilon_{t}$ and $E\left(u_{t} u_{t}^{\prime}\right)=A(A)^{\prime} \equiv \Sigma$. The theoretical appeal of the infinite VAR representation lies in the fact that it may be rationalized as a reduced form associated to a DSGE model if some conditions are satisfied, as shown by Fernández-Villaverde et al. (63). ${ }^{5}$ In the exercises that follows, these conditions are satisfied, so we are able to map the structural parameters of the DSGE model solution in the VAR representation.

Given the VAR representation, if we are interested in the effects of a particular shock, only one column of A have to be identified. Supposing we are interested only in the effects of monetary policy shocks, Uhlig's "pure sign restriction approach" to calculate IRFs works as follows. Consider $A$ the true SVAR contemporaneous impact matrix and its individual columns as $\left[a_{1}, a_{2}, \ldots, a_{n}\right]$. Uhlig (26) shows that, for any matrix $\tilde{A}$ that satisfies $\tilde{A} \tilde{A}^{\prime}=\Sigma$ (the Cholesky decomposition of $\Sigma$, for example), $a$ is a column of $A$ if and only if there is an n-dimensional vector $\alpha$ of unit length, so that $a$ can be characterized as $a=\tilde{A} \alpha$ (proposition A.1 of Uhlig (26)). Hence, his "pure sign restriction approach" consists of repeating the following steps:

1. Draw a random vector $\bar{\alpha}$ from the unit sphere.

2. Compute $\bar{a}=\tilde{A} \bar{\alpha}$ and the IRFs associated to $\bar{a}$.

3. Keep only those IRFs that satisfy the sign restrictions.

To impose the monetary neutrality restrictions, we use Arias et al. (32) algorithm to mix equality and inequality restrictions. It basically adds a previous step to Uhlig's "pure sign restriction approach" in which the vector $\bar{\alpha}$ is draw conditional on the imposed equality restrictions. Then, we calculate the impulse response functions and keep those that satisfy the sign restrictions.

All exercises that follows make use of these techniques. Specifically, we depart from the VAR equation (2-1) and try to recover the effects of

\footnotetext{
${ }^{5}$ Specifically, the number of observed variables and the number of orthogonal shocks in the model must be the same. Also, some conditions regarding the stability of a particular combination of the matrices representing the state-space solution of the model are necessary. We call these the invertibility conditions. In other words, the existence of an infinity VAR representation is conditional on the history of observed variables being perfectly informative about the current state variables.
} 
monetary policy shocks with sign and zero restrictions, assuming the true contemporaneous impact matrix, $A$, is unknown. This exercise simulates the procedures carried through by an empirical macroeconomist with real data. To focus exclusively on identification issues and avoid parameter estimation uncertainty, we use the true VAR parameters of the underlying model. ${ }^{6}$ We also employ a sufficient number of lags in the VAR to avoid lag truncation bias. As the underlying DGP, we consider in subsection 2.3.3 the standard 3-equation new-keynesian model. In section 2.4, we consider the Smets \& Wouters (51) model, a proper DGP for US data.

A problem with this approach is that, even if there is a single shock that satisfies the imposed restrictions, identification may be confounded by linear combinations of other structural disturbances. Uhlig (26) recognizes this issue and Wolf (49) shows that this is indeed the problem behind the conclusions of some empirical papers that made use of sign restrictions [(26), (61)]. To clearly see this point, note that the "pure sign restriction approach" implies the existence of an orthonormal matrix $Q$ that satisfies:

$$
A=\tilde{A} Q \Rightarrow A Q^{\prime}=\tilde{A}
$$

Thus, a candidate $\bar{a}$, given by a draw $\bar{\alpha}$ from the unit sphere, can be represented as:

$$
\bar{a}=\tilde{A} \bar{\alpha}=A Q^{\prime} \bar{\alpha}=A \bar{q}=a_{1} \bar{q}_{1}+a_{2} \bar{q}_{2}+\ldots+a_{n} \bar{q}_{n},
$$

where $\bar{q}_{i}$ is the element $i$ of the unit length vector $Q^{\prime} \alpha$. That is, $\bar{a}$ is a linear combination of the true columns of $\mathrm{A}$, with weights given by the vector $\bar{q}$. Hence, Uhlig's "pure sign restriction approach" delivers a set of linear combinations of structural shocks that satisfy the sign restrictions.

In the following sections, we show that the introduction of monetary policy neutrality restrictions can remove combinations of structural disturbances that confound the identification of monetary policy shocks when only sign restrictions on interest rates and inflation are imposed.

\subsection{2}

\section{Monetary neutrality restrictions in the medium-run}

Besides standard sign restrictions on inflation and interest rates, we propose that monetary policy should have no real effects ten years after the shock. We label this time horizon as medium run. The reason why these restrictions help the identification of monetary shocks is because it

\footnotetext{
${ }^{6}$ Since there are no identification issues regarding the estimation of VAR parameters, we would have obtained the same results simulating an arbitrarily large sample from the model, estimating VAR parameters and imposing the equality and inequality restrictions to recover the effects of monetary policy shocks.
} 
eliminates combinations of persistent supply and demand shocks that confound the identification of monetary disturbances when only sign restrictions are imposed. The 10-year neutrality restrictions, though, shrink the identified set of impulse responses in the direction of true monetary policy effects.

How reasonable are these restrictions? In practice, central banks are getting increasingly concerned about monetary policy transparency and predictability. Ben Bernanke, for example, left this message clear in a 2007 speech:

"The fact that the public is uncertain about and must learn about the economy provides a reason for the central bank to strive for predictability and transparency".

Greater predictability and transparency might mean that, given a monetary shock, central bank authorities will strive to conduct the economy rapidly to it's equilibrium path, thus reducing the persistence of the shock. Since the longevity of real effects of monetary policy are correlated to the shock persistence, the neutrality restrictions seem compatible with central banks intention to enhance predictability of policy decisions.

The hypothesis of monetary policy neutrality in 10 years is also consistent with a large group of empirical papers that employ different methods to identify the effects of monetary policy shocks. The neutrality restrictions are consistent, for example, Romer \& Romer (64) narrative method to identify monetary shocks, with Gertler \& Karadi (53) high frequency identification in VAR's and Evans \& Marshall (65), Boivin et al. (22) and Uhlig \& Pooyan (35) identification of monetary shocks in FAVARs. Boivin et al. (22) test the absence of relative sectoral price changes ten years after a monetary contractionary shock (what could induce a medium-run monetary non-neutrality) and find that the hypothesis of monetary neutrality in ten years is not rejected at a $10 \%$ significance level.

The proposed neutrality restrictions also have a large theoretical background. Models with very different ways to incorporate nominal rigidities feature monetary neutrality ten years after the shock. Examples include exogenous time-dependent price changes models (51), menu costs models (66) and models with rationally inattentive firms (67). In fact, we are not aware of a model with nominal rigidities in which the proposed restrictions don't hold at least approximately. For this reason, we believe the neutrality restrictions don't impose relevant additional structure on the underlying DGP, what make us feel comfortable of not departing from the agnostic proposal of the set identification literature. It is important to note, however, that the length of time for monetary policy to reach neutrality varies significantly among these models. In state-dependent price models, for example, monetary effects are usually "faster" than time-dependent price models. For this reason, we impose that sign restrictions are binding only until one quarter after the shock. Table 2.1 presents the restrictions that will be used throughout this paper. Time periods are defined quarterly. The central column shows the standard sign restrictions on interest rates and inflation used to identify a monetary contractionary shock. We call this set 
Chapter 2. "Still" an agnostic procedure to identify monetary policy shocks with sign restrictions

of restrictions the "sign restrictions only" approach. The right column adds the proposed neutrality restrictions, where $z_{t}$ represents a vector of real macroeconomic variables.

Table 2.1: Agnostic restrictions on impulse response functions

\begin{tabular}{lcc}
\hline \hline Variables & $\begin{array}{c}\text { Sign restrictions } \\
\text { only }\end{array}$ & $\begin{array}{c}\text { Sign and zero } \\
\text { restrictions }\end{array}$ \\
\hline$i_{t+h}$ & $\geq 0$ & $\geq 0$ \\
$\pi_{t+h}$ & $\leq 0$ & $\leq 0$ \\
$z_{t+40}$ & $?$ & $=0$ \\
\hline \hline
\end{tabular}

Notes: for the restrictions on inflation and interest rates we set $h=0,1$. The vector $z_{t}$ represents real wages, consumption, hours worked, output and investment when the DGP is given by the (51) model (section 4) and only output when the DGP is given by the 3 -equation model.

\subsection{3}

\section{3-equation model example}

To have a first glimpse on the impact of the medium-run neutrality restrictions on the identification of monetary shocks, we consider as the underlying DGP the canonical 3-equation model of Gali (62):

$$
\begin{array}{ccc}
y_{t}= & E_{t}\left(y_{t+1}\right)-\sigma^{-1}\left(i_{t}-E_{t}\left(\pi_{t+1}\right)-r^{*}\right)+e_{d, t}, \\
\pi_{t}= & \beta E_{t}\left(\pi_{t+1}\right)+\kappa y_{t}+e_{s, t}, \\
i_{t}= & \left(1-\phi_{r}\right)\left[r^{*}+\phi_{\pi} \pi_{t}+\phi_{y} y_{t}\right]+e_{i, t},
\end{array}
$$

where: $e_{j, t}=\rho_{j} e_{j, t-1}+\epsilon_{j, t}, j \in\{d, s, i\}$. In this stylized model, the IRF dynamics come from the shocks persistence, since there are no state variables besides the autoregressive shocks. The calibrated parameter values are presented in table B.1.1 in Appendix B.1.

Notice that only monetary policy shocks can drive interest rates and inflation in opposite directions. This feature is, indeed, present in a large group of newkeynesian models. Hence, it may appear at first glance that sign restrictions alone are sufficient to identify monetary policy shocks. Figure 2.1 presents the IRF's of a standard deviation monetary shock when identification is given by sign restrictions alone. Since we are not imposing enough restrictions to pin down a unique contemporaneous impact matrix $A$ (i.e.: a unique model associated with the VAR), we report IRF bounds computed for different matrices $A$ that satisfy the imposed restrictions. As emphasized in Fry \& Pagan (27), these bounds represent model uncertainty. For computing them, we run Uhlig's "pure sign restrictions" algorithm until we recover 10,000 accepted draws that satisfy the sign restrictions. 
The identified bounds of IRFs are presented with dashed red lines, the corresponding median is painted in black and the true model IRFs are presented in dashed blue lines. The identified IRFs are consistent with Uhlig's original findings: the sign of the output response is inconclusive ${ }^{7}$ and its median is positive. This is not a novel finding in the literature, as shown by Paustian (47), Castelnuovo (48) and Wolf (49). However, when the neutrality restriction on output is added to the sign restrictions, the IRF bounds became strictly negative, as presented in figure $2.2{ }^{8}$ Not only the upper and lower bounds of IRFs have the correct sign, but the bounds interval is tight, providing valuable information about the output response magnitude. Thus, for both measures of shock identification performance usually employed (i.e.: the fraction of responses with correct sign and the tightness of IRF bounds), an empirical macroeconomist who introduces the neutrality restriction will improve the identification of monetary policy shocks in a VAR.
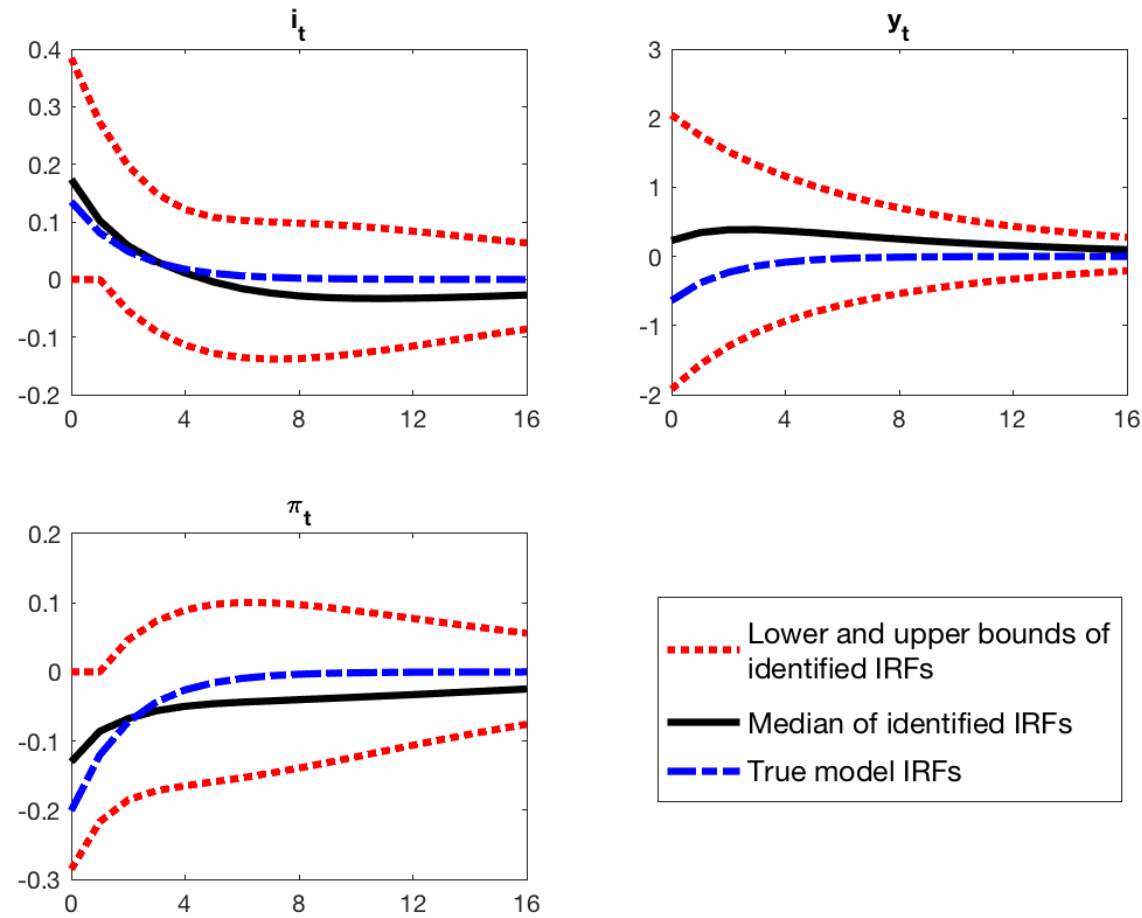

Figure 2.1: IRF's of a $\sigma_{i}$ contractionary monetary policy shock identified with only sign restrictions (3-equation model)

The reason behind this finding lies in the persistence of the underlying shocks. In this regard, the lower persistence of monetary shocks vis-a-vis other shocks is essential for the performance of our approach, since the neutrality restriction excludes confounding combination of persistent demand and supply shocks that satisfy the sign restrictions. This picture gets clear when we investigate the structural shock weights behind accepted draws of Uhlig's "pure sign restriction" algorithm (i.e.:

${ }^{7}$ Since we are not estimating any parameters, the term "statistically zero" would be inappropriate.

${ }^{8}$ This time we use Arias et al. (32) algorithm to mix equality and inequality restrictions until we accept 10,000 draws. 
the weight vector $\bar{q}$ in equation $(2-4)) .{ }^{9}$ For identified IRFs, figure 2.3 presents the output responses on impact (x axis) and the weights associated with each structural disturbance (y axis), both for the "sign restrictions only" case (left panel) and the sign and zero restriction case (right panel). The vertical line represents the true model effect. As we can see, the true IRF of output on impact is obtained for both cases when the monetary policy shock weight is close to one and other weights are close to zero. Figure 2.3 also makes clear that the improvement in identification performance due to the introduction of a 10-year neutrality restriction really reflects better identification of monetary shocks and not some spurious combinations of other structural disturbances. Hence, we argue the proposed neutrality restriction shrinks the identified set of impulse responses toward the true monetary policy effects.
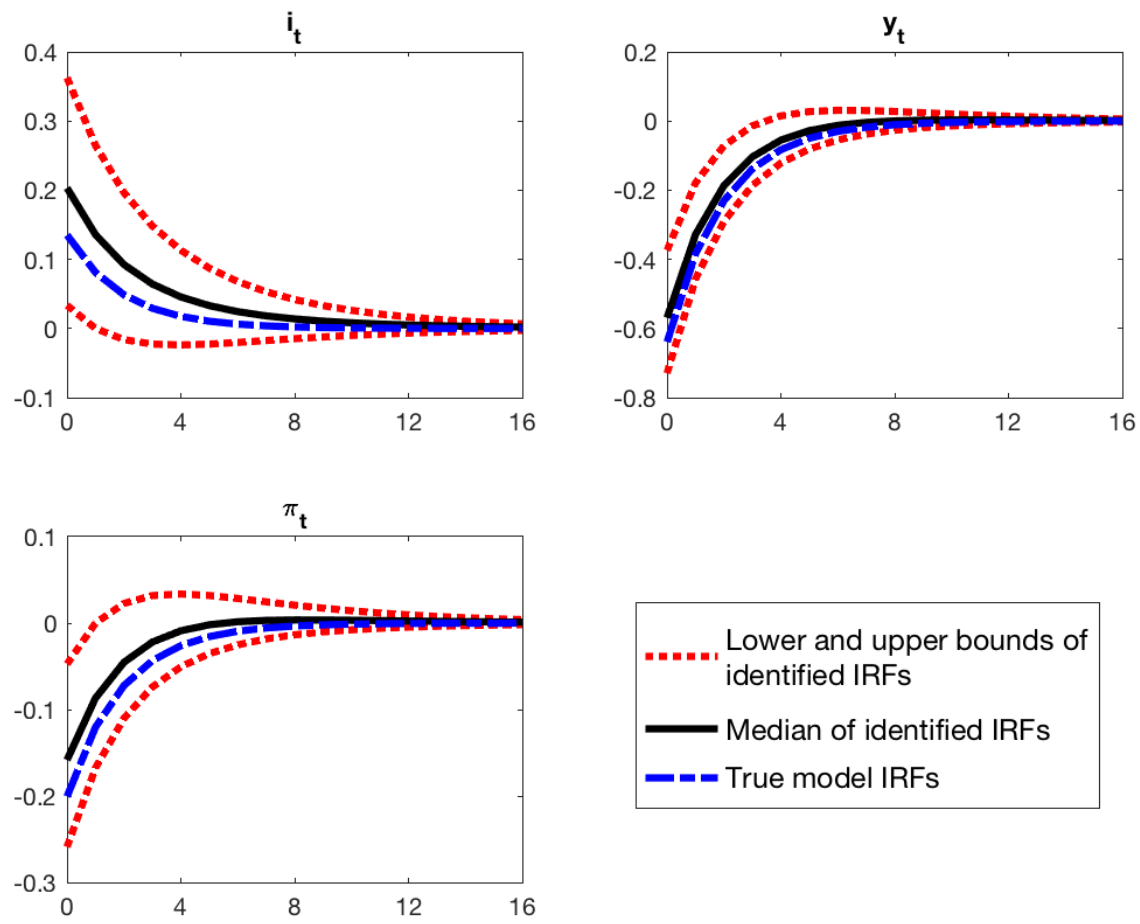

Figure 2.2: IRF's of a $\sigma_{i}$ contractionary monetary policy shock identified with sign restrictions and monetary neutrality restrictions (3-equation model)

\section{4}

\section{Smets and Wouters (2007) model}

In this section, we repeat last section exercises, but for a proper DGP, the Smets \& Wouters (51) model. We also compare the model consistency and efficiency of the medium-run monetary neutrality restrictions with recent identification restrictions proposed by Arias et al. (31) and Wolf (49). We argue our proposed restrictions are more model consistent and more effective at recovering true monetary policy shocks.

${ }^{9}(49)$ originally proposed this investigation. We follow his approach and present a similar figure. To smooth the original weights, we follow Wolf (49) and plot the weights filtered with a HP filter. 

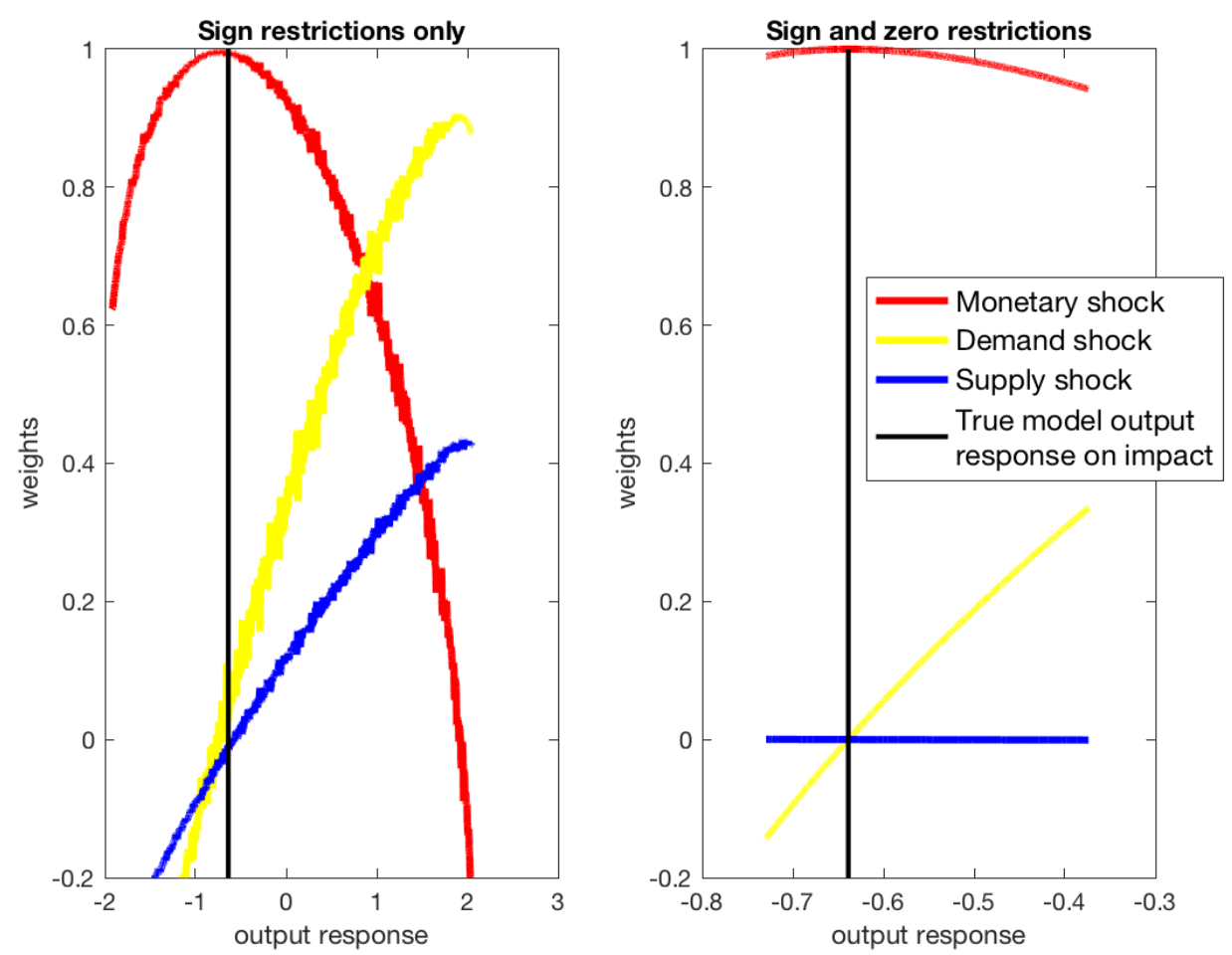

Figure 2.3: Structural shocks weights versus output impact responses for identified IRFs (3-equation model)

The Smets \& Wouters (51) model represents a theoretical rich environment, since it embodies important features to fit the data, such as habit formation in consumption, investment adjustment costs and variable capacity utilization of capital. For this purpose, it also includes price and wage rigidities. All of these elements contribute for the existence for reasonable hump-shaped impulse responses of seven different disturbances: government expenditure shocks, monetary policy shocks, risk premium shocks, investment shocks, mark-up shocks of wages and prices and total factor productivity shocks. This elaborated microfounded structure delivers a good probabilistic description of the data that makes the model a proper environment for policy analysis. That is why the Smets \& Wouters (51) model is the benchmark DGP used in this paper.

The dashed blue lines in figures 2.4 and 2.5 show the true effects of a standard deviation contractionary monetary shock for the Smets \& Wouters (51) model. We calculate all VAR parameters and IRF's for the mode estimated by the authors. We present the responses of all the observable variables used to estimate the model: interest rates $(i)$, real output $(y)$, inflation $(\pi)$, hour worked $(l a b)$, real wages $(w)$, real consumption $(c)$ and real investment $(i n v)$. As expected, the real variables present a hump-shaped negative response. Figure 2.4 also presents the identified impulse response bounds when only sign restrictions are imposed until one quarter after the shock. We can see the sign restrictions are not enough to deliver either the correct direction or reasonable bounds of real variables responses to a monetary shock, not even approximately. 

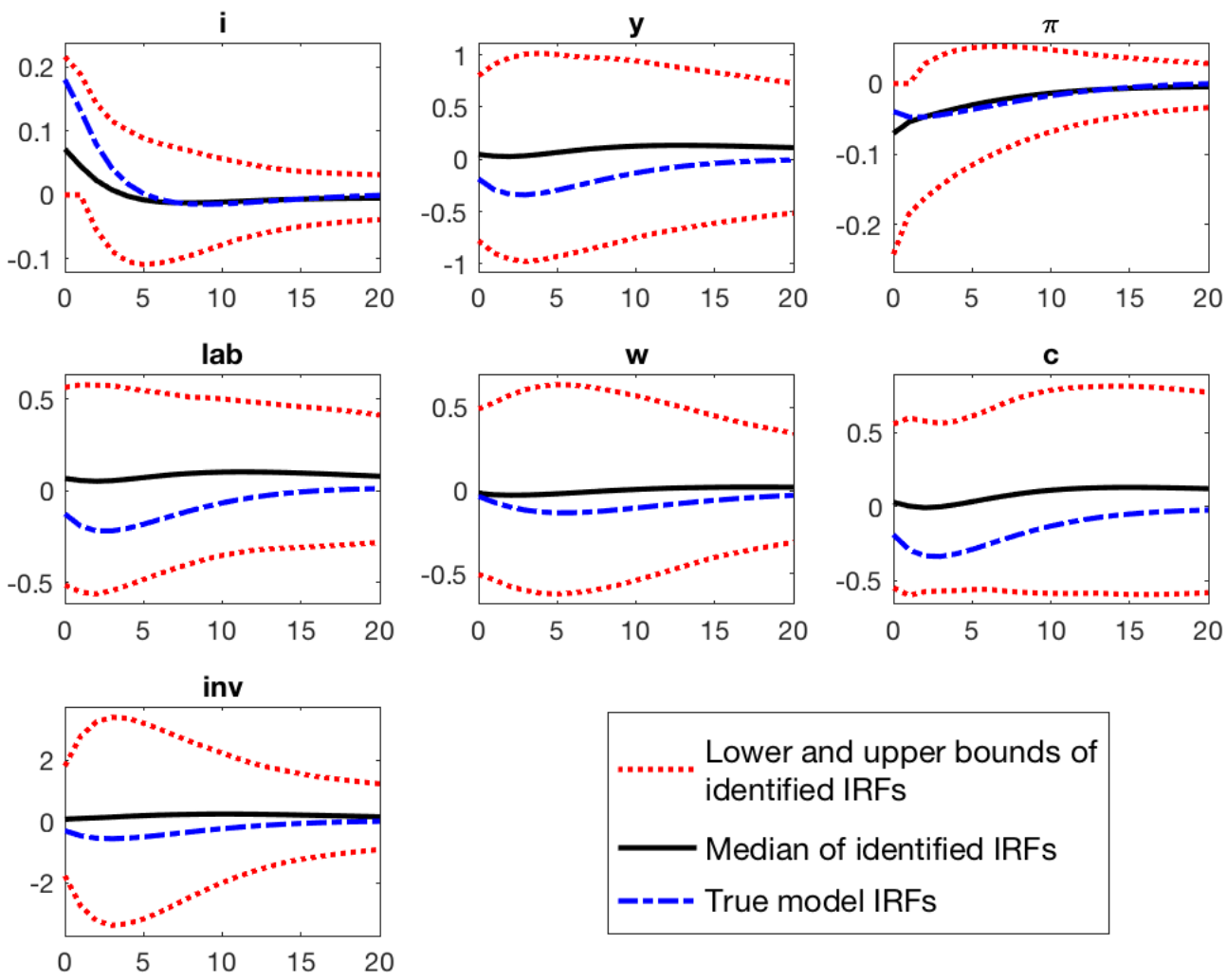

Figure 2.4: IRF's of a $\sigma_{i}$ contractionary monetary policy shock identified with only sign restrictions - SW(2007) model

As in the last section, when we impose the additional neutrality restrictions that monetary policy doesn't have real effects 10 years after the shock, identification improves substantially, as shown in figure 2.5. ${ }^{10}$ In comparison with figure 2.4, we can notice that the range of admissible responses is severely reduced. Despite the possibility of positive values for all real variables responses in the initial periods following the shock, the median is negative with a hump-shaped format. For almost all real variables, the underlying model IRFs are inside the identified bounds or at least very close to the lower bounds. ${ }^{11}$ Thus, as a first measure of identification performance, we can see that the range of identified IRF's provides valuable information regarding monetary policy effects. Also, we can notice that the median is always slightly underestimated, so it can be interpreted, at least for this DGP, as a lower bound for monetary policy effects.

Only the identified bounds and the median IRF's were shown in figures 2.4 and 2.5, hence it is important to present other features regarding the distribution of IRF's in these intervals. The close proximity between the lower bounds and the

${ }^{10}$ For the SW (2007) model, we impose monetary neutrality for all observed real variables: output, consumption, investment, hours worked and wages.

${ }^{11}$ The only exception is the investment response, since small weights to the investmentspecific shock have large effects on this variable. The reason why the underlying model IRFs lie bellow the identified lower bounds in some cases is due to small weights given to confounding shocks. Since all these confounding shocks are expansionist, they always push monetary policy responses in the opposite direction of its true effects. 
median for real variables responses gives a first hint that most identified responses are negative. As a second measure of identification performance, tables 2.2 and 2.3 show the proportion of negative responses for all real variables in different horizons after the monetary shock for the identification with only sign restrictions and the identification that adds monetary neutrality restrictions, respectively. As we can see, the former identification approach performs poorly, with almost all combinations of variables and IRF horizons below $50 \%$ of negative responses. The introduction of neutrality restrictions improves identification substantially. All IRF's proportion of negative responses are higher than $90 \%$ four quarters after the shock. This percentage increases with the IRF horizon, reaching strictly negatives responses for almost all real variables. ${ }^{12}$ In this sense, an empirical macroeconomist employing our identification strategy for this DGP would undoubtedly recover negative effects of a contractionary monetary policy shock, in contrast with the case when only sign restrictions are imposed, as in Uhlig (26).

Again, the reason behind the sharp identification improvement with the introduction of neutrality restrictions lies in the exclusion of combinations of persistent structural disturbances that confound the identification of monetary shocks when only sign restrictions are imposed. In figure 2.6, we report shock weights versus output responses on impact for identified IRFs, in the same lines of figure 2.3. Following Wolf (49), we split all the disturbances but monetary shocks between positive demand and positive supply shocks according to their sign impacts on output and inflation. ${ }^{13}$ The weights presented were averaged in these categories. Overall, the introduction of neutrality restrictions reduces the range of admissible impact responses for all real variables (mostly for positive values) and considerably increases the weight of monetary disturbances in the accepted draws of the algorithm.

How these results compare with Arias et al. (31) and Wolf (49) proposed identification restrictions when the DGP is given by the Smets \& Wouters (51) model? Tables 2.4 and 2.5 replicates the previous results incorporating the restrictions proposed by these authors, respectively. Arias et al. (31) most important restrictions for their results concern the parameters of the equation that describes the monetary policy rule in the SVAR. In particular, they impose that the interest rate responds positively to contemporaneous movements in inflation and output. ${ }^{14}$ That is, taking the SVAR representation in equation 2-1 as example, they impose that the entries of the $A$ matrix associated to output and inflation in the monetary rule equation must be negative. ${ }^{15}$ The authors claim model consistency of their restrictions, since

\footnotetext{
${ }^{12}$ Results are robust to imposing the neutrality restrictions in different time horizons, as shown in tables B.2.1 to B.2.4 in Appendix B.2.

${ }^{13}$ Demand shocks: investment-specific shock, risk premium shock, government expenditure shock. Supply shocks: total factor productivity shock, wage mark-up shock, price mark-up shock.

${ }^{14}$ They also impose that interest rates are not affected contemporaneously by total and nonborrowed reserves, but these restriction are not the ones driving down output after a contractionary monetary shock in their empirical exercise.

${ }^{15}$ Moving contemporaneous output and inflation to the right side of this equation, we can
} 

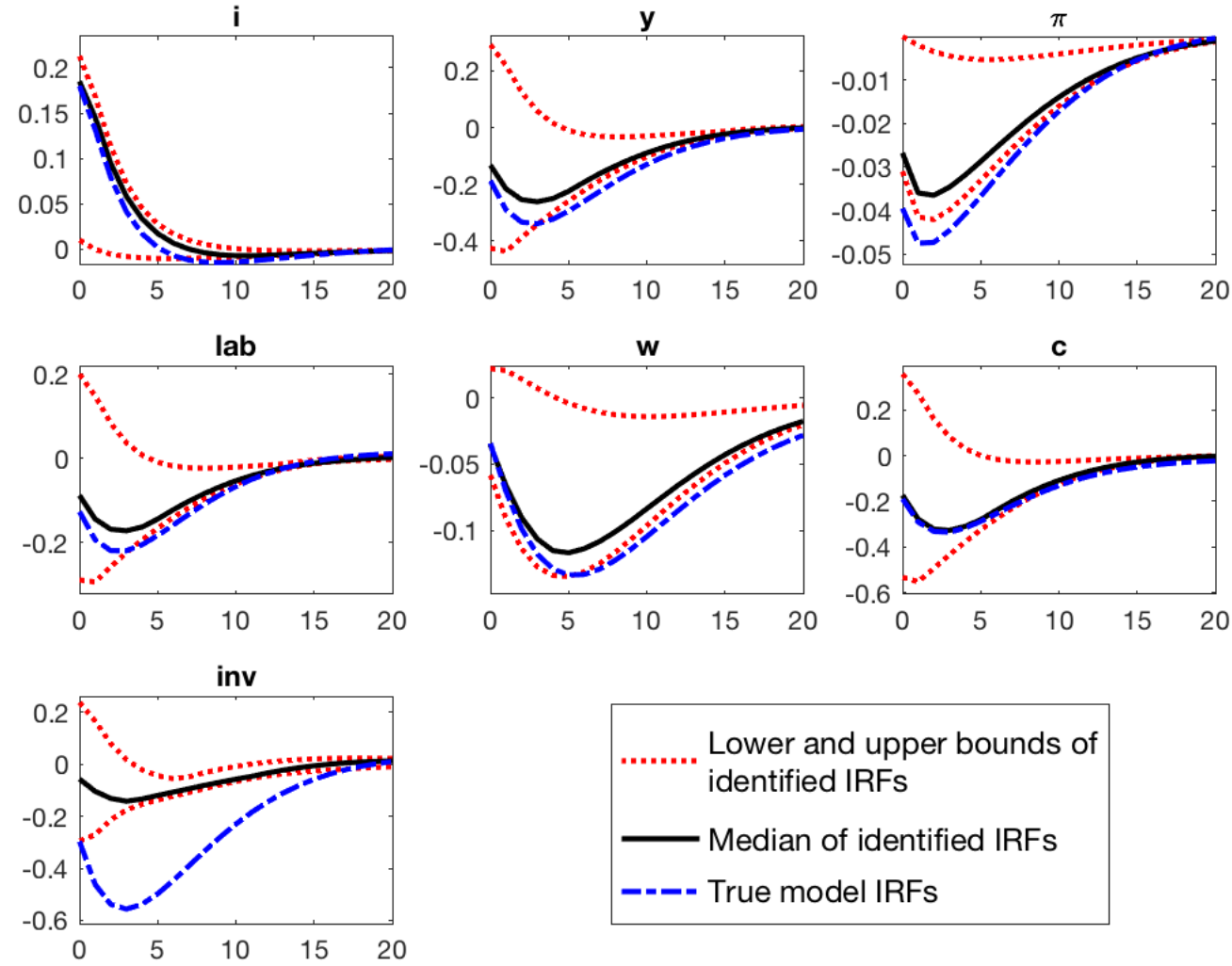

Figure 2.5: IRF's of a $\sigma_{i}$ contractionary monetary policy shock identified with sign and zero restrictions - SW(2007) model

most new keynesian models incorporate Taylor rules with these features. However, as Wolf (49) points out, the sign on the monetary rule parameters associated to output and inflation in the SVAR are sensible to the monetary rule specification and to the definition of output gap used in this equation. In the Smets \& Wouters (51) model, for example, their restrictions don't hold for the estimated parameter mode, even if we define the variables in the VAR precisely the same way as in the model. Even if we remove from the Taylor rule specification the deviation of the output growth from its potential level, a novel term in the SW (2007) policy specification, Arias et al. (31) restrictions on contemporaneous SVAR parameters won't be verified in the SW (2007) model. ${ }^{16}$ This feature explains the poor performance of results when we incorporate Arias et al. (31) restrictions on structural parameters. In this case, the proportion of negative responses resembles those of the "sign restrictions only" specification, with almost al pairs of real variables and IRF horizons presenting positive responses after a contractionary monetary policy shock.

Besides standard sign restrictions on interest rates and inflation, Wolf (49) proposes a restriction to rule out implausibly large responses of output to a monetary shock. Specifically, he imposes the absolute value of (output response)/(interest rate response) to be lower than 1.2 on impact. While this restriction seems compatible see these restrictions imply that the interest rate is a positive function of these variables.

${ }^{16}$ For this exercise, we didn't reestimate the model. We considered the original parameters mode. 


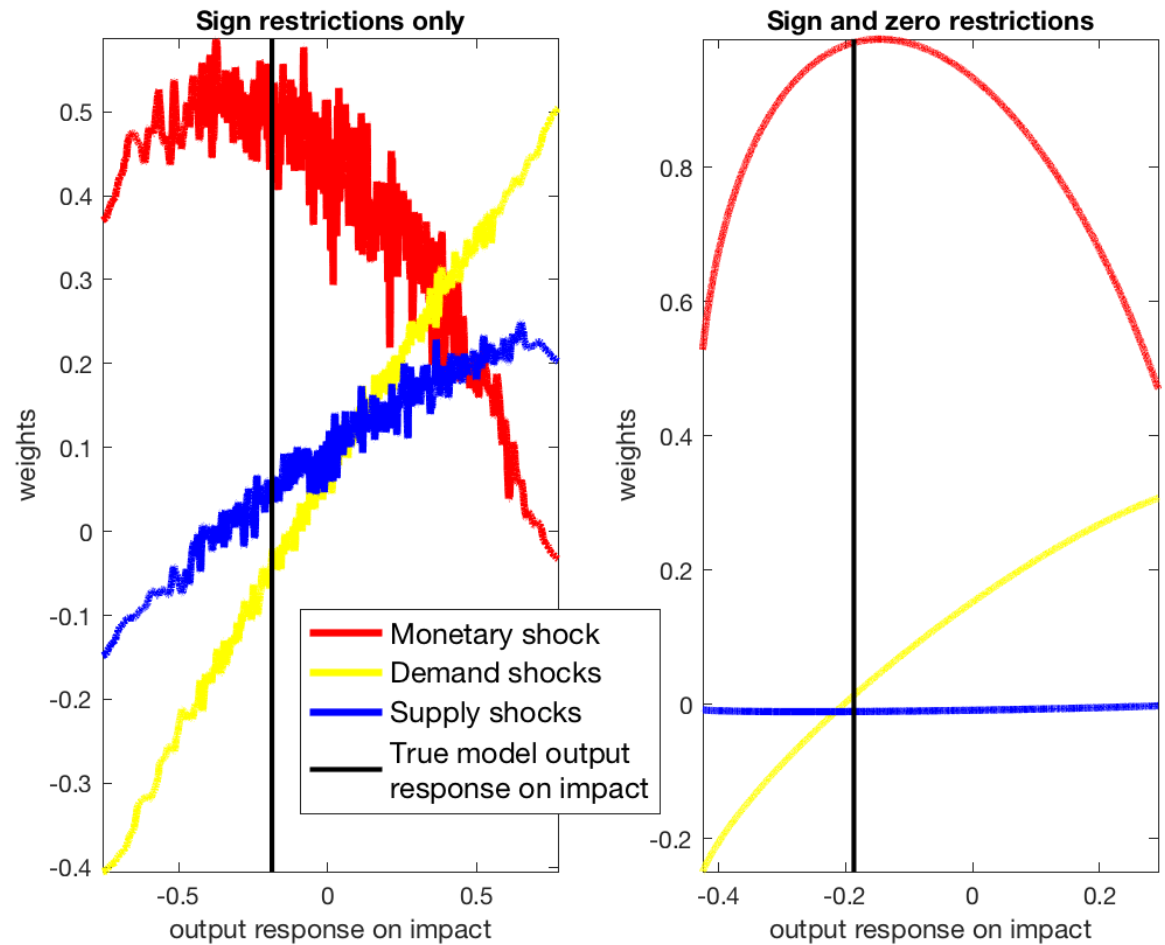

Figure 2.6: Accepted impulse weights of identified monetary shocks - SW(2007) model

with a large group of empirical papers that estimate the effects of monetary policy shocks, it appears not sufficient to recover strictly negative real variables responses following a contractionary monetary shock when the DGP is given by the Smets \& Wouters (51) model, as shown in table 2.5. ${ }^{17}$ Despite the slightly improvement in relation to the "sign restriction only" approach, we notice that all pairs of variables and IRF horizons show proportions of negative responses below $70 \%$.

The performance of our identification approach vis-a-vis those of Arias et al. (31) and Wolf (49) can also be compared through an analysis of disturbance weights in the accepted draws of Uhlig (26) and Arias et al. (32) algorithms. Table 2.6 presents the mean shock weights for identified IRFs with different identification strategies. We notice that our proposal with monetary neutrality restrictions gives substantially higher weight to the monetary shock and less weight to other disturbances. As can be seen, Wolf (49) fares better than the "sign restriction only" approach, but much worse than ours, while Arias et al. (31) performs even worse than the former for the DGP used in this paper. ${ }^{18}$ In this sense, the identified set

${ }^{17}$ An important disclaimer has to be made here. In his paper, Wolf (49) shows the model consistency of his approach using a non-invertible 3 variable VAR representation of the Smets \& Wouters (51) model. For what we have tested, his specification looks worse here than in his paper mostly because we are dealing with the full VAR ( 7 - variable) representation of the model. Also, a small part of this divergence is probably due to some slight difference in the parameters used to calibrate the model.

${ }^{18}$ Here we notice that the strange results for the investment IRF comes from the 0.11 mean weight given to the investment-specific shock. Although this value does not seen so large, the investment-specific shock has a large positive effect on investment, what explains 
Chapter 2. "Still" an agnostic procedure to identify monetary policy shocks

with sign restrictions

Table 2.2: Proportion of negative responses for different IRF horizons - sign restrictions only

\begin{tabular}{lccccccc}
\hline \hline Variables & $\mathbf{h}=\mathbf{0}$ & $\mathbf{h}=\mathbf{2}$ & $\mathbf{h}=\mathbf{4}$ & $\mathbf{h}=\mathbf{6}$ & $\mathbf{h}=\mathbf{8}$ & $\mathbf{h}=\mathbf{1 0}$ & $\mathbf{h}=\mathbf{1 2}$ \\
\hline $\mathbf{y}$ & $44 \%$ & $47 \%$ & $45 \%$ & $41 \%$ & $38 \%$ & $36 \%$ & $34 \%$ \\
lab & $38 \%$ & $42 \%$ & $39 \%$ & $35 \%$ & $30 \%$ & $28 \%$ & $27 \%$ \\
$\mathbf{w}$ & $53 \%$ & $54 \%$ & $53 \%$ & $52 \%$ & $50 \%$ & $48 \%$ & $47 \%$ \\
$\mathbf{c}$ & $45 \%$ & $51 \%$ & $48 \%$ & $42 \%$ & $37 \%$ & $35 \%$ & $34 \%$ \\
inv & $45 \%$ & $46 \%$ & $45 \%$ & $43 \%$ & $41 \%$ & $39 \%$ & $37 \%$ \\
\hline \hline
\end{tabular}

Table 2.3: Proportion of negative responses for different IRF horizons - sign and zero restrictions

\begin{tabular}{|c|c|c|c|c|c|c|c|}
\hline Variables & $\mathbf{h}=\mathbf{0}$ & $\mathrm{h}=2$ & $\mathrm{~h}=4$ & $\mathrm{~h}=6$ & $\mathrm{~h}=8$ & $\mathrm{~h}=10$ & $\mathrm{~h}=12$ \\
\hline $\mathrm{y}$ & $65 \%$ & $84 \%$ & $97 \%$ & $100 \%$ & $100 \%$ & $100 \%$ & $100 \%$ \\
\hline lab & $65 \%$ & $84 \%$ & $98 \%$ & $100 \%$ & $100 \%$ & $100 \%$ & $100 \%$ \\
\hline $\mathbf{w}$ & $82 \%$ & $94 \%$ & $100 \%$ & $100 \%$ & $100 \%$ & $100 \%$ & $100 \%$ \\
\hline c & $66 \%$ & $84 \%$ & $96 \%$ & $100 \%$ & $100 \%$ & $100 \%$ & $100 \%$ \\
\hline inv & $59 \%$ & $82 \%$ & $100 \%$ & $100 \%$ & $100 \%$ & $100 \%$ & $91 \%$ \\
\hline
\end{tabular}

of IRFs with the addition of neutrality restrictions is closer to the true effects of monetary shocks than competing identification strategies.

Finally, to reinforce that our proposal improves identification through the exclusion of persistent confounding combinations of shocks other than monetary, we present in tables 2.7 and 2.8 two distinct measures of shock persistence for different identification setups and the SW (2007) model. Table 2.7 plots the mean absolute IRFs of all real variables 40 quarters after the shock. By design, our approach restricts to zero these responses. But we notice that other competing strategies accept as confounding monetary shocks combinations of highly persistent shocks. The range of these values are between 0.04 and 0.16 percent deviation from the steady state, in absolute terms, depending on the identification setup and the real variable analyzed. For each real variable, it represents roughly a third of the lowest values verified in the true model responses. ${ }^{19}$

Table 2.8 reports the half-lives of shocks, defined as the number of periods at which responses are higher then half their values on impact. Despite the pitfalls with this measure of shock persistence when the IRFs are not monotonically behaved, as is the case for the Smets \& Wouters (51) model, it presents another evidence that our findings for the investment response.

${ }^{19}$ In the model, the valley occurs at 3 quarters after the shock for output, consumption, investment and hours worked, and at 5 quarters after the shock for real wages. We also note that in all cases there isn't a persistent movement in the interest rate to justify these results. 
Chapter 2. "Still" an agnostic procedure to identify monetary policy shocks with sign restrictions

Table 2.4: Proportion of negative responses for different IRF horizons - Arias et al. (31)

\begin{tabular}{lccccccc}
\hline \hline Variables & $\mathbf{h}=\mathbf{0}$ & $\mathbf{h}=\mathbf{2}$ & $\mathbf{h}=\mathbf{4}$ & $\mathbf{h}=\mathbf{6}$ & $\mathbf{h}=\mathbf{8}$ & $\mathbf{h}=\mathbf{1 0}$ & $\mathbf{h}=\mathbf{1 2}$ \\
\hline $\mathbf{y}$ & $42 \%$ & $46 \%$ & $45 \%$ & $42 \%$ & $40 \%$ & $38 \%$ & $37 \%$ \\
lab & $30 \%$ & $36 \%$ & $35 \%$ & $32 \%$ & $29 \%$ & $27 \%$ & $27 \%$ \\
$\mathbf{w}$ & $50 \%$ & $51 \%$ & $50 \%$ & $49 \%$ & $48 \%$ & $47 \%$ & $47 \%$ \\
$\mathbf{c}$ & $41 \%$ & $49 \%$ & $48 \%$ & $43 \%$ & $39 \%$ & $37 \%$ & $36 \%$ \\
inv & $43 \%$ & $44 \%$ & $44 \%$ & $43 \%$ & $42 \%$ & $40 \%$ & $39 \%$ \\
\hline \hline
\end{tabular}

Table 2.5: Proportion of negative responses for different IRF horizons - Wolf (49)

\begin{tabular}{|c|c|c|c|c|c|c|c|c|}
\hline Variables & $\mathbf{h}=\mathbf{0}$ & $\mathrm{h}=2$ & $\mathrm{~h}=4$ & $\mathrm{~h}=6$ & $\mathrm{~h}=8$ & \multicolumn{2}{|c|}{$\mathrm{h}=10$} & $\mathrm{~h}=12$ \\
\hline $\mathbf{y}$ & $50 \%$ & $63 \%$ & $58 \%$ & $51 \%$ & $44 \%$ & \multicolumn{2}{|c|}{$40 \%$} & $38 \%$ \\
\hline lab & $40 \%$ & $49 \%$ & $47 \%$ & $41 \%$ & $35 \%$ & \multicolumn{2}{|c|}{$31 \%$} & $29 \%$ \\
\hline $\mathbf{w}$ & $56 \%$ & $60 \%$ & $61 \%$ & $59 \%$ & $58 \%$ & \multicolumn{2}{|c|}{$56 \%$} & $54 \%$ \\
\hline c & $44 \%$ & $58 \%$ & $56 \%$ & $48 \%$ & $43 \%$ & \multicolumn{2}{|c|}{$39 \%$} & $37 \%$ \\
\hline inv & $51 \%$ & $53 \%$ & $52 \%$ & $50 \%$ & $47 \%$ & \multicolumn{2}{|c|}{$44 \%$} & $42 \%$ \\
\hline \multicolumn{9}{|c|}{ Table 2.6: Mean identified shock weights for different identification strategies } \\
\hline \multicolumn{2}{|c|}{ dentification setup } & $\epsilon_{r}$ & $\epsilon_{a}$ & $\epsilon_{p}$ & $\epsilon_{b}$ & $\epsilon_{g}$ & $\epsilon_{I}$ & $\epsilon_{w}$ \\
\hline \multicolumn{2}{|c|}{ ign restrictions only } & 0.40 & -0.06 & -0.21 & 0.17 & 0.05 & 0.05 & -0.15 \\
\hline \multicolumn{2}{|c|}{ Volf $(2017)$} & 0.53 & -0.09 & -0.19 & 0.21 & 0.02 & 0.02 & -0.15 \\
\hline \multicolumn{2}{|c|}{ Irias et al (2016) } & 0.36 & -0.11 & -0.24 & 0.21 & 0.06 & 0.07 & -0.14 \\
\hline \multicolumn{2}{|c|}{$\begin{array}{l}\text { Sign and zero } \\
\text { restrictions }\end{array}$} & 0.82 & -0.00 & 0.02 & 0.03 & 0.00 & 0.11 & 0.00 \\
\hline
\end{tabular}

Table 2.7: Mean absolute IRFs after 40 quarters (in percent) for different identification strategies

\begin{tabular}{lccccccc}
\hline \hline Identification setup & $\mathbf{i}$ & $\mathbf{y}$ & $\boldsymbol{\pi}$ & lab & w & c & inv \\
\hline True model & $\mathbf{0 . 0 0}$ & $\mathbf{0 . 0 0}$ & $\mathbf{0 . 0 0}$ & $\mathbf{0 . 0 0}$ & $\mathbf{0 . 0 0}$ & $\mathbf{0 . 0 1}$ & $\mathbf{0 . 0 1}$ \\
Sign restrictions only & 0.01 & 0.12 & 0.01 & 0.06 & 0.05 & 0.16 & 0.16 \\
Wolf (2017) & 0.01 & 0.11 & 0.01 & 0.06 & 0.04 & 0.15 & 0.16 \\
Arias et al (2016) & 0.01 & 0.11 & 0.01 & 0.06 & 0.04 & 0.15 & 0.16 \\
$\begin{array}{l}\text { Sign and zero } \\
\text { restrictions }\end{array}$ & $\mathbf{0 . 0 0}$ & $\mathbf{0 . 0 0}$ & $\mathbf{0 . 0 0}$ & $\mathbf{0 . 0 0}$ & $\mathbf{0 . 0 0}$ & $\mathbf{0 . 0 0}$ & $\mathbf{0 . 0 0}$ \\
\hline \hline
\end{tabular}


Chapter 2. "Still" an agnostic procedure to identify monetary policy shocks with sign restrictions

Table 2.8: Mean half lives of identified monetary shocks (in time periods) for different identification strategies

\begin{tabular}{lccccccc}
\hline \hline Identification setup & $\mathbf{i}$ & $\mathbf{y}$ & $\boldsymbol{\pi}$ & lab & w & c & inv \\
\hline True model & $\mathbf{2}$ & $\mathbf{1 2}$ & $\mathbf{1 0}$ & $\mathbf{1 1}$ & $\mathbf{2 4}$ & $\mathbf{1 2}$ & $\mathbf{1 2}$ \\
Sign restrictions only & 9 & 28 & 9 & 25 & 26 & 31 & 26 \\
Wolf (2017) & 5 & 36 & 10 & 26 & 25 & 32 & 27 \\
Arias et al (2016) & 9 & 28 & 8 & 25 & 26 & 31 & 26 \\
$\begin{array}{l}\text { Sign and zero } \\
\text { restrictions }\end{array}$ & $\mathbf{3}$ & $\mathbf{9}$ & $\mathbf{1 2}$ & $\mathbf{9}$ & $\mathbf{2 1}$ & $\mathbf{9}$ & $\mathbf{9}$ \\
\hline \hline
\end{tabular}

the competing identification strategies are confounded by combinations of persistent shocks. We can see that the half-lives of all real variables responses are above 20 for other identification setups (sometimes above 30), in discrepancy with the half-lives observed in the model for all real variables but wages. In sum, for both measures of shock persistence, we note the identification with neutrality restrictions delivers the acceptance of less persistent shocks, in accordance to the effects observed for monetary shocks in the model.

We end this section pointing that the introduction of monetary policy neutrality in a ten year horizon as an identification hypothesis, along standard sign restrictions on inflation and interest rates, substantially improves identification. It still does not perfectly recover the effects of monetary shocks: a fraction of identified real variables responses in the initial periods following a contractionary shock are still positive and the true model responses lie outside the identified bounds in some cases. But our approach improves identification "at a very low cost", since neutrality restrictions have strong theoretical background. Thus, we believe this strategy does not compromise the agnostic spirit of set identification literature. According to the two measures of shock identification performance, it also performs better than competing identification setups of Arias et al. (31) and Wolf (49). For this, our identification strategy provides valuable information for empirical macroeconomists who are evaluating the trade-off between imposing additional identification structure and enhancing estimated IRF's precision.

\section{5}

\section{Empirical application}

In this section we give a simple example with real data showing the monetary neutrality restrictions might be important to identify real effects of monetary policy. For consistency with previous sections, we employ part of the quarterly data that Smets \& Wouters (51) used to estimate their model. The data sample ranges from 1956Q1 to 2004Q4. Specifically, we estimate a 3-variable VAR with 4 lags composed by the quarterly Fed Funds Rate, the log difference of GDP deflator and the real 
per capita GDP growth. ${ }^{20}$ This VAR can be rationalized as a reduced form for the 3-equation model or a non-invertible 3-equation VAR representation of the Smets \& Wouters (51) model, as in Wolf (49).

For comparison, we identify the IRF's to a standard deviation contractionary shock using both identification setups specified before: the "sign restrictions only" approach and the approach incorporating the proposed neutrality restriction. The sign restrictions remain the same as in previous sections: following a contractionary monetary policy shock, the Fed Funds Rate rises and the inflation decreases for 2 periods. Since the VAR includes the real GDP per capita growth as real variable, the monetary neutrality restriction implies that the cumulative sum of this variable must be zero 40 quarters after the shock. Additionally, to make sure the output response stays very close to zero from quarter 40 onward, we impose the restriction that its cumulative sum between quarters 40 and 80 must be zero. ${ }^{21}$ It is important to note that this second restriction pins down a unique column of the contemporaneous impact matrix $A$ of the SVAR. Thus, there is no longer model uncertainty regarding the estimation of IRF's to monetary policy shocks, allowing inference to be conducted the usual way. In other words, for the identification setup that features neutrality restrictions, we are back in the standard VAR case where IRF bounds represent only parameter uncertainty. For the "sign restrictions only" approach, two sources of uncertainty of different nature compound in the computation of IRFs: the one related to parameter estimation and the model uncertainty, since this setup doesn't impose enough restrictions to pin down a unique $A$ contemporaneous impact matrix of the SVAR.

Inference is conducted the usual way for Bayesian estimated VARs. We assume a noninformative Jeffrey's prior for the coefficients $(\phi)$ and the variancecovariance matrix $(\Sigma)$, i.e.: $p(\phi, \Sigma) \propto|\Sigma|^{\frac{-(n+1)}{2}}$. Kadiyala \& Karlsson (68) deliver the posterior for $(\phi, \Sigma) .{ }^{22}$ For the "sign restrictions only" identification setup, we draw 10,000 parameter vectors from the posterior distribution. For each, we draw 100 candidate impulse responses with Uhlig's sign restrictions algorithm and keep the ones satisfying the sign restrictions. ${ }^{23}$ For the identification setup that incorporates neutrality restrictions, we use Arias et al. (32) algorithm to mix equality and inequality restrictions. In this case, we draw 10,000 parameters from the posterior and compute IRF bounds as is standard in Bayesian VAR exercises.

Figure 2.7 presents the IRF's of a standard deviation monetary shock for the "sign restriction only" approach (first row) and the identification setup incorporating

${ }^{20}$ I refer the reader to the Smets \& Wouters (51) data appendix for detailed information about the corresponding codes of these time series in the FRED database.

${ }^{21}$ Without this restriction, the median output response crosses the zero line 40 quarters after the shock and becomes positive onward, although not statistically significant. This feature was not present in previous sections when we specified the DGP. Results are invariant to changing the time length of this second restriction.

${ }^{22}$ For a sample of the size we are using, this procedure is similar to drawing from the joint likelihood of $(\phi, \Sigma)$, despite a slight increase in the degrees of freedom.

${ }^{23}$ We accept close to $30 \%$ of the draws. 

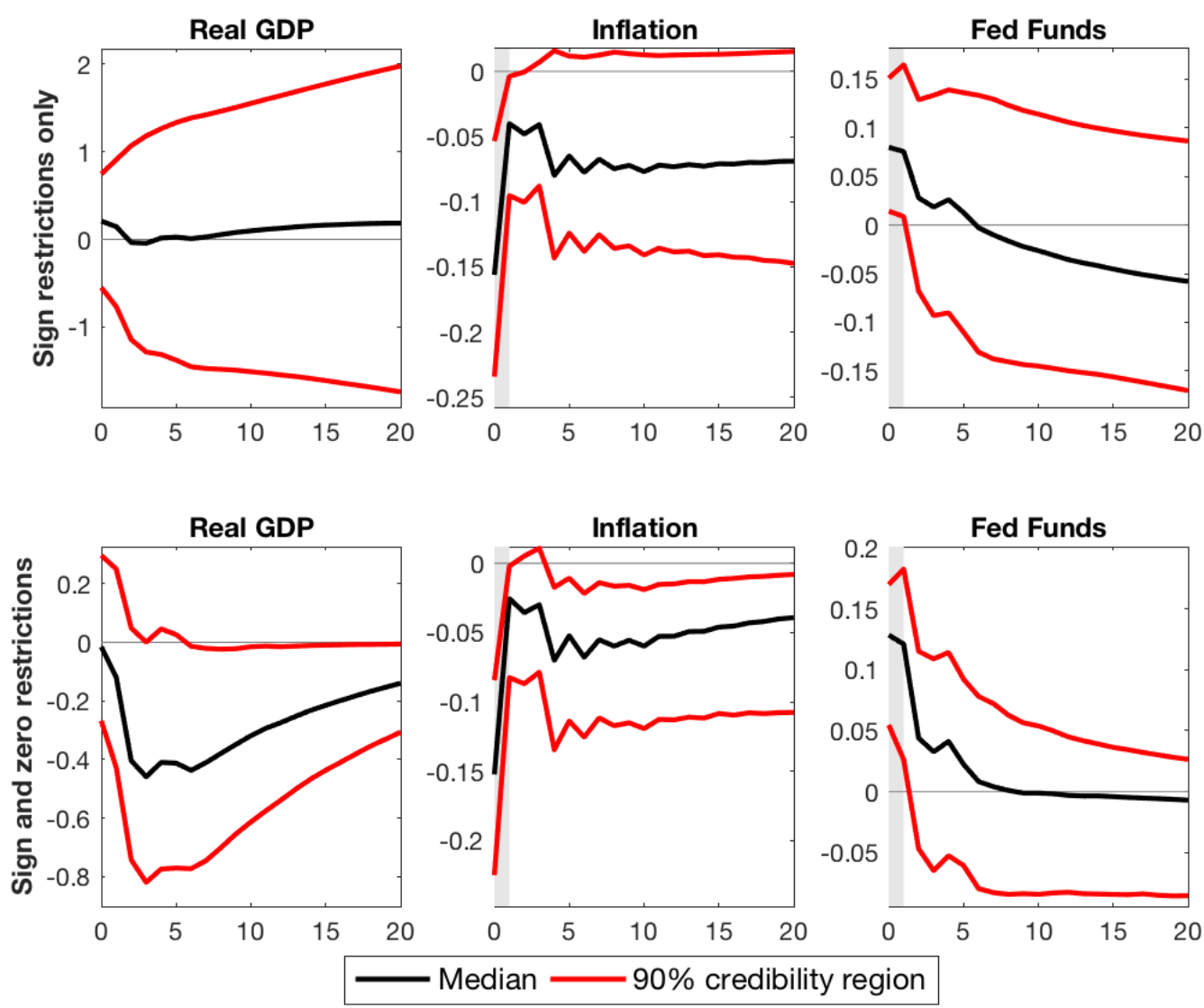

Figure 2.7: Identified IRF's of a $\sigma_{i}$ contractionary monetary shock for the "sign restriction only" approach (first row) and the identification setup incorporating the neutrality restrictions (second row). Estimated 3-variable VAR with US data. Sample: 1956Q1 - 2004Q4

the neutrality restrictions (second row). The median is painted in black and the red lines represent a 90\% credibility region. By design, the Fed Funds Rate rises and inflation drops until one quarter after the shock. We clearly see that for the "sign restriction only" case the direction of real output response is ambiguous and its median is positive, as in Uhlig (26). When we additionally impose the neutrality restrictions, the real output response becomes statistically negative at $10 \%$ level of significance 5 quarters after the shock, with its median lowest point reaching roughly -0.40 three to five periods after the shock, a pattern precisely in accordance with the Smets \& Wouters (51) model.

In Appendix B.3, we implement some robustness exercises. First, we vary the length at which we impose monetary neutrality. Figure B.3.1 shows real output responses when monetary neutrality binds between 7 and 13 years. ${ }^{24}$ All of them point to the real effects of monetary policy when the additional neutrality restrictions are imposed. We also consider in figure B.3.2 the same exercise done in figure 2.7, but for a shorter sample that ranges from 1978Q1 to 2004Q4. We split the sample this way, since there might be structural breaks in a large sample like the one used by

${ }^{24}$ To save space, we omit the Fed Funds Rate and inflation responses. 
Smets \& Wouters (51). Again, we notice the introduction of neutrality restrictions is sufficient to recover a statistically significant negative output response following a contractionary monetary shock.

\section{6}

\section{Conclusion}

Throughout this paper we defended the introduction of a small set of model consistent restrictions to identify monetary shocks in a set identified SVAR framework. Specifically, we proposed to combine standard sign restrictions on interest rates and inflation IRF's with equality restrictions that prevent monetary policy from having real effects 10 years after the shock. We showed that this novel set of neutrality restrictions eliminate important confounding elements that are present when only sign restrictions are imposed. The algorithm introduced by Arias et al. (32) to mix equality and inequality restrictions was used to this end.

To assess the theoretical plausibility of our set of restrictions, we first checked their identification performance in controlled environments, that is, when the DGP is given by prominent models used in the literature. As a first example, we showed the neutrality restriction is sufficient to perfectly recover negative effects of a contractionary monetary policy shock when the DGP is given by the canonical 3equation model of Gali (62). Then, we conducted the same exercise for a proper DGP, the Smets \& Wouters (51) model. It could be seen in this case that our approach substantially shrinks the identified set of impulse responses toward the true effects of monetary policy shocks. We also noted that, for this DGP, our proposed identification setup is more effective to recover monetary policy effects than recent identification approaches driven by model consistent restrictions suggested by Arias et al. (31) and Wolf (49).

Finally, as a simple empirical application, we estimated a VAR with US data and showed the additional neutrality restrictions might help to identify real effects of monetary policy shocks. While other restrictions could be imposed with the same goal, our minimalist approach keeps the agnostic spirit of the set identification literature, which aims to impose a limited number of restrictions backed by strong theoretical support. We believe it represents valuable information for empirical macroeconomists who are evaluating the trade-off between imposing additional identification structure and improving estimated IRF's precision. 


\section{3 \\ Do foreign banks overcome borrower informational asymme- tries by relying on their peer's behavior?}

We show that foreign banks can mitigate informational barriers vis-a-vis private domestic banks by observing their peers' behavior. This is particularly true when foreign banks evaluate borrowers in markets where their informational disadvantages are larger, such as small and medium enterprises bank loan market. Conditional on a loan application being filed by a SME firm, we find that the existence of past loans of this firm with private domestic banks constitute a more important predictor that a loan will be granted by foreign banks in comparison to private domestic banks. Our results are compatible with the view that the higher ability of private domestic banks to access informationally opaque business credit risks makes past loans with these banks a more valuable signal for foreign lenders loan offer decision.

JEL codes: D80, D81, D82, G21

Keywords: Foreign banks, information asymmetry, bank loans, SME firms

\section{1}

\section{Introduction}

Information asymmetries play a crucial role in credit markets. Adverse selection problems in the pool of borrowers may prevent efficient allocation of resources and, thus, limit economic development (69). In this regard, financial intermediaries are seen to have a key role in credit markets, since they can collect, store and process large amounts of information otherwise not easily accessible to ordinary savers. Heterogeneities across lenders may arise in this job, since some financial intermediaries might have comparative advantages in processing information for certain classes of borrowers. In particular, the literature has documented that foreign owned banks usually shy away from extending loans to small and medium enterprises (SME). ${ }^{1}$ Different theories help to explain these findings and point to disadvantages of foreignowned banks in processing soft information, since hard data availability for SME firms are usually scarce. ${ }^{2}$ This problem is even more severe in underdeveloped coun-

${ }^{1}$ See Berger et al. (70), Clarke \& Peria (71), Mian (72) and Berger et al. (73).

${ }^{2}$ Throughout the paper we adopt Liberti and Petersen (74) characterization that hard information is usually simple to characterize in numbers whereas soft information is not. 
tries, where other aspects (eg: weak enforcement of creditor rights) may compound in contributing to foreign-owned banks focusing only on a limited group of large and financially transparent firms.

In this paper we document a novel mechanism used by foreign banks to mitigate their information disadvantages vis-a-vis private domestic banks. We conjecture that recent loans granted by other banks to a noncurrent borrower may represent valuable information regarding this borrower's financial condition. That is, when deciding whether or not to grant a loan to a noncurrent borrower, financial intermediaries may interpret the existence of recent loans granted to this borrower by other banks as a signal of its quality. This should be particularly true when foreign owned banks are evaluating SME firms that borrowed from domestic private banks in the recent past, since these banks may have informational advantages in evaluating the prospects of informationally opaque firms. Our findings are consistent with this hypothesis.

Financial liberalization in a large number of countries allowed foreign bank presence to expand in the 90's and 2000's. Using a rich database that encompasses 137 countries, Claessens \& Horen (75) show the average proportion of foreign banks among countries jumped from $20 \%$ in 1995 to $34 \%$ in $2009 .{ }^{3}$ The increase is specially pronounced in emerging markets, where this share rose from $18 \%$ to $36 \%$ in the same period. This upward trend gave rise to a number of studies that tried to understand the behaviors of foreign-owned banks and its consequences for credit markets.

The effectiveness of the entry of foreign banks in alleviating credit constraints is an open question in the literature. While it undoubtedly improves conditions for the targeted market segment (typically large firms), some papers have shown that foreign banks might "cream skim" the pool of borrowers of domestic banks, intensifying adverse selection problems for the remaining part of the pool, deteriorating small firms ability to access bank loans $[(69),(76)]$. Others argue that foreign banks entry enhances small firms access to external funding, even if this occurs through general equilibrium effects that force domestic banks to expand credit to these firms $[(77),(78),(79),(80)]$. Despite these disagreements, most part of the literature assumes or presents evidences that foreign banks target large and financially transparent firms. Theoretically, this is done through assumptions that foreign banks have lower screening or monitoring costs relative to domestic banks when dealing with borrowers that are intensive on hard information (69) or that foreign banks have informational disadvantages relative to domestic banks in assessing small firms prospects (77). Empirically, a number of papers documented that foreign banks loan portfolios are biased toward large, foreign owned corporations and firms that have multiple banking relationships [(70), (71), (72), (73), (79)].

In order to explain the mechanisms behind foreign banks aversion to SME firms, the literature usually points to distance related information asymmetries.

\footnotetext{
${ }^{3}$ In terms of bank assets share, Barth et al. (13) document an increase in the average share of total bank assets held by foreign banks from $29 \%$ in 1999 to $47 \%$ in 2011 .
} 
Greater geographical distances between the headquarters and the subsidiaries of foreign banks may increase agency problems in the transmission and verification of SME firms soft information. Regarding organizational distance, foreign banks are also usually larger than domestic banks, thus its various hierarchical layers might impair the proper transmission of soft information between the high management and the loan officer generating the information [(81), (82), (83)]. Since evaluating and monitoring SME firms are activities intensive in soft information, foreign banks would be at disadvantage from this perspective. Cultural distance might also create difficulties for foreign banks to perform relationship intensive activities, such as lending to SME firms and renegotiating past due credit obligations (72). Other regulatory differences between home and host countries might create barriers to foreign banks, although not specifically for SME firms in this case.

As a way to overcome informational barriers, we test if foreign banks rely on their peer's behaviors in order to decide the outcome of a loan application. For that, we match a comprehensive database of bank-borrower loan information requests to individual loans data. Our data comprises roughly all information requests and loan approvals about firms located in the city of Sao Paulo from 2013 to 2016. Information requests are filed by financial institutions about potential borrowers to the Central Bank of Brazil, who collects and stores loan level information in its credit registry.

In contrast to the international pattern, Brazil represents a case where banking internationalization has contracted in the past. After a large-scale entry in the late 90 s, foreign banks have retreated, being absorbed by their domestic competitors (84). Therefore, foreign banks that survived in Brazil can perhaps be seen as the ones who managed to adopt the more successful strategies to cope with the adverse environment of doing business oversees. One of those adversities is precisely their informational disadvantages in dealing with SMEs. Thus, to the extent that the survivor foreing banks in Brazil have overcome such challenge, the use of the Brazilian setting over a recent sample helps us to unveil succeeding informational strategies of such banks.

According to Brazilian rules, financial institutions are allowed to request firms bank loans information only if they have explicit authorization of the firm. Since this authorization is automatically given by firms when they engage in a credit relationship, we focus on information requests for noncurrent borrowers. We do that for two reasons. First, the absence of loans with a given firm implies the bank doesn't have the information usually gathered through credit relationships, a valuable information about borrower quality (85). Thus, it increases the chances the bank will look after other sources of information to reach a decision. Second, and more important, the requests for noncurrent borrowers constitute a better proxy for loan applications, since requests for current borrowers might have different reasons other than evaluating a loan demand (eg: updating loan credit scores). With this procedure, we intend to disentangle the demand determinants of bank loans, so we can identify more clearly what drives loan supply schedules. 
To address firm unobservables and firm selection concerns across domestic and foreign owned banks, our benchmark specification controls for all time varying firm heterogeneity. With firm-month fixed effects, we focus only on firms that made loan applications for different banks within the same month. We find that when a firm applies for loans in both domestic and foreign banks in the same month, the existence of previous operations in the past 3 months increases more the probability that the loan will be granted by foreign banks. Our estimates are also economically relevant. We estimate that this differential probability between foreign and private domestic banks is $9 \%$ for large firms and $22 \%$ for SME firms. This finding is consistent with the hypothesis that foreign banks mitigate their information disadvantages by looking at their competitor's past behaviors towards a given firm. Also, it stresses that this mechanism is more pronounced in markets where informational barriers are higher (ie: SME firms). As a way to evaluate if firm quality signals given by previous loans vary with previous lenders ownership type, we discriminate past credit operations granted by foreign banks from those granted by private domestic banks. We estimate that previous credit operations with private domestic banks increase the chance a loan will be granted for SME firms by $22 \%$ more for foreign banks in comparison to private domestic banks. Similar estimates for large firms are close to zero and not statistically significant. Since firm size proxies for the ability of firms to provide hard information, we interpret these results as an evidence that foreign banks reliance on their domestic competitor's behavior is of most value in market segments where their information disadvantages are larger. Our estimates also indicate that previous loans with foreign lenders enhance the chance of loan being granted by $17 \%$ more for foreign banks, independent of firm size. We interpret this finding as another evidence that foreign banks overcome borrower information asymmetries by relying on their peers behavior.

We also test whether previous loans with public banks are a good signal of firm quality. Since public banks objective may be other than profit making (eg: directing funds to specific sectors, financing government owned firms or financing politically connected firms), there is reason to believe that recent loans with public banks should not constitute valuable information about a firm quality. Compatible with this hypothesis, we find no change in probability for foreign banks granting loans to firms that borrowed from public banks in the last 3 months. Our results are robust to a number of tests, even to a more saturated specification that introduces bank-month fixed effects. Results stand for different time horizons of past credit operations ( 3 or 6 months), for different measures of firm size and for clustering of standard errors in different ways.

This paper connects to different parts of the banking literature. Beck et al. (86) show that foreign owned banks can overcome distance-related information asymmetries through contract design. By requiring collateral more often and granting shorter maturity loans, foreign banks can provide services to the same clientele as domestic banks. Moreover, as long as the loan contract satisfies these conditions, foreign 
bank loans don't present more repayment problems than domestic bank loans. In the same spirit, Sengupta (87) competition model shows that foreign banks may require collateral as a screening device to mitigate asymmetric information problems with domestic banks. In a cross-country study, Clarke et al. (71) suggest that strong and accessible credit bureaus might be important to mitigate informational barriers between foreign and domestic banks. Our paper relates to those in the sense that we provide a novel mechanism through which foreign banks can mitigate informational disadvantages vis-a-vis private domestic banks.

We also relate to the bank competition literature that studies in what extent borrowers became captured if information gathered through a lending relationship is not public knowledge (77). This capability of locking-in a borrower should be higher in market segments with higher information asymmetries (eg: markets for SME firms) and should also vary with the ability of banks to process soft information. ${ }^{4}$ To the extent that noncurrent borrowers loan applicants already have a previous credit relationship, this might give previous lenders a comparative advantage to attend these firms needs, thus reducing the probability they will get a loan from a new lender. This "capture effect" should be higher for SME firms, since greater information asymmetries in this segment might obstruct external lenders competition. Also, for SME firms the competition effects might be higher against foreign competitors, given the disadvantages of these banks to deal with relationship intensive borrowers. Thus, if anything, the existence of a competition effect that goes in the opposite direction of our hypothesis underestimate our findings.

Section 3.2 describes the database, presents summary statistics regarding the market share of banks by ownership type and reveals anecdotal evidence that foreign banks also shy way from SME firms in Brazil (in comparison to domestic banks). Section 3.3 presents the empirical strategy. It includes the econometric specification, the hypothesis tested and discusses identification concerns. Section 3.4 presents our main results and section 3.5 presents robustness experiments regarding these results. Section 3.6 discusses our findings and relate them to the literature. The last section concludes.

\section{2 \\ Data}

\subsection{1}

\section{Data description}

Our dataset comprises roughly 409 thousand monthly information requests from 2013M01 to 2016M09 filed by banks about potential borrowers matched to the occurrence of new loans in the months following the requests. We define as potential

${ }^{4}$ In a number of papers this ability is proxied by the geographical distance between borrowers and lenders, since soft information requires some kind of personal contact to be gathered [(88), (89), (90)] 
borrowers those firms that don't have a credit relationship with the bank making the request at the time the request is made. Requests are stored in a transactional database operated by the Central Bank of Brazil that records for each request the identity of the bank making the request and the firm and time period to be researched. For the requested periods and firms, the Central Bank automatically returns the number of loans and the repayment schedule amounts aggregated by loan type (eg: working capital, long-term loans, etc). It also returns the number of credit operations under litigation and their corresponding amounts. This information is collected and stored in the Brazilian Credit Register. The Brazilian credit register is a comprehensive repository of loan-level data that encompasses all loans with more than 5,000 reais. ${ }^{5}$ We employ credit registry data from 2012M01 to 2017M06. The main piece of data from the registry employed in our paper will be, however, the months in which new loans are granted by every bank to every firm. The past loans of firms can be inferred by banks through information requests. The information requested for each firm can track up to the last 12 months, so banks can follow the trajectory of a firm bank debt over this period. Loan level information, like interest rates, loan term and lender ownership are not disclosed. However, current market practices suggest that, following replies to information requests, banks go after more disaggregated information, including the bank identity or at least the ownership of the potential borrower previous lenders. This usually occurs informally through personal contacts between loan applicants and banks (eg: bank interviews with firm managers).

We interpret these information requests as proxies for loan applications. Reasons for the requests not related to loan demand are unlikely in this case. One might be concerned that banks usually request borrower information to monitor its credit risk, but this is very much the reason why we focus on information requests for noncurrent borrowers. It may also be a cause of concern that banks are requesting information to prospect new loan borrowers. But Brazilian regulation demands that banks have explicit client authorization to request its bank loan information stored in the Brazlian credit registry, so it's unlikely that requests are being made to prospect unknown firms.

We match the bank information requests database to loan level data in order to check the existence of new loans following the loan application. A binary variable indicating a new loan is granted up to 3 months after the loan application will be the dependent variable in our regressions. Since we focus on loans to noncurrent borrowers, loan renewals and renegotiated loans are not a source of concern. We consider only loan applications and loans granted to firms located in the city of Sao Paulo, for different reasons. First, given that Sao Paulo is the financial center of Brazil, the presence of foreign-owned banks is more pervasive there, so it constitutes

\footnotetext{
${ }^{5}$ Since march/2016, this threshold is 1,000 reais. Nevertheless, we consider only loans above 5,000 reais to ensure time-consistency of our data.
} 
a more balanced environment for our analysis. ${ }^{6}$ Second and more important, the greater geographical sparcity of foreign banks in Brazil typically unbalances the playing field between foreign and domestic banks, a characteristic of our setting we want to control for. Indeed, monitoring and screening costs that require personal contacts between borrowers and lenders, for example, are expected to be higher the greater the distance between the bank loan officer and the borrower. Thus, the geographical concentration of borrowers in Sao Paulo eliminates concerns that foreign banks are at information disadvantages in evaluating SME firms because they are, on average, more distant from potential borrowers. We also exclude financial firms and other very small firms (those with maximum outstanding debt bellow 30,000 reais)..$^{7}$ [colocar na nota de rodapé a parte em vermelho] Finally, we exclude information requests filed by public banks, since their behavior is not the primary focus of this paper.

In order to control for bank determinants of loan offers, we introduce bank balance sheet data that serve us to build measures of bank financial conditions. Bank balance sheet data come from the accounting database of Brazilian financial institutions (COSIF). Commonly used financial indicators in the banking literature are employed, such as liquidity ratios and return on asset ratios. At the firm level, however, there is a scarcity of available data in Brazil for SME firms, the focus of this paper. For this reason, our benchmark specification controls for all time-varying heterogeneity at the firm level through the inclusion of firm-month fixed effects.

\subsection{2}

\section{Loan market share and firm size distribution by bank ownership}

Table 3.1 presents the bank loan market share for foreign and private domestic banks in Sao Paulo. As we can see, $45 \%$ of 132 banks are foreign owned. This number is accounted for at the individual bank level, hence more than one bank may belong to the same bank holding in our analysis. Further results of this paper are also defined at the bank level. Since individual banks in the same holding might target different market segments, have different remuneration policies and specific financial statements, we believe its appropriate to treat them individually. Despite having more than 100 participants in Sao Paulo, the bank loan market is concentrated. In

\footnotetext{
${ }^{6}$ In march-2015, foreign banks owned $16 \%$ of loan officers in Brazil. When we restrict the sample to the city of Sao Paulo, this number jumps to $25 \%$. This information is available in the Central Bank of Brazil website.

${ }^{7}$ The maximum outstanding debt corresponds to the maximum monthly amount between 2005 and 2017 (in 2005 BRL values) of the sum of outstanding loans, past-due loans, writeoffs and guarantees. Since firm-level data is scarce, we used this measure throughout the paper as a proxy of firm size. It's a widely used measure in the Brazilian Financial Stability Report. This exclusion aims at removing firms comprising a single individual that behave precisely as individuals, a common practice used in Brazil to reduce employment taxes and contributions. It also allows the exclusion of some types of bank debt that resemble loans to individuals rather than corporate bank loans (eg: credit cards).
} 
Chapter 3. Do foreign banks overcome borrower informational asymmetries by relying on their peer's behavior?

our sample period, the top 10 banks with more loan applications account for $85 \%$ of all loan applications of noncurrent borrowers.

Table 3.1: Bank loan market share by ownership

\begin{tabular}{lcccc}
\hline \hline $\begin{array}{l}\text { Bank } \\
\text { Ownership }\end{array}$ & $\begin{array}{c}\text { Number of } \\
\text { banks }\end{array}$ & $\begin{array}{c}\text { Number of } \\
\text { borrowers } \\
\text { (thous.) }\end{array}$ & $\begin{array}{c}\text { Number of } \\
\text { loans (thous.) }\end{array}$ & $\begin{array}{c}\text { Total loans } \\
\text { granted (BRL } \\
\mathbf{2 0 1 5} \text { billions) }\end{array}$ \\
\hline $\begin{array}{l}\text { Foreign } \\
\begin{array}{l}\text { Private } \\
\text { domestic }\end{array}\end{array}$ & 60 & 70 & 1,141 & 227 \\
Total & 72 & 162 & 2,809 & 359 \\
\hline \hline
\end{tabular}

Note: Market shares computed over a sample of private banks loans to all firms located in the city of Sao Paulo from 2012M01 to 2017M06.

Foreign banks own a significant share of private loans in Sao Paulo, roughly $30 \%$ of new loans and $39 \%$ of the overall loan amount. They also provide credit services for a considerable clientele, 70,000 firms. ${ }^{8}$ Table 3.1 suggests that the portfolio composition of foreign and domestic banks might be different: the average borrower of a foreign bank got 3.2 million reais in bank loans while the average borrower of a private domestic banks got 2.2 millions. Nevertheless, there is substantial firm size variability both within bank ownership type and across domestic and foreign banks. Figure 3.1 presents the distributions of total loans by firm size according to bank ownership types firm size. Vertical axis are in percent. In each plot, both blue and red bars sum to one. Four different firm size proxies are shown: ${ }^{9}$

A. Total Loans. Total amount of banks loans taken by firms from 2012M01 to 2017M06. Since the distribution of firms according to this variable is highly asymmetric, we divide the distribution in firm percentiles ranges, going from the smallest $50 \%$ of firms to the largest $1 \%$ of firms.

B. Maximum Outstanding Debt. Definition is explained in footnote 7. Again, since firm distribution according to maximum outstanding debt is asymmetric, the horizontal axis is converted to discrete percentile ranges.

C. Number of credit relationships. Number of different banks from which firms borrowed in our sample size. It includes loans with public banks.

D. Gross revenues category. For each loan, firms are divided in categories according to their gross annual revenues and total assets. Categories range from 1 (micro firms) to 4 (large firms). ${ }^{10}$ 

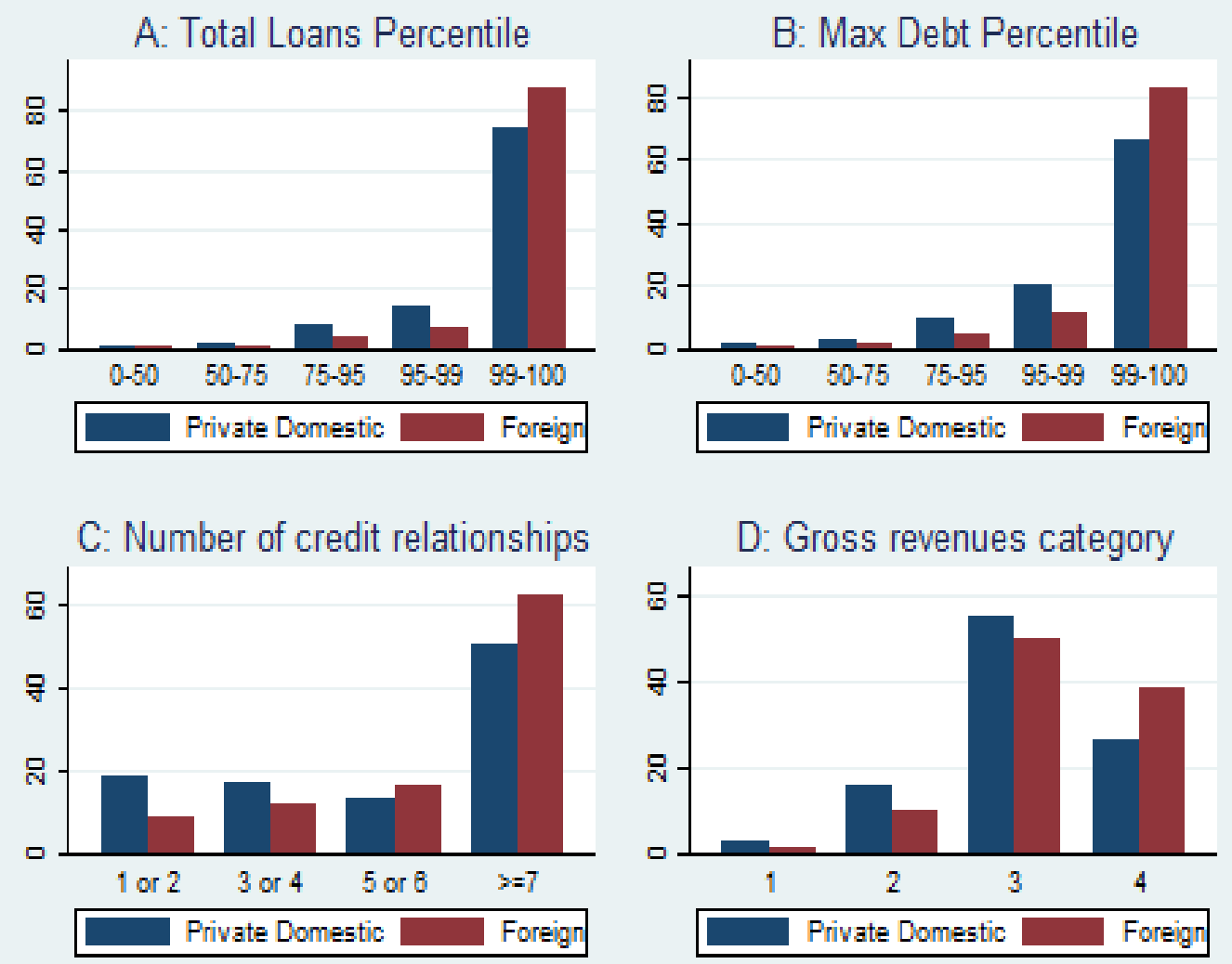

Figure 3.1: Distribution of the total amount of loans by ownership type by four different measures of firm size: total loans, maximum outstanding debt, number of credit relationships and gross revenues. All loans granted by private banks to firms located in Sao Paulo from 2012M01 to 2017M06 are considered. Vertical axis are in percent.

In comparison to domestic banks, figure 3.1 shows that a larger fraction of foreign bank loans goes to larger firms. This finding is also robust to all four measures of firm size proxy used. At first sight, this suggests that, vis-a-vis domestic banks, foreign banks may shy away from lending to SME firms and is therefore consistent with related findings in the literature $[(70),(71),(72),(73),(79)] .{ }^{11}$ Figure 3.2 repeats the same exercise of figure 3.1, but using the number of new loans instead of

${ }^{8}$ The total number of borrowers in table 3.1 is not the result of the sum of foreign and private domestic bank borrowers because some firms borrow from both foreign and domestic banks.

${ }^{9}$ This figure is analogous to the one presented in (72) for Pakistan bank data.

${ }^{10}$ Micro firms have annual gross revenues bellow 360 thousand reais. Small firms have annual gross revenues between 360 and 4,800 thousand reais. Medium firms have annual gross revenues between 4.8 and 300 millions and total assets bellow 240 millions. Finally, large firms have annual gross revenues above 300 millions or total assets above 240 millions.

${ }^{11}$ Although we have used the number of credit relationships as a measure of firm size, there might be other reasons why foreign bank firms engage in multiple relationships. Clarke et al. (71) point out that foreign banks may have weaker ties to the home country and other investment opportunities overseas. Therefore, firms that are clients to foreign banks may want to establish multiple bank relationships as a safe precaution in the case their foreign lender exits the country. 
the total loan amount. The difference in firm size distribution between foreign and domestic banks portfolio is even more striking in this case. ${ }^{12}$

A: Total Loans Percentile

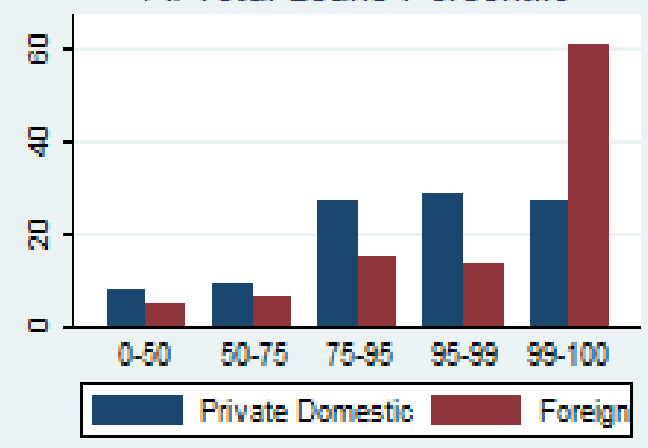

C: Number of credit relationships

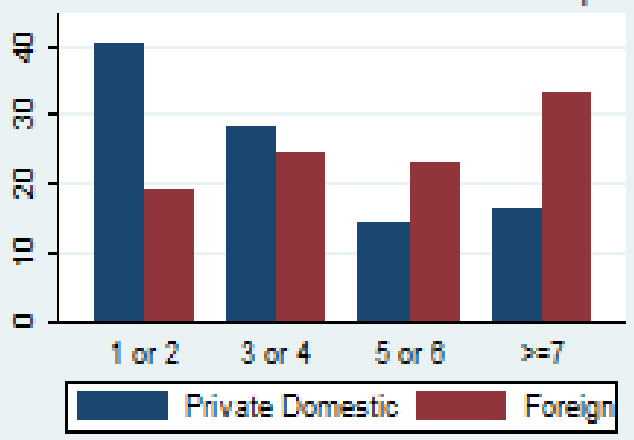

B: Max Debt Percentile

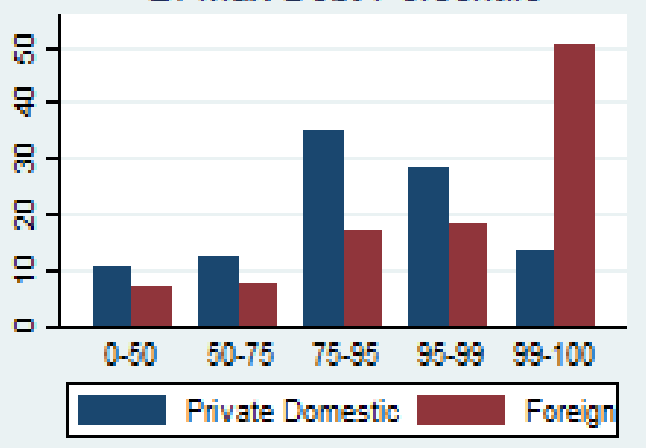

D: Gross revenues category

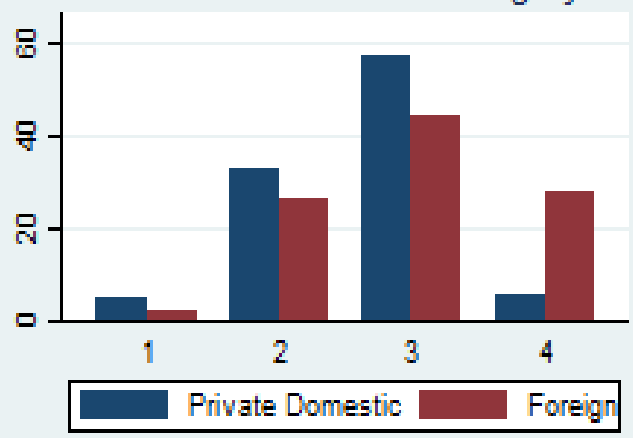

Figure 3.2: Frequency of loans by ownership type for four different measures of firm size: total loans, maximum outstanding debt, number of credit relationships and gross revenues. All loans granted by private banks to firms located in Sao Paulo from 2012M01 to 2017M06 are considered. Vertical axis are in percent.

The previous figures constitute only anecdotal evidence that foreign banks tend to lend more to larger firms. However, in those figures we do not control for different characteristics of loan demand facing foreign and domestic banks, nor we control for other bank variables that might be correlated to ownership type. If, for instance, foreign banks are larger on average, the driving force behind figures 3.1 and 3.2 might be bank size rather than ownership. ${ }^{13}$ Nevertheless, this anecdotal evidence is consistent with the findings of the banking literature that show that foreign banks have information disadvantages vis-a-vis domestic banks regarding lending to SME firms. In the next section, we formally specify our hypothesis that

\footnotetext{
${ }^{12}$ Together, figures 3.1 and 3.2 imply that, although a higher fraction of foreign bank loan amount finances larger firms, the average loan amount is smaller for foreign banks than those of domestic banks for larger firms.

${ }^{13}$ However, this is unlikely the case here. Of the top 20 banks with larger bank assets, the average size of private domestic banks is roughly twice the size of the average foreign bank.
} 
Chapter 3. Do foreign banks overcome borrower informational asymmetries by relying on their peer's behavior?

foreign banks mitigate these informational asymmetries by relying on their peers' behavior and present an econometric strategy to test it.

\section{3}

\section{Empirical strategy}

In this section we specify the empirical strategy. We detail regression equations, dependent and independent variables and present our hypothesis. Also, we present likely causes for concerns with the methodology adopted and how we address these issues. In the next section we conduct a number of robustness exercises regarding some features of our econometric specifications.

\subsection{1}

\section{Econometric specification}

Equation 3-1 presents our initial regression specification. $f, b, t$ index an information request submitted by bank $b$ about firm $f$ in month $t$. The dependent variable, LoanGranted, takes the value 1 if a loan is granted to the firm up to 3 months after the information request, and 0 otherwise. ${ }^{14} S M E$ is an indicator variable for small and medium firms. We define SME as those firms with maximum outstanding debt bellow 23 millions (the maximum value taken over the period 2005-2017 in 2005 BRL values). This threshold encompasses the $99 \%$ smallest firms. Nevertheless, we show in the next section that results are robust to other proxies of firm size underlying the SME definition. $\mathcal{F}$ is a variable that indicates that the loan is being applied in a foreign owned bank. The variable PreviousLoan is also binary. It indicates whether or not the firm had borrowed from another bank in the last 3 months. The vector Bank represents bank controls. It comprises financial indicators calculated through bank balance sheet data and it's defined at the bank holding level. To allow for different individual bank effects, even if in the same bank holding, some regression specifications introduce bank and bank-month fixed effects, represented by the vector $\mathbf{B}$, to control for bank unobservables. Finally, the vectors $\mathbf{F}$ and $\mathbf{M}$ represent fixed effects that aim to control for unobserved effects of firms and macroeconomic variables, respectively.

$$
\begin{aligned}
\text { LoanGranted }_{f b t}= & +\beta_{0} S M E_{f}+\beta_{1} \mathcal{F}_{b t}+\beta_{2} \text { PreviousLoan }_{f t}+\gamma_{1} \mathcal{F}_{b t} \bullet S M E_{f} \\
& +\gamma_{2} \mathcal{F}_{b t} \bullet \text { PreviousLoan }_{f t}+\gamma_{3} \text { PreviousLoan }_{f t} \bullet S M E_{f} \\
& +\lambda \mathcal{F}_{b t} \bullet \text { PreviousLoan }_{f t} \bullet S M E_{f} \\
& +\theta_{b}^{\prime} \text { Bank }_{\mathbf{b t}-\mathbf{1}}+\mathbf{F}_{\mathbf{f t}}+\mathbf{B}_{\mathbf{b t}}+\mathbf{M}_{\mathbf{t}}+\epsilon_{f b t}
\end{aligned}
$$

Equation 3-1 presents the variables we believe might affect the probability of a loan being granted, conditional on a loan application being filed. Specifically, $\beta_{1}$

${ }^{14}$ The regression specification closely follows Jimenez et al. (42) and Jimenez et al. (91). 
measures the impact of bank ownership on this probability. ${ }^{15}$ It indicates whether foreign banks loan supply was different in a systematic way from private domestic banks loan supply over our sample period. $\beta_{2}$ allow us to access if large firms recent loans granted by other lenders affect the probability of a new loan being granted by a new lender. In this regard, it's estimate captures two different effects with opposing directions. On the one side, $\beta_{2}$ measures competition effects, since previous lenders already have a credit relationship with the firm, thus they possibly have information advantages that help them to attend firms loans needs. Hence, we expect a negative contribution of the competition effect to $\beta_{2}$. On the other side, $\beta_{2}$ also indicates information effects, since recent loans of potential borrowers might reveal important information about their quality, what represents a positive contribution to $\beta_{2}$. Since large firms are usually transparent, both competition and information effects should be of secondary importance for them, thus $\beta_{2}$ sign's can go either way.

This regression specification also features interactions of $\mathcal{F}$, PreviousLoan and $S M E$ among themselves. $\gamma_{1}$ measures if loan supply of foreign banks are more sensitive to firm size. If foreign banks have greater difficulties in evaluating relationship intensive borrowers, this coefficient should be negative. Also, $\gamma_{2}$ indicates if the mixture of competition/information effects regarding large firms are more intensive for foreign banks, while $\gamma_{3}$ indicates if its more intensive for SME firms, independent of bank ownership type. If informationally opaque borrowers are more susceptible to being captured by previous lenders, as predicted in Dell'Ariccia \& Marquez (77) and Hauswald \& Marquez (89) theoretical models, we would expect $\gamma_{3}$ to inform a larger competition effect, hence it should be negative. But at the same time, if previous loans of these firms are more valuable as a source of information, given that they are not fully transparent, informational effects should also be larger for SME firms. However, information effects might be different between foreign and private domestic banks. Thus, the triple interaction effect, measured by $\lambda$, is what helps us to disentangle information from competition effects. Current empirical evidence states that foreign banks are at comparative disadvantage in screening firms that rely on soft information (ie: SME firms). Hence, vis-a-vis private domestic banks, the existence of previous loans of SME firms should constitute more valuable information for foreign banks. In equation 3-1, this hypothesis means $\lambda>0$.

A careful description of the variables, as well as their mean values and standard deviations by bank ownership type, are shown in table 3.2. After loan applications are filed, roughly $10 \%$ of them turn into credit operations. Also, $90 \%$ of foreign banks information requests are about SME firms. This compares to $85 \%$ for private domestic banks. Regarding foreign banks requests, the researched firms are more likely to have borrowed from another lender in the recent past in comparison to private domestic banks. This finding also holds when we restrict the previous lenders' ownership type. This finding seems consistent with our hypothesis. According to our

\footnotetext{
${ }^{15}$ Due to the lack of firm variables in our data, even our less saturated specification includes firm fixed-effects, thus we don't present estimates for $\beta_{0}$.
} 
Chapter 3. Do foreign banks overcome borrower informational asymmetries by relying on their peer's behavior?

hypothesis, SME firms enhance their chances of getting a loan from a foreign bank once they borrowed from other lenders in the recent past. Hence, it makes sense if firms choose domestic banks for the first credit relationship.

Table 3.2: Description and sample statistics of the regression variables

\begin{tabular}{|c|c|c|c|c|}
\hline Variable & Description & Foreign & $\begin{array}{c}\text { Private } \\
\text { Domestic }\end{array}$ & Total \\
\hline LoanGranted $_{f b t}$ & $\begin{array}{l}=1 \text { if loan is granted from } t \text { to } t+3,=0 \\
\text { otherwise }\end{array}$ & $\begin{array}{c}0.117 \\
(0.321)\end{array}$ & $\begin{array}{c}0.099 \\
(0.298)\end{array}$ & $\begin{array}{c}0.104 \\
(0.305)\end{array}$ \\
\hline $\mathcal{F}_{b t}$ & $\begin{array}{l}=1 \text { if the information request was submitted by } \\
\text { a foreign bank, }=0 \text { otherwise }\end{array}$ & $\begin{array}{c}1.000 \\
(0.000)\end{array}$ & $\begin{array}{c}0.000 \\
(0.000)\end{array}$ & $\begin{array}{c}0.272 \\
(0.445)\end{array}$ \\
\hline$S M E$ & $\begin{array}{l}=1 \text { if information request is about an } S M E \\
\text { firm, }=0 \text { otherwise }\end{array}$ & $\begin{array}{c}0.904 \\
(0.295)\end{array}$ & $\begin{array}{c}0.850 \\
(0.357)\end{array}$ & $\begin{array}{c}0.864 \\
(0.343)\end{array}$ \\
\hline PreviousLoan & $\begin{array}{l}=1 \text { if the firm borrowed from another bank } \\
\text { from } t-3 \text { to } t-1,=0 \text { otherwise }\end{array}$ & $\begin{array}{c}0.328 \\
(0.470)\end{array}$ & $\begin{array}{c}0.225 \\
(0.417)\end{array}$ & $\begin{array}{c}0.253 \\
(0.435)\end{array}$ \\
\hline 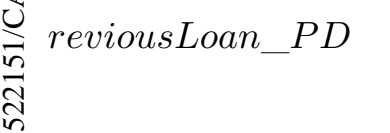 & $\begin{array}{l}=1 \text { if the firm borrowed from another private } \\
\text { domestic bank from } t-3 \text { to } t-1,=0 \text { otherwise }\end{array}$ & $\begin{array}{c}0.283 \\
(0.451)\end{array}$ & $\begin{array}{c}0.179 \\
(0.383)\end{array}$ & $\begin{array}{c}0.207 \\
(0.405)\end{array}$ \\
\hline 忘 & $\begin{array}{l}=1 \text { if the firm borrowed from another foreign } \\
\text { bank from } t-3 \text { to } t-1,=0 \text { otherwise }\end{array}$ & $\begin{array}{c}0.098 \\
(0.297)\end{array}$ & $\begin{array}{c}0.087 \\
(0.282)\end{array}$ & $\begin{array}{c}0.090 \\
(0.286)\end{array}$ \\
\hline 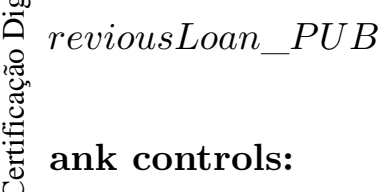 & $\begin{array}{l}=1 \text { if the firm borrowed from a public bank } \\
\text { from } t-3 \text { to } t-1,=0 \text { otherwise }\end{array}$ & $\begin{array}{c}0.118 \\
(0.322)\end{array}$ & $\begin{array}{c}0.074 \\
(0.262)\end{array}$ & $\begin{array}{c}0.086 \\
(0.280)\end{array}$ \\
\hline 's_ln_assets & $\begin{array}{l}\text { The log of bank holding total assets in the } \\
\text { quarter associated to month } t\end{array}$ & $\begin{array}{l}25.048 \\
(1.628)\end{array}$ & $\begin{array}{l}25.851 \\
(2.274)\end{array}$ & $\begin{array}{l}25.632 \\
(2.148)\end{array}$ \\
\hline $\mathcal{R}_{\text {iag_liq_ratio }}$ & $\begin{array}{l}\text { The bank holding liquid assets to total assets } \\
\text { ratio in the quarter associated to month } t\end{array}$ & $\begin{array}{c}0.194 \\
(0.086)\end{array}$ & $\begin{array}{c}0.164 \\
(0.074)\end{array}$ & $\begin{array}{c}0.172 \\
(0.078)\end{array}$ \\
\hline lag_cap_ratio & $\begin{array}{l}\text { The bank holding capital to total assets ratio in } \\
\text { the quarter associated to month } t\end{array}$ & $\begin{array}{c}0.157 \\
(0.051)\end{array}$ & $\begin{array}{c}0.166 \\
(0.045)\end{array}$ & $\begin{array}{c}0.163 \\
(0.047)\end{array}$ \\
\hline lag_ROA & $\begin{array}{l}\text { The return on assets ratio of the bank holding in } \\
\text { the quarter associated to month } t\end{array}$ & $\begin{array}{c}0.004 \\
(0.019)\end{array}$ & $\begin{array}{c}0.015 \\
(0.018)\end{array}$ & $\begin{array}{c}0.012 \\
(0.019)\end{array}$ \\
\hline lag_Sd_ROA & $\begin{array}{l}\text { Two year moving average standard deviation of } \\
\text { annually ROA ratio of the bank holding }\end{array}$ & $\begin{array}{c}0.004 \\
(0.005)\end{array}$ & $\begin{array}{c}0.003 \\
(0.006)\end{array}$ & $\begin{array}{c}0.004 \\
(0.006)\end{array}$ \\
\hline lag_credit_assets & $\begin{array}{l}\text { The loan stock to assets ratio of the bank } \\
\text { holding in the quarter associated to month } t\end{array}$ & $\begin{array}{c}0.562 \\
(0.162)\end{array}$ & $\begin{array}{c}0.515 \\
(0.089)\end{array}$ & $\begin{array}{c}0.528 \\
(0.116)\end{array}$ \\
\hline lag_NPL & $\begin{array}{l}\text { The share of non performing loans of the bank } \\
\text { holding in the quarter associated to month } t\end{array}$ & $\begin{array}{c}0.069 \\
(0.034)\end{array}$ & $\begin{array}{c}0.058 \\
(0.020)\end{array}$ & $\begin{array}{c}0.061 \\
(0.025)\end{array}$ \\
\hline lag_credit_growth & $\begin{array}{l}\text { The growth rate of loan stock of the bank } \\
\text { holding in the quarter associated to month } t\end{array}$ & $\begin{array}{c}0.022 \\
(1.013)\end{array}$ & $\begin{array}{c}0.006 \\
(0.036)\end{array}$ & $\begin{array}{c}0.010 \\
(0.530)\end{array}$ \\
\hline
\end{tabular}

Note: Mean values of variables are displayed by bank ownership type. Standard errors in parenthesis. Sample statistics computed over the period from 2013M01 to 2016M09. 
Equation 3-1 assumes that, following responses to the information requests about potential borrowers, banks became aware of the existence of recent loans granted to these borrowers by other lenders. As long as banks file information requests for multiple months, they can see the recent trajectory of the firm bank debt. Furthermore, even though loan-level information is not disclosed following information requests, it is a common practice in Brazilian credit markets for banks to ask for more details about potential borrowers previous loans, including their recent lenders' identities and/or their ownership type. In order to check if the signal about borrower quality given by the existence of recent loans varies across ownership types, equation 3-2 splits recent loans granted by private domestic and foreign owned banks:

$$
\begin{aligned}
\text { LoanGranted }_{f b t}= & +\beta_{0} S M E_{f}+\beta_{1} \mathcal{F}_{b t}+\beta_{2} \text { PreviousLoan_PD } D_{f t} \\
& +\beta_{3} \text { PreviousLoan_F } F_{f t}+\gamma_{1} \mathcal{F}_{b t} \bullet S M E_{f} \\
& +\gamma_{2} \mathcal{F}_{b t} \bullet \text { PreviousLoan_PD } \\
& +\gamma_{3} \mathcal{F}_{b t} \bullet \text { PreviousLoan_F } \\
& +\gamma_{4} \text { PreviousLoan_PD } D_{f t} \bullet S M E_{f} \\
& +\gamma_{5} \text { PreviousLoan_F } F_{f t} \bullet S M E_{f} \\
& +\lambda_{1} \mathcal{F}_{b t} \bullet \text { PreviousLoan_PD } D_{f t} \bullet S M E_{f} \\
& +\lambda_{2} \mathcal{F}_{b t} \bullet \text { PreviousLoan_F } F_{f t} \bullet S M E_{f} \\
& +\theta_{b}^{\prime} \mathbf{B a n k}_{\mathbf{b t}-\mathbf{1}}+\mathbf{F}_{\mathbf{f t}}+\mathbf{B}_{\mathbf{b t}}+\mathbf{M}_{\mathbf{t}}+\epsilon_{f b t}
\end{aligned}
$$

where PreviousLoan_PD takes the value 1 if the firm borrowed from another private domestic bank in the last three months, and equals 0 otherwise. PreviousLoan_F is an analogous variable, but for recent loans with foreign lenders. Equation 3-2 coefficients interpretation mimic those presented before for equation $3-1$, but split recent loans with private domestic and foreign banks. We implement this change for one reason: if private domestic banks are more suited to screen SME firms, past loans with them should be particularly informative about these firms quality. This translates into $\lambda_{1}>0$ in equation $3-2$, our second and most important hypothesis to be tested in this paper.

In the next section, we also test a specification that includes the effect of past loans with public banks. The banking literature points both to the possibility of public banks being not profit oriented (7) and to their lower performance in comparison to private competitors [(12), (92)]. Hence, past loans with public banks should not constitute a good signal about the firm quality, therefore they should not interfere on banks' decision to grant a loan. If our estimates confirm this history, our hypothesis regarding the importance of information conveyed by the existence of recent loans for foreign banks will be further strengthened. 
Equations 3-1 and 3-2 constitute a linear probability model. We avoid estimating a conditional logit, since it restricts the sample to those firms that both borrowed and were denied a loan within the same month. Also, conditional logit estimation makes marginal effects interpretation non standard when the independent variables of interest are binary. Standard errors are clustered at the bank-month level, since it is the locus where the effect of interest is defined. Nevertheless, our results are robust to clustering errors at the bank or firm level.

\subsection{2 \\ Identification concerns}

Departing from equations 3-1 and 3-2, our aim is to study if past loans of a potential borrower constitute valuable information for the foreign lender loan supply decision. However, a number of identification concerns may have a bearing on the estimation of the desired parameters. Traditionally, disentangling loan demand from loan supply effects has been a challenge in the banking literature since loan applications data and denied loan offers data are usually not available. ${ }^{16}$ But, as long as our bank information requests represent a good proxy for loan applications, demand for bank loans is controlled for by design. Of course, the firm can always reject a loan offer, so even our data don't rule out completely demand side effects. Nevertheless, it suit to indirectly estimate loan offer determinants by displaying if loans are granted after loan applications. ${ }^{17}$

We define lagged values of bank financial indicators, so its realization occurs prior to macroeconomic effects that might influence them (ie: to avoid bad control problems). Similarly, possible identification problems regarding the covariates of interest, namely PreviousLoan and its interactions, are addressed by the fact that this variable is defined ex-ante, previous to loan applications. It's possible that the variable PreviousLoan correlates to firm omitted variables that are important for the loan approval. If, for example, we fail to account for firm characteristics that are important to measure its creditworthiness, our coefficients might be biased, since these characteristics are probably correlated to the bank loan decision and whether or not the firm got previous loans. For this reason, our benchmark specification uses firm-month fixed effects to control for all time-varying heterogeneity at the firm level. In this specification, identification of the parameters of interest necessarily come from firms that applied for loans in both foreign and private domestic banks in the same month.

Another reason for concern may be due to unobserved complementarities between loans granted by foreign and private domestic banks. Consider, for example,

${ }^{16}$ Exceptions are Jimenez et al. (42), Jimenez et al. (91), Liberti \& Mian (82) and Agarwal \& Hauswald (90). The first two use bank information requests to proxy for loan demands. The latter two use loan application data from a specific bank.

${ }^{17}$ Ideally, it would be optimal to observe if, following a loan application, the bank offered the firm a loan proposal. Unfortunately, this data are not available. 
Chapter 3. Do foreign banks overcome borrower informational asymmetries by relying on their peer's behavior?

that private domestic banks specialize in granting loans of a particular type and that foreign banks specialize on another loan type. If these loans are complementary, such that firms have to borrow first the loan type provided by domestic banks and latter the loan type provided by foreign banks, the coefficients of interest might by overstated. In the next section, we argue this scenario is unlikely for our data.

\section{4}

\section{Results}

This section presents estimates of regressions 3-1 and 3-2 together with comments of our main findings.

\subsection{1}

\section{Unidentified bank ownership of potential borrowers previous lenders}

Table 3.3 presents OLS estimates of equation 3-1. It assumes that following a loan application of a noncurrent borrower, banks are aware of the existence of loans granted to this borrower in the last 3 months by other lenders. This information is readily available through replies to loan information requests. Up to this point, we also assume that bank ownership of previous lenders are unknown. From columns (1) to (4), we increasingly saturate the estimation with fixed effects. Overall, we intend to control for variables that might influence the lender decision to grant a loan to a potential borrower and that might be also correlated to the bank ownership, firm size and whether or not this firm borrowed from other lenders in the previous 3 months.

Column (1) features a number of bank financial indicators that might be related to the bank ability or willingness to grant a loan, including measures of bank size, liquidity, earnings, capital, importance of loans to its total assets and loan growth. It also includes month fixed effects that aim to control for macroeconomic variables that affect loan supply schedules in a similar fashion across banks. Firm fixed effects are included to control for time-invariant heterogeneities at the firm level. It controls, for example, for the firm economic sector, the quality of its managers and the firm size. These characteristics might change in the long run for a given firm, but are unlikely to change substantially in a 4 your horizon.

Table 3.3: Linear probability model estimates of equation (3-1). Dependent variable: LoanGranted $_{f b t}$

\begin{tabular}{lcccc}
\hline \hline Variables & $(1)$ & $(2)$ & $(3)$ & $(4)$ \\
\hline $\mathcal{F}_{b t}$ & $0.024^{* * *}$ & & & \\
& $(0.004)$ & & & \\
$\mathcal{F}_{b t} \bullet S M E_{f}$ & $-0.023^{* * *}$ & 0.001 & 0.004 & 0.003 \\
& $(0.004)$ & $(0.004)$ & $(0.004)$ & $(0.004)$ \\
PreviousLoan & 0.003 & $0.006^{* *}$ & &
\end{tabular}


Chapter 3. Do foreign banks overcome borrower informational asymmetries by relying on their peer's behavior?

Table 3.3: Linear probability model estimates of equation (3-1). Dependent variable: . LoanGranted $_{f b t}$ (continued)

\begin{tabular}{|c|c|c|c|c|}
\hline Fixed effects: & (1) & $(2)$ & $(3)$ & $(4)$ \\
\hline & $(0.002)$ & $(0.002)$ & & \\
\hline \multirow[t]{2}{*}{$\mathcal{F}_{b t} \bullet$ PreviousLoan $_{f t}$} & -0.003 & $-0.014^{* * *}$ & $0.010^{*}$ & $0.009^{*}$ \\
\hline & $(0.005)$ & $(0.005)$ & $(0.005)$ & $(0.005)$ \\
\hline \multirow{2}{*}{ PreviousLoan $_{f t} \bullet S M E_{f}$} & $-0.037^{* * *}$ & $-0.034^{* * *}$ & & \\
\hline & $(0.003)$ & $(0.003)$ & & \\
\hline \multirow[t]{2}{*}{$\mathcal{F}_{b t} \bullet$ PreviousLoan $_{f t} \bullet S M E_{f}$} & $0.012^{* *}$ & $0.017^{* * *}$ & $0.016^{* *}$ & $0.014^{*}$ \\
\hline & $(0.006)$ & $(0.006)$ & $(0.007)$ & $(0.007)$ \\
\hline \multicolumn{5}{|l|}{ Bank controls: } \\
\hline \multirow[t]{2}{*}{ lag_ln_assets } & 0.000 & 0.001 & -0.009 & \\
\hline & $(0.001)$ & $(0.006)$ & $(0.006)$ & \\
\hline \multirow[t]{2}{*}{ lag_liq_ratio } & $-0.241^{* * *}$ & -0.006 & $0.107^{* * *}$ & \\
\hline & $(0.030)$ & $(0.024)$ & $(0.023)$ & \\
\hline \multirow[t]{2}{*}{ lag_cap_ratio } & $0.108^{* * *}$ & -0.005 & $-0.048^{*}$ & \\
\hline & $(0.019)$ & $(0.024)$ & $(0.027)$ & \\
\hline \multirow[t]{2}{*}{ lag_ROA } & $0.217^{* * *}$ & -0.006 & 0.075 & \\
\hline & $(0.059)$ & $(0.035)$ & $(0.046)$ & \\
\hline \multirow[t]{2}{*}{ lag_Sd_ROA } & $-1.019^{* * *}$ & -0.321 & -0.328 & \\
\hline & $(0.201)$ & $(0.228)$ & $(0.245)$ & \\
\hline \multirow[t]{2}{*}{ lag_credit_assets } & -0.021 & 0.005 & $0.057^{* * *}$ & \\
\hline & $(0.018)$ & $(0.021)$ & $(0.020)$ & \\
\hline \multirow[t]{2}{*}{ lag_NPL } & $-0.178^{* * *}$ & $-0.078^{*}$ & -0.027 & \\
\hline & $(0.060)$ & $(0.044)$ & $(0.048)$ & \\
\hline \multirow[t]{2}{*}{ lag_credit_growth } & 0.002 & 0.000 & $0.021^{* * *}$ & \\
\hline & $(0.003)$ & $(0.003)$ & $(0.004)$ & \\
\hline \multicolumn{5}{|l|}{ Fixed effects: } \\
\hline Month & Yes & Yes & - & - \\
\hline Bank & No & Yes & Yes & - \\
\hline Firm & Yes & Yes & - & - \\
\hline Firm-month & No & No & Yes & Yes \\
\hline Bank-month & No & No & No & Yes \\
\hline Observations & 378,558 & 378,558 & 101,067 & 101,067 \\
\hline
\end{tabular}

Note: Standard errors in parentheses, clustered at the bank-month level. ${ }^{*} p<0.1,{ }^{* *} p<0.05$, ${ }^{* * *} p<0.01$. Columns (1) and (2) present 53,497 firm fixed effects. Columns (3) and (4) present 42,082 firm-month fixed effects.

Table 3.3 estimates show that following a loan application, the probability a loan is granted in the next 3 months is larger for foreign banks, but this increase is 
offset if the loan applicant is a SME firm. Also, the existence of new loans in the last 3 months has little effect on the probability that a loan is granted for large firms, but has large and negative effects for SME firms, what is shown in table 3.3 by the coefficients associated to PreviousLoan and PreviousLoan $\times S M E$, respectively. This last finding is consistent with the banking competition literature. Current lenders might lock-in their costumers due to private information accumulated in the course of the credit relationship [(77), (87), (90)]. This capture effect tends to be larger in market segments with higher degrees of information asymmetries. In the regression setup, the bank to whom the loan applicantion is filed has a potential competitor: the bank from whom the applicant borrowed recently. Hence, this competitor has an informational advantage, which justifies negative effects for the probability of a loan being granted by the new bank.

Apart from the competition story, our hypothesis stipulates that recent loans might represent a more important signal of firm quality for foreign banks. Also, this effect should be larger in market segments where foreign banks have higher information disadvantages (ie: SME firms). Table 3.3 corroborates this hypothesis. The triple interaction of $S M E, \mathcal{F}$ and PreviousLoan is positive and statistically significant. In this case, the positive firm quality signal for foreign banks mitigates potential competition effects.

It's important to note here that the absence of heterogeneous competition effects across bank types is what allow us to disentangle competition from informational effects in our narrative. It would be a problem for our analysis, for example, if previous lenders are less able to lock-in their SME borrowers from foreign competitors. In this scenario, we would capture asymmetric competition effects instead of informational effects. However, we believe this scenario is unlikely because greater informational problems faced by foreign banks in this market are more likely to reduce, not to increase, their ability to serve SME firms. Hence, it is more likely for our coefficients of interest to be underestimated due to asymmetric competition effects rather than overestimated.

Column (2) introduces individual bank fixed effects. Since bank controls are defined at the holding level, fixed effects might control for individual bank heterogeneities that are important to determine loan supply. Although bank control estimates differ substantially from column (1), our findings regarding the independent variables of interest remain roughly unaltered.

Column (3) adds firm-month fixed effects to equation 3-1. It's estimation is based on firms that applied for loans in different banks in the same month. Since the coefficients of interest require variation in bank ownership, identification of these parameters with firm-month fixed effects comes from firms that necessarily applied for loans in at least one foreign and one private domestic bank in the same month. Thus, it controls not only for the unobserved time-varying credit risk of the firm, but also for the self-selection of firms to bank ownership types. In this regard, it reduces concerns prompted, for example, by the possibility that firms with higher 
quality are more likely to apply for loans in foreign-owned banks. This specification is our benchmark. Coefficient estimates in this specification show that, following loan applications, the existence of past loans with other lenders increases the chance the loan will be granted for foreign banks in comparison to domestic banks. In economic terms, these estimates indicate a $9 \%$ rise in the probability of a loan being granted for large firms and $22 \%$ for SME firms. ${ }^{18}$ Not only our estimated coefficients are statistically significant but their magnitudes are also material.

It's possible that banks react to each other depending on the current credit market shares of each one, leading to more aggressive or looser movements in their loan supply policies. In order to avoid that this fight for market shares confounds the estimation of our parameters, column (4) introduces bank-month fixed effects. It presents a vary saturated specification that features both firm-month and bankmonth fixed effects. Thus, column (4) controls for all time varying heterogeneity at both firm and bank levels that affect loan supply schedules. Our findings stand this saturated specification at a $10 \%$ level of statistical significance.

\subsection{2}

\section{Identified bank ownership of potential borrowers previous lenders}

Table 3.4 presents coefficient estimates of equation 3-2, that separates past loans according to bank ownership. Columns (1) and (2) seem to support the banking competition borrower-capture history. These findings stand for past loans with both types of bank ownership. Given loan applications of SME noncurrent borrowers, the probability of a loan being granted is significantly smaller for SME firms that borrowed from other lenders in the recent past. This effect is stronger (ie: more negative) for firms that borrowed from private domestic banks, which suggests a better ability of these banks to lock-in their SME borrowers. In this regard, it might represent an indirect evidence of domestic banks higher ability to process soft information.

Estimation of equation 3-2 allows us to test if the borrower quality signal given by its previous loans vary with the previous lender ownership. As mentioned in the last section, private domestic banks are at informational advantage regarding lending to SME firms. Thus, past loans of SME firms with private domestic banks should constitute more valuable information for foreign banks. Indeed, the estimated coefficients corroborate this hypothesis: vis-a-vis private domestic banks, past loans of SME firms with private domestic banks are relatively more informative for foreign lenders. The same isn't true for large firms. In economic terms, the probability of a foreign bank granting a loan increases $22 \%$ for SME firms that borrowed previously from private domestic banks. Our results also show that past loans with foreign lenders are more informative for foreign banks in comparison to private

${ }^{18}$ These numbers are calculated through a comparison of coefficient estimates and the foreign banks' unconditional mean of a loan being granted. That is, for large firms 0.010/0.117 $=9 \%$ and for SME firms 0.026/0.117 $=22 \%$. 
Chapter 3. Do foreign banks overcome borrower informational asymmetries by relying on their peer's behavior?

domestic banks, albeit there is no differential effect across firm size categories. ${ }^{19}$ This finding further strengths our claim that foreign banks overcome borrower information asymmetries by relying on their peers' behavior.

Table 3.4: Linear probability model estimates of equation (3-2). Dependent variable: LoanGranted $_{f b t}$

\begin{tabular}{|c|c|c|c|c|}
\hline Variables & $(1)$ & $(2)$ & $(3)$ & $(4)$ \\
\hline $\mathcal{F}_{b t}$ & $\begin{array}{c}0.024^{* * *} \\
(0.004)\end{array}$ & & & \\
\hline $\mathcal{F}_{b t} \bullet S M E_{f}$ & $\begin{array}{c}-0.023^{* * *} \\
(0.004)\end{array}$ & $\begin{array}{c}0.002 \\
(0.004)\end{array}$ & $\begin{array}{c}0.004 \\
(0.004)\end{array}$ & $\begin{array}{c}0.003 \\
(0.004)\end{array}$ \\
\hline PreviousLoan_PDft & $\begin{array}{l}0.005^{*} \\
(0.002)\end{array}$ & $\begin{array}{c}0.007^{* * *} \\
(0.003)\end{array}$ & & \\
\hline $\mathcal{F}_{b t} \bullet$ PreviousLoan_PD $D_{f t}$ & $\begin{array}{l}-0.008 \\
(0.006)\end{array}$ & $\begin{array}{c}-0.013^{* *} \\
(0.006)\end{array}$ & $\begin{array}{c}0.001 \\
(0.006)\end{array}$ & $\begin{array}{c}0.001 \\
(0.006)\end{array}$ \\
\hline PreviousLoan_F $F_{f t}$ & $\begin{array}{l}-0.002 \\
(0.003)\end{array}$ & $\begin{array}{c}0.000 \\
(0.003)\end{array}$ & & \\
\hline $\mathcal{F}_{b t} \bullet$ PreviousLoan_F $F_{f t}$ & $\begin{array}{c}0.008 \\
(0.006)\end{array}$ & $\begin{array}{l}-0.002 \\
(0.007)\end{array}$ & $\begin{array}{c}0.017^{* *} \\
(0.007)\end{array}$ & $\begin{array}{l}0.016^{* *} \\
(0.007)\end{array}$ \\
\hline PreviousLoan_P $D_{f t} \bullet S M E_{f}$ & $\begin{array}{c}-0.037^{* * *} \\
(0.004)\end{array}$ & $\begin{array}{c}-0.032^{* * *} \\
(0.004)\end{array}$ & & \\
\hline $\mathcal{F}_{b t} \bullet$ PreviousLoan_P $D_{f t} \bullet S M E_{f}$ & $\begin{array}{c}0.017^{* * *} \\
(0.006)\end{array}$ & $\begin{array}{c}0.017^{* *} \\
(0.007)\end{array}$ & $\begin{array}{c}0.025^{* * *} \\
(0.008)\end{array}$ & $\begin{array}{c}0.024^{* * *} \\
(0.008)\end{array}$ \\
\hline PreviousLoan_F $F_{f t} \bullet S M E_{f}$ & $\begin{array}{c}-0.022^{* * *} \\
(0.005)\end{array}$ & $\begin{array}{c}-0.024^{* * *} \\
(0.005)\end{array}$ & & \\
\hline $\mathcal{F}_{b t} \bullet$ PreviousLoan_F $F_{f t} \bullet S M E_{f}$ & $\begin{array}{c}0.001 \\
(0.009)\end{array}$ & $\begin{array}{c}0.004 \\
(0.009)\end{array}$ & $\begin{array}{l}-0.005 \\
(0.011)\end{array}$ & $\begin{array}{l}-0.007 \\
(0.012)\end{array}$ \\
\hline Bank controls: & Yes & Yes & Yes & - \\
\hline Fixed effects: & & & & \\
\hline Month & Yes & Yes & - & - \\
\hline Bank & No & Yes & Yes & - \\
\hline Firm & Yes & Yes & - & - \\
\hline Firm-month & No & No & Yes & Yes \\
\hline Bank-month & No & No & No & Yes \\
\hline Observations & 378,558 & 378,558 & 101,067 & 101,067 \\
\hline
\end{tabular}

Note: Standard errors in parentheses, clustered at the bank-month level. ${ }^{*} p<0.1,{ }^{* *} p<0.05$, *** $p<0.01$. Columns (1) and (2) present 53,497 firm fixed effects. Columns (3) and (4) present 42,082 firm-month fixed effects

, However, this finding is not robust to some of our robustness exercises, as shown in table 3.7 . 
We mentioned before that banks have to resort to impersonal means in order to get information from noncurrent borrowers previous lenders ownership type. In this regard, our results are also an ex-post evidence that some banks are aware of this information, even if it's not supplied by automatic replies to information requests filed by banks.

\subsection{3 \\ Heterogeneities in the signal given by loans with domestic banks}

To confirm that informational asymmetries are the driving force behind our results, it's important to explore heterogeneity in the quality of signals given by domestic banks' previous loans to SME firms. In this regard, previous loans with specific domestic lenders might constitute better information about firm quality. If, for example, some domestic lenders are more productive in screenning firms, which can occur due to better technology in gathering and processing borrower information or better credit scoring methods, then previous loans with these lenders should constitute more valuable information. Also, the existence of past loans is more useful if previous lenders' objectives are more aligned with the banks that are accessing noncurrent borrowers prospects. For both reasons, recent loans with public banks should not constitute important information for other banks' loan offer decisions. In the first case, public banks are seem to be less productive than other banks, so it's unlike that public banks have better technology to evaluate borrowers than their private domestic competitors. Indeed, their lower performance seem in accordance to this fact [(12), (92)]. Second, public banks' objectives may encompass other factors, including the provision of services to specific sectors (1), government owned firms (76) or the financing of firms that have political connections with the government $(7)$.

In order to test these implications, table 3.5 presents a specification that incorporates a binary variable, PreviousLoan_PUB $B_{f t}$, that indicates whether or nor the firm borrowed from public banks in the last 3 months. We also include interactions of this variable with binary indicators of foreign bank ownership and SME firms. All of the coefficients associated to PreviousLoan_PU $B_{f t}$ are small and not statistically significant in the benchmark specification. In accordance with the previous discussion, these findings suggest that public banks are not able to capture their borrowers, which points to their lower ability to compete with private lenders. Also, and more importantly, the existence of past loans with public banks doesn't provide valuable information for foreign banks decision to grant loans to noncurrent borrowers. We interpret these findings as corroborating our view that past loans with public banks are a weak signal about borrower quality. 
Chapter 3. Do foreign banks overcome borrower informational asymmetries by relying on their peer's behavior?

Table 3.5: Linear probability model estimates. Dependent variable: LoanGranted $_{f b t}$

\begin{tabular}{|c|c|c|c|c|}
\hline Variables & $(1)$ & $(2)$ & $(3)$ & $(4)$ \\
\hline \multirow[t]{2}{*}{$\mathcal{F}_{b t}$} & $0.023^{* * *}$ & & & \\
\hline & $(0.004)$ & & & \\
\hline \multirow[t]{2}{*}{$\mathcal{F}_{b t} \bullet S M E_{f}$} & $-0.024^{* * *}$ & 0.002 & 0.004 & 0.003 \\
\hline & $(0.004)$ & $(0.004)$ & $(0.004)$ & $(0.004)$ \\
\hline \multirow[t]{2}{*}{ PreviousLoan_PD $f t$} & $0.004^{*}$ & $0.006^{* *}$ & & \\
\hline & $(0.002)$ & $(0.002)$ & & \\
\hline \multirow[t]{2}{*}{$\mathcal{F}_{b t} \bullet$ PreviousLoan_PD $D_{f t}$} & $-0.009^{*}$ & $-0.014^{* *}$ & -0.001 & -0.002 \\
\hline & $(0.005)$ & $(0.006)$ & $(0.006)$ & $(0.006)$ \\
\hline \multirow[t]{2}{*}{ PreviousLoan_F $F_{f t}$} & -0.003 & -0.000 & & \\
\hline & $(0.003)$ & $(0.003)$ & & \\
\hline \multirow[t]{2}{*}{$\mathcal{F}_{b t} \bullet$ PreviousLoan_F $F_{f t}$} & 0.007 & -0.003 & $0.015^{* *}$ & $0.014^{*}$ \\
\hline & $(0.007)$ & $(0.007)$ & $(0.007)$ & $(0.007)$ \\
\hline \multirow[t]{2}{*}{ PreviousLoan_PUB $B_{f t}$} & $0.010^{* *}$ & $0.010^{* *}$ & & \\
\hline & $(0.005)$ & $(0.005)$ & & \\
\hline \multirow[t]{2}{*}{$\mathcal{F}_{b t} \bullet$ PreviousLoan_PU $B_{f t}$} & 0.005 & 0.007 & 0.013 & 0.016 \\
\hline & $(0.008)$ & $(0.008)$ & $(0.010)$ & $(0.010)$ \\
\hline \multirow[t]{2}{*}{ PreviousLoan_PD $D_{f t} \bullet S M E_{f}$} & $-0.037^{* * *}$ & $-0.032^{* * *}$ & & \\
\hline & $(0.004)$ & $(0.004)$ & & \\
\hline \multirow[t]{2}{*}{$\mathcal{F}_{b t} \bullet$ PreviousLoan_PDft $\bullet S M E_{f}$} & $0.018^{* * *}$ & $0.017^{* * *}$ & $0.025^{* * *}$ & $0.025^{* * *}$ \\
\hline & $(0.006)$ & $(0.007)$ & $(0.008)$ & $(0.008)$ \\
\hline \multirow[t]{2}{*}{ PreviousLoan_F $F_{f t} \bullet S M E_{f}$} & $-0.021^{* * *}$ & $-0.023^{* * *}$ & & \\
\hline & $(0.005)$ & $(0.005)$ & & \\
\hline \multirow[t]{2}{*}{$\mathcal{F}_{b t} \bullet$ PreviousLoan_F $F_{f t} \bullet S M E_{f}$} & 0.001 & 0.004 & -0.006 & -0.007 \\
\hline & $(0.009)$ & $(0.009)$ & $(0.012)$ & $(0.012)$ \\
\hline \multirow[t]{2}{*}{ PreviousLoan_PU $B_{f t} \bullet S M E_{f}$} & 0.008 & 0.006 & & \\
\hline & $(0.006)$ & $(0.006)$ & & \\
\hline \multirow[t]{2}{*}{$\mathcal{F}_{b t} \bullet$ PreviousLoan_PU $B_{f t} \bullet S M E_{f}$} & 0.001 & 0.002 & 0.002 & -0.001 \\
\hline & $(0.010)$ & $(0.010)$ & $(0.015)$ & $(0.015)$ \\
\hline Bank controls: & Yes & Yes & Yes & - \\
\hline \multicolumn{5}{|l|}{ Fixed effects: } \\
\hline Month & Yes & Yes & - & - \\
\hline Bank & No & Yes & Yes & - \\
\hline Firm & Yes & Yes & - & - \\
\hline Firm-month & No & No & Yes & Yes \\
\hline Bank-month & No & No & No & Yes \\
\hline Observations & 378,558 & 378,558 & 101,067 & 101,067 \\
\hline
\end{tabular}


Chapter 3. Do foreign banks overcome borrower informational asymmetries by relying on their peer's behavior?

Table 3.5: Linear probability model estimates. Dependent variable: LoanGranted $_{f b t}$ (continued)

\begin{tabular}{l}
\hline \hline Variable \\
\hline \hline Note: Standard errors in parentheses, clustered at the bank-month level. ${ }^{*} p<0.1,{ }^{* *} p<0.05$, \\
${ }^{* * *} p<0.01$. Columns (1) and (2) present 53,497 firm fixed effects. Columns $(3)$ and $(4)$ present \\
42,082 firm-month fixed effects.
\end{tabular}

\subsection{4}

Possible complementarities among loan types

One might be concerned that complementarities among loan types confound our estimates. In principle, this may not be a problem, since this complementarity idea is about loan types, not about bank ownership types. But, if banks specialize in granting loans of a specific kind, and if this specialization correlates to the complemantarities among loan types, concerns related to identification may increase. Consider, for instance, that loans of types A and B are complementary, such that firms borrow first loans of type $\mathrm{A}$ and, then, loans of type $\mathrm{B}$. If private domestic banks specialize in granting loans of type A, while foreign banks specialize in granting loans of type $\mathrm{B}$, one might be concerned that our estimates are biased. We argue that this is unlikely the reason behind our findings.

Columns (1) and (2) of table C.2.5 present market shares of loan types, conditional on bank ownership, for loans granted up to 3 months after information requests. As we can see, private domestic banks specialize in granting short-term loans (89\%), while these shares are more balanced for foreign banks. Table 3.6 shows two transition matrices across loan types calculated for loans granted by foreign banks up to 3 months after information requests to SME firms that borrowed previously from other lenders. Matrix entry $(\mathrm{i}, \mathrm{j})$ identifies the share of firms that took loans of type $i$ in $[t-1, t-3]$ that moved to loan type $j$ in $[t, t+3]$. We separate loans on only two different types: short-term loans (eg: working capital, lines of credit, etc) and other loans (eg: real state loans, import and export loans, etc). The left matrix shows a transition matrix for firms that borrowed from other foreign lenders in the last 3 months, while the matrix on the right shows a transition matrix for firms that borrowed from private domestic banks in the same period. In both cases, we see that more than $50 \%$ of firms borrow the same loan types in the last 3 months and in the next 3 months following information requests.

If the idea of complementarities among loan types is true, we would expect that a larger share of SME firms borrow first the loan type which is private domestic banks' specialty (ie: short-term loans) and, latter, the loan type which is foreign banks specialty (other loan types). That is, the entry $(1,2)$ of the matrix on the left panel should be larger than the same element of the matrix on the right panel. However, in comparison to firms that borrowed from private domestic banks in the 
last 3 months, a larger share of firms that borrowed recently from foreign banks migrate from short-term loans to other loans (33\% compared to $25 \%$ ). This finding seem at odds with the complementarity history stated above. ${ }^{20}$

To further shed light on this issue, we give in appendix C.2 an example with simulated data that shows the combination of an unconditional transition matrix verified in the data and different market shares of loan types don't necessarily generates statistical significant coefficients for the triple interaction of $(\mathcal{F}, S M E$ and PreviousLoan_PD). In summary, we generate loan application data that replicate market shares of loan types by bank ownership and the unconditional transition matrix, among other data moments. Than, we run the same kind of OLS regressions that we've done so far. As expected, regression estimates based on artificial data don't replicate our findings. Further details are given in appendix C.2.

Table 3.6: Transition matrices across loan types calculated for loans granted by foreign banks up to 3 months after information requests to SME firms that borrowed previously from other lenders. Matrix entry $(i, j)$ identifies the share of firms that took loans of type $i$ in $[t-1, t-3]$ that moved to loan type $j$ in $[t, t+3]$.

Panel A:

$\mathcal{F}=1, \mathrm{SME}=1$, PreviousLoan_PD $=1$

short-term other loans

hort-term

ther loans

$$
75 \%
$$

$25 \%$

$46 \%$

Panel B:

$$
\mathcal{F}=1, \mathrm{SME}=1, \text { PreviousLoan_F }=1
$$

short-term other loans

short-term $\quad 67 \% \quad 33 \%$

other loans
$29 \%$

\section{5 \\ Robustness}

In this section we perform some robustness analysis to variations in specification and definitions adopted in the previous estimations. For brevity, we present only estimates with firm-month and bank fixed effects, our benchmark specification (column (3) in previous regression tables). Table 3.7 presents new estimates for the robustness exercises. Each column represents a modification in relation to our previous setup.

First, one might be concerned that regression errors of banks' decisions are serially correlated. In this case, clusters at the bank-month level would be too narrow, overstating the statistical significance of the estimated coefficients. For this

\footnotetext{
${ }^{20}$ In fact, for this complementarity history to explain our estimates regarding the triple interaction of $\mathcal{F}, S M E$ and PreviousLoan_PD, it has to hold only for SME firms that applied for loans in foreign banks in period $t$ and that borrowed from private domestic banks from $t-3$ to $t-1$. That is, among all 8 possible different transition matrices for variables $(\mathcal{F}, S M E$, PreviousLoan_PD and PreviousLoan_F), it should be a unique feature of the matrix in panel left of figure 3.6. In unreported results, we checked these other matrices and this seems not to be the case.
} 
reason, column (1) defines error clusters at the bank level. Since only 10 banks concentrate $85 \%$ of loan applications, clustering at the bank level allows errors of a large number of observations to be serially correlated. Nevertheless, our findings remain statistically significant at $5 \%$. In unreported results, we also verify that our findings are robust to clustering errors at the firm level.

Second, we also verify if our findings are sensitive to the definition of SME firms. With this purpose, we employ an alternative categorization of firm size based on gross revenues and total assets categories shown in plot D of figures 3.1 and 3.2. We redefine as SMEs those firms that are in categories 1,2 or 3 of this variable, that is, firms with annual gross revenues and total assets bellow 300 millions and 240 millions. Results for this specification are shown in column 2. After this modification, our findings are still statistically significant at $5 \%$. In unreported results, we replace the indicator variable for SME firms by a continuous variable proxy for firm size, the monthly total outstanding debt (defined in footnote 7). Our findings also stand to this specification.

The PreviousLoan_PD $D_{f t}$ and PreviousLoan_F $F_{f t}$ variables are defined based on 3 months prior to the information request. It's possible that previous bank loans further in the past are informative about borrower quality, so we modify these variables to account for the existence of previous loans in the last 6 months. Column (3) presents estimates for this specification. Our results are also unaltered in this case.

It might also prompt some concern the possibility that banks submit multiple information requests for the same borrower in a short interval. If borrowers approach lenders that just denied them bank loans in the very recent past, chances of getting a new loan this time might be even slimmer. ${ }^{21}$ This could cast doubts on the use of information requests to noncurrent borrowers as good proxies for loan applications. Hence, we test a specification that filters in only bank information requests on borrowers about whom no information requests were filed by this same bank in the last 6 months. Results are displayed in column (4). Despite the large drop in the number of observations, our findings are still statistically significant at $10 \%$. The coefficient of interest is considerably larger in this case.

Table 3.7: Robustness exercises. Dependent variable: LoanGranted $_{f b t}$

\begin{tabular}{lcccc}
\hline \hline Variable & $\begin{array}{c}\text { Errors } \\
\text { clustered at } \\
\text { the bank level }\end{array}$ & $\begin{array}{c}\text { SME defined } \\
\text { according to } \\
\text { gross revenues }\end{array}$ & $\begin{array}{c}\text { Past loans in } \\
\text { the last 6 } \\
\text { months }\end{array}$ & $\begin{array}{c}\text { Minimum } \\
\text { 6-month } \\
\text { window }\end{array}$ \\
\hline $\mathcal{F}_{b t} \bullet S M E_{f}$ & 0.004 & -0.005 & 0.003 & 0.020 \\
& \\
${ }^{21}$ Given our focus on information requests to noncurrent borrowers, multiple information \\
requests in a short period interval are unlike for firms that were actually granted a loan, since, \\
in this case, they would no longer satisfy the noncurrent borrower criteria for subsequent \\
loans.
\end{tabular}


Chapter 3. Do foreign banks overcome borrower informational asymmetries by relying on their peer's behavior?

Table 3.7: Robustness exercises. Dependent variable: LoanGranted fbt $_{\text {(contin- }}$ ued).

\begin{tabular}{|c|c|c|c|c|}
\hline Variable & $\begin{array}{l}\text { Errors } \\
\text { clustered at } \\
\text { the bank level }\end{array}$ & $\begin{array}{l}\text { SME defined } \\
\text { according to } \\
\text { gross revenues }\end{array}$ & $\begin{array}{l}\text { Past loans in } \\
\text { the last } 6 \\
\text { months }\end{array}$ & $\begin{array}{l}\text { Minimum } \\
\text { 6-month } \\
\text { window }\end{array}$ \\
\hline & $(0.005)$ & $(0.004)$ & $(0.004)$ & $(0.016)$ \\
\hline \multirow[t]{2}{*}{$\mathcal{F}_{b t} \bullet$ PreviousLoan_PD $D_{f t}$} & 0.001 & -0.002 & -0.002 & -0.025 \\
\hline & $(0.009)$ & $(0.008)$ & $(0.005)$ & $(0.019)$ \\
\hline \multirow{2}{*}{$\mathcal{F}_{b t} \bullet$ PreviousLoan_PD $f t \bullet S M E_{f}$} & $0.025^{* *}$ & $0.020^{* *}$ & $0.024^{* * *}$ & $0.041^{*}$ \\
\hline & $(0.011)$ & $(0.010)$ & $(0.008)$ & $(0.024)$ \\
\hline \multirow{2}{*}{$\mathcal{F}_{b t} \bullet$ PreviousLoan_F $F_{f t}$} & $0.017^{*}$ & 0.003 & $0.021^{* * *}$ & $0.086^{* * *}$ \\
\hline & $(0.009)$ & $(0.009)$ & $(0.006)$ & $(0.021)$ \\
\hline \multirow[t]{2}{*}{$\mathcal{F}_{b t} \bullet$ PreviousLoan_F $F_{f t} \bullet S M E_{f}$} & -0.005 & 0.011 & -0.008 & -0.018 \\
\hline & $(0.012)$ & $(0.011)$ & $(0.010)$ & $(0.030)$ \\
\hline Bank controls: & Yes & Yes & Yes & Yes \\
\hline \multicolumn{5}{|l|}{ Fixed effects: } \\
\hline Month & - & - & - & - \\
\hline Bank & Yes & Yes & Yes & Yes \\
\hline Firm & - & - & - & - \\
\hline Firm-month & Yes & Yes & Yes & Yes \\
\hline Bank-month & No & No & No & No \\
\hline Observations & 101,067 & 101,067 & 99,020 & 13,091 \\
\hline \multicolumn{5}{|c|}{$\begin{array}{l}\text { Standard errors in parentheses, }{ }^{*} p<0.1,{ }^{* *} p<0.05,{ }^{* * *} p<0.01 . \text { Columns }(1) \text { and }(2) \text { present } \\
42,802 \text { firm-month fixed effects. Column }(3) \text { presents } 41,954 \text { firm-month fixed effects and column } \\
\text { (4) presents } 6,192 \text { firm-month fixed effects. }\end{array}$} \\
\hline $\begin{array}{l}\text { We also try a placebo exe } \\
\text { usual textbook placebo exercise } \\
\text { in time. The exercise is conduc } \\
\text { effect is supposed to happen. An } \\
\text { each information request. We set } \\
\text { such that the share of informatic } \\
\text { Tables C.1.1 and C.1.2 in the app } \\
\text { We verify that none of the coeffi } \\
\text { benchmark specification. }\end{array}$ & $\begin{array}{l}\text { ise to confirm t } \\
\text { the treatment } \mathrm{e} \\
d \text { by randomly } \\
\text { ogously, we rand } \\
\text { probability of t } \\
\text { requests made l } \\
\text { dix present the } \\
\text { ents of interest }\end{array}$ & $\begin{array}{l}\text { e robustness of } \\
\text { ect occurs in a } \\
\text { ltering the time } \\
\text { mly modify banl } \\
\text { bank ownershi] } \\
\text { foreign banks a } \\
\text { timates of this p } \\
\text { e statistically si }\end{array}$ & $\begin{array}{l}\text { ur results. In } \\
\text { pecified point } \\
\text { ownership treatment } \\
\text { being foreign, } \\
\text { e preserved. } \\
\text { cebo exercise. } \\
\text { hificant in the }\end{array}$ & \\
\hline
\end{tabular}




\section{6}

\section{Discussion}

Our findings relate to a group of papers that studies the importance of information provided through agents' actions. In particular, the Informational Cascades model of (93) can rationalize our hypothesis. In the model, binary decisions of agents are taken sequentially. Each agent observes a private random signal about the quality of the object being evaluated and the decisions taken by previous peers towards this object (but not previous peers' private signals). An analogy to our case is straightforward. Banks observe a signal regarding borrowers projects quality and have to decide whether or not to finance a project. Besides their signal, they observe previous lenders actions toward financing the same borrower. In the model of (93), the sequence of decisions evolve in such a way that with high probability agents end up following their peers' actions independent of their own private signals.

(93) model also encompasses a scenario with heterogeneity across agent signals' precision. Some agents have a lower variance signal regarding the object of interest. Hence, if agents with higher signal precision decide first, conformity to their decisions by following agents occurs even faster. Also, the existence of costs of delaying the decision (i.e.: if banks face an opportunity cost for not financing a viable project) induces agents of more precise signals to act first and others to free-ride on their decisions. This general scenario closely mimics our narrative that domestic banks have information advantages (ie: more precise signals) in evaluating SME firms quality. Thus, previous decisions taken by domestic banks towards financing these firms have a higher chance of being followed by foreign owned banks.

This paper also relates to empirical findings regarding the importance of bank loans to convey nonpublic information about borrower quality. James (94) shows that stock returns present abnormal returns in the time range surrounding bank loan agreements. In comparison, the announcement of other forms of external finance, such as public straight debt offerings, don't cause the same impact on stock prices. Moreover, these findings are not related to the purpose of the loan. James (94) states that bank loans reveal inside information of firms, which differentiates them from other forms of private debt. In the same line, Lummer \& McConnel (95) goes deeper in the previous results of James (94) by separating loan credit agreements into new loans and loan renewals. The author finds that excess stocks returns are exclusively attributable to the latter. This finding points to the fact that the information acquired in the course of the relationship, rather than information gathered at the first contact with the firm, is what justify excess stock returns. These papers and ours share the common view that bank loans provide a singular and important source of information regarding borrower quality. 


\section{7}

\section{Conclusion}

We have shown that foreign banks can mitigate informational barriers visa-vis private domestic banks by observing their peers' behavior. The existence of new bank loans in the last months constitute valuable hard information about SME borrower quality. In particular, past loans of SME firms with private domestic banks are specially valuable since the latter are at comparative advantage in evaluating informationally opaque firms. In this regard, our results are adherent to the vast literature that documents foreign bank disadvantages in assessing prospects of borrowers that rely on relationship lending.

Through proxies of loan applications made by noncurrent borrowers, we estimate the impact that the existence of new loans in the last three months have on the probability of a loan being granted. For SME firms that applied for loans, this probability can increase up to $22 \%$ more for foreign banks in comparison to private domestic banks. Consistent with the asymmetric information narrative, the existence of loans with public banks isn't informative for foreign banks loan supply schedules. These findings are robust to different definitions and specifications underlying our estimations.

Our findings have direct policy implications. At a general level, they point to the need to reduce informational barriers across bank ownership types. Thus, more available public information at the firm level can balance the competition playing field across lenders. In particular, borrower information accessible through (positive) credit bureaus can alleviate informational constraints. In this case, even if some loan information cannot be transmitted to other lenders for confidentiality reasons, the availability of aggregate information by ownership type can substantially affect foreign banks' loan offer. 


\section{Bibliography}

[1] BONOMO, M. A.; MARTINS, B. ; BRITO, R.. Macroeconomic and Financial Consequences of the After Crisis Government-Driven Credit Expansion in Brazil. Journal of International Money and Finance, 2017.

[2] BERNANKE, B. S.; BOIVIN, J. ; ELIASZ, P.. Measuring the Effects of Monetary Policy: A Factor-Augmented Vector Autoregressive (FAVAR) Approuch. Quarterly Journal of Economics, (February):387-422, 2005.

[3] MOON, H. R.; SCHORFHEIDE, F.. Bayesian and Frequentist Inference in Partially Identified Models. Econometrica, 80(2):755-782, 2012.

[4] BAumeister, C.; HAMilton, J. D.. Sign Restrictions, Structural Vector Autoregressions, and Useful Prior Information. Econometrica, 83(5):1963-1999, 2015.

[5] GIACOMINI, R.; KITAGAWA, T.. Robust inference about partially identified SVARs. mimeo, (June):1-47, 2015.

[6] DINÇ, I. S.. Politicians and banks: Political influences on governmentowned banks in emerging markets. Journal of Financial Economics, 77(2):453-479, 2005.

[7] CARVALHO, D.. The real effects of government-owned banks: Evidence from an emerging market. The Journal of Finance, 69(2):577-609, 2014.

[8] MICCO, A.; PANIZZA, U.. Bank ownership and lending behavior. Economics Letters, 93(2):248-254, 2006.

[9] BertAy, A. C.; DEMIRGÜÇ-KUNT, A. ; HUIZINGA, H.. Bank ownership and credit over the business cycle: Is lending by state banks less procyclical? Journal of Banking \& Finance, 50:326-339, 2015.

[10] SAPIENZA, P.. The effects of government ownership on bank lending. Journal of financial economics, 72(2):357-384, 2004.

[11] BONIN, J. P.; HASAN, I. ; WACHTEL, P.. Bank performance, efficiency and ownership in transition countries. Journal of banking \& finance, 29(1):3153, 2005.

[12] MICCO, A.; PANIZZA, U. ; YANEZ, M.. Bank ownership and performance. does politics matter? Journal of Banking \& Finance, 31(1):219-241, 2007. 
[13] BARTH, J. R.; CAPRIO JR, G. ; LEVINE, R.. Bank regulation and supervision in 180 countries from 1999 to 2011. Journal of Financial Economic Policy, 5(2):111-219, 2013.

[14] LA PORTA, R.; LOPEZ-DE SILANES, F. ; SHLEIFER, A.. Government ownership of banks. The Journal of Finance, 57(1):265-301, 2002.

[15] MANKIW, N. G.. The allocation of credit and financial collapse. The Quarterly Journal of Economics, 101(3):455-470, 1986.

[16] GALE, W. G.. Economic effects of federal credit programs. The American Economic Review, p. 133-152, 1991.

[17] PODPIERA, J.. Using credit subsidies to counteract a credit bust: Evidence from serbia. IMF Working Paper, 2011.

[18] CASTRO, P. H. D. S.. Governmental credit and monetary policy power: micro and macro considerations. mimeo, 2017.

[19] SILVA, I. E. M.; PAES, N. L. ; BEZERRA, J. F.. Evidences of incomplete interest rate passthrough, directed credit and cost channel of monetary policy in brazil. mimeo, 2016.

[20] BONOMO, M. A.; MARTINS, B.. The Impact of Government-Driven Loans in the Monetary Transmission Mechanism: what can we learn from firm-level data? Banco Central do Brazil, Working Paper Series, 2016.

[21] SIMS, C. A.. Interpreting the macroeconomic time series facts: The effects of monetary policy. European Economic Review, 36(5):975-1000, 1992.

[22] BOIVIN, J.; GIANNONI, M. P. ; MIHOV, I.. Sticky prices and monetary policy: Evidence from disaggregated us data. American Economic Review, 99(1):350-384, 2009.

[23] STOCK, J. H.; WATSON, M. W.. Macroeconomic Forecasting Using Diffusion Indexes. Journal of Business \& Economic Statistics, 20(2):147-162, 2002.

[24] STOCK, J. H.; WATSON, M. W.. Dynamic factor models, factoraugmented vector autoregressions, and structural vector autoregressions in macroeconomics. In: HANDBOOK OF MACROECONOMICS, volumen 2, p. 415-525. Elsevier, 2016.

[25] MUMTAZ, H.; SURICO, P.. The transmission of international shocks: a factor-augmented var approach. Journal of Money, Credit and Banking, 41(s1):71-100, 2009. 
[26] UHLIG, H.. What are the effects of monetary policy on output? Results from an agnostic identification procedure. Journal of Monetary Economics, 52(2):381-419, 2005.

[27] SIMS, C. A.. Macroeconomics and reality. Econometrica: Journal of the Econometric Society, p. 1-48, 1980.

[27] FRY, R.; PAGAN, A.. Sign restrictions in structural vector autoregressions: A critical review. Journal of Economic Literature, 49(4):938-60, 2011.

[28] CANOVA, F.; DE NICOLO, G.. Monetary disturbances matter for business fluctuations in the g-7. Journal of Monetary Economics, 49(6):1131-1159, 2002.

[29] BLANCHARD, O. J.; QUAH, D.. The dynamic effects of aggregate demand and supply disturbances, 1988.

[30] BENATI, L.. Estimating the financial crisis' impact on potential output. Economics letters, 114(1):113-119, 2012.

[31] ARIAS, J.; CALDARA, D. ; FRANCISCO, R.-R. J.. The systematic component of monetary policy in svars: an agnostic identification procedure. mimeo, 2016.

[32] ARIAS, J. E.; RUBIO-RAMÍREZ, J. F. ; WAGGONER, D. F.. Inference Based on SVARs Identified with Sign and Zero Restrictions : Theory and Applications. Federal Reserve Bank of Atlanta, (30), 2016.

[33] ChRISTIANO, L. J.; EICHENBAUM, M. ; EVANS, C. L.. Nominal rigidities and the dynamic effects of a shock to monetary policy. Journal of political Economy, 113(1):1-45, 2005.

[34] BAI, J.; NG, S.. Determining the Number of Factors in Approximate Factor Models. Econometrica, 70(1):191-221, 2002.

[35] UHLIG, H.; AHMADI, P. A.. Sign Restrictions in Bayesian FaVARs with an Application to Monetary Policy Shocks. NBER Working Paper Series, 2015.

[36] D'AMICO, S.; KING, T. B.. What does anticipated monetary policy do? mimeo, 2015.

[37] PERDIGAO, B.. Still" an agnostic procedure to identify monetary policy shocks with sign restrictions. mimeo, 2018.

[38] BeRnANKE, B. S.; GERTLER, M.. Inside the Black Box: The Credit Channel of Monetary Policy Transmission. Journal of Economic Perspectives, 9(4):27-48, 1995. 
[39] KASHYAP, A. K.; STEIN, J. C.. The impact of monetary policy on bank balance sheets. In: CARNEGIE-ROCHESTER CONFERENCE SERIES ON PUBLIC POLICY, volumen 42, p. 151-195. Elsevier, 1995.

[40] KASHYAP, A. K.; STEIN, J. C.. What do a million observations on banks say about the transmission of monetary policy? American Economic Review, p. 407-428, 2000.

[41] GAMBACORTA, L.. Inside the bank lending channel. European Economic Review, 41(7):1737-1759, 2005.

[42] JIMÉneZ, G.; ONGenA, S.; PEYDRÓ, J.-L. ; SAURINA, J.. Credit Supply and Monetary Policy: Identifying the Bank Balance-Sheet Channel with Loan Applications. American Economic Review, 102(1025):2301-2326, 2012 .

[43] NAKAMURA, E.; STEINSSON, O.. Identification in Macroeconomics. Columbia University, 2017.

[44] RAMEY, V. A.. Macroeconomic shocks and their propagation. Handbook of Macroeconomics, 2:71-162, 2016.

[45] CARLSTROM, C. T.; FUERST, T. S. ; PAUSTIAN, M.. Monetary policy shocks, Choleski identification, and DNK models. Journal of Monetary Economics, 56(7):1014-1021, 2009.

[46] CASTELNUOVO, E.. Monetary policy shocks and financial conditions: A Monte Carlo experiment. Journal of International Money and Finance, 32:282-303, 2013.

[47] PAUSTIAN, M.. Assessing sign restrictions. The BE Journal of Macroeconomics, 7(1):23, 2007.

[48] CASTELnUOVO, E.. Monetary Policy Neutrality? Sign Restrictions Go to Monte Carlo. 2012(July):1-32, 2012.

[49] WOLF, C. K.. Masquerading shocks in sign-restricted vars. Manuscript, Princeton University, 2017.

[50] CANOVA, F.; PAUSTIAN, M.. Business cycle measurement with some theory. Journal of Monetary Economics, 58(4):345-361, 2011.

[51] SMETS, F.; WOUTERS, R.. Shocks and Frictions in US Business Cycles: A Bayesian DSGE Approach. American Economic Review, 2007.

[52] GÜRKAYNAK, R. S.; SACK, B. P. ; SWANSON, E. T.. Do Actions Speak Louder Than Words? The Response of Asset Prices to Monetary Policy Actions and Statements. Inernational Journal of Central Banking, 1(1):55-93, 2005. 
[53] GERTLER, M.; KARADI, P.. Monetary Policy Surprises, Credit Costs and Economic Activity *. American Economic Journal: Macroeconomics, 7(1):7(1): 44-76, 2015.

[54] STOCK, J. H.; WATSON, M. W.. Disentangling the Channels of the 2007-09 Recession. Brookings Papers on Economic Activity, 2012(1):81-135, 2012.

[55] MERTENS, K.; RAVN, M. O.. The Dynamic Effects of Personal and Corporate Income Tax Changes in the United States. American Economic Review, 103(4):1212-1247, 2013.

[56] COIBION, O.. Are the effects of monetary policy shocks big or small? American Economic Journal: Macroeconomics, 4(2):1-32, 2012.

[57] CHARI, V. V.; KEHOE, P. J. ; MCGRATTAN, E. R.. Are structural vars with long-run restrictions useful in developing business cycle theory? Journal of Monetary Economics, 55(8):1337-1352, 2008.

[58] PEERSMAN; STRAUB. Technology Shocks and Robust Sign Restrictions in a Euro area SVAR. International Economic Review, 50(3), 2009.

[59] MOUNTFORD, A.; UHLIG, H.. What are the effects of fiscal policy shocks? Journal of applied econometrics, 24(6):960-992, 2009.

[60] KILIAN, L.; MURPHY, D. P.. Why agnostic sign restrictions are not enough: understanding the dynamics of oil market var models. Journal of the European Economic Association, 10(5):1166-1188, 2012.

[61] DEDOLA, L.; NERI, S.. What does a technology shock do? A VAR analysis with model-based sign restrictions. Journal of Monetary Economics, 54(2):512-549, 2007.

[62] GALÍ, J.. Monetary policy, inflation, and the business cycle: an introduction to the new Keynesian framework and its applications. Princeton University Press, 2015.

[63] FERNÁNDEZ-VILLAVERDE, J.; RUBIO-RAMÍREZ, J. F.; SARGENT, T. J. ; WATSON, M. W.. ABCs (and Ds) of understanding VARs. American Economic Review, 97(3):1021-1026, 2007.

[64] ROMER, C. D.; ROMER, D. H.. A New Measure of Monetary Shocks: Derivation and Implications. American Economic Review, 94(4):1055-1084, 2004.

[65] EVANS, C. L.; MARSHALL, D. A.. Fundamental economic shocks and the macroeconomy. Journal of Money, Credit and Banking, 41(8):1515-1555, 2009. 
[66] GOLOSOV, M.; LUCAS JR, R. E.. Menu costs and phillips curves. Journal of Political Economy, 115(2):171-199, 2007.

[67] MAĆKOWIAK, B.; WIEDERHOLT, M.. Optimal sticky prices under rational inattention. American Economic Review, 99(3):769-803, 2009.

[68] KADIYALA, K.; KARLSSON, S.. Numerical methods for estimation and inference in Bayesian VAR-models. Journal of Applied Econometrics, 12(December 1994):99-132, 1997.

[69] DetRagiACHE, E.; TRESSEL, T. ; GUPTA, P.. Foreign banks in poor countries: theory and evidence. The Journal of Finance, 63(5):2123-2160, 2008

[70] Berger, A. N.; KLAPPER, L. F. ; UDELL, G. F.. The ability of banks to lend to informationally opaque small businesses. Journal of Banking \& Finance, 25(12):2127-2167, 2001.

[71] CLARKE, G.; CULL, R.; PERIA, M. S. M. ; SÁNCHEZ, S. M.. Bank lending to small businesses in latin america: Does bank origin matter? Journal of Money, Credit and Banking, p. 83-118, 2005.

[72] MIAN, A.. Distance constraints: The limits of foreign lending in poor economies. The Journal of Finance, 61(3):1465-1505, 2006.

[73] BERGER, A. N.; KLAPPER, L. F.; PERIA, M. S. M. ; ZAIDI, R.. Bank ownership type and banking relationships. Journal of Financial Intermediation, 17(1):37-62, 2008.

[74] LIBERTI, J. M.; PETERSEN, M. A.. Information: Hard and soft. Rev. Corporate Finance Stud, 2017.

[75] CLAESSENS, S.; HOREN, N.. Foreign banks: Trends and impact. Journal of Money, Credit and Banking, 46(s1):295-326, 2014.

[76] GORMLEY, T. A.. The impact of foreign bank entry in emerging markets: Evidence from india. Journal of Financial Intermediation, 19(1):2651, 2010.

[77] DELL'ARICCIA, G.; MARQUEZ, R.. Information and bank credit allocation. Journal of Financial Economics, 72(1):185-214, 2004.

[78] CLARKE, G. R.; CULL, R. ; PERIA, M. S. M.. Foreign bank participation and access to credit across firms in developing countries. Journal of comparative economics, 34(4):774-795, 2006.

[79] GIANNETTI, M.; ONGENA, S.. Lending by example: Direct and indirect effects of foreign banks in emerging markets. Journal of International Economics, 86(1):167-180, 2012. 
[80] BRUNO, V.; HAUSWALD, R.. The real effect of foreign banks. Review of Finance, 18(5):1683-1716, 2013.

[81] STEIN, J. C.. Information production and capital allocation: Decentralized versus hierarchical firms. The Journal of Finance, 57(5):1891-1921, 2002.

[82] LIBERTI, J. M.; MIAN, A. R.. Estimating the effect of hierarchies on information use. The Review of Financial Studies, 22(10):4057-4090, 2009.

[83] CANALES, R.; NANDA, R.. A darker side to decentralized banks: Market power and credit rationing in sme lending. Journal of Financial Economics, 105(2):353-366, 2012.

[84] FACHADA, P.. Foreign bank's entry and departure: the recent brazilian experience (1996-2006). Banco Central do Brasil Working Paper Series, 164, 2008.

[85] PETERSEN, M. A.; RAJAN, R. G.. The benefits of lending relationships: Evidence from small business data. The journal of finance, 49(1):3-37, 1994.

[86] BECK, T.; IOANNIDOU, V. ; SCHÄFER, L.. Foreigners vs. natives: Bank lending technologies and loan pricing. Management Science, 2017.

[87] SENGUPTA, R.. Foreign entry and bank competition. Journal of Financial Economics, 84(2):502-528, 2007.

[88] DEGRYSE, H.; ONGENA, S.. Distance, lending relationships, and competition. The Journal of Finance, 60(1):231-266, 2005.

[89] HAUSWALD, R.; MARQUEZ, R.. Competition and strategic information acquisition in credit markets. The Review of Financial Studies, 19(3):9671000, 2006.

[90] AGARWAL, S.; HAUSWALD, R.. Distance and private information in lending. The Review of Financial Studies, 23(7):2757-2788, 2010.

[91] JIMÉNEZ, G.; ONGENA, S.; PEYDRÓ, J.-L. ; SAURINA, J.. Hazardous times for monetary policy: What do twenty-three million bank loans say about the effects of monetary policy on credit risk-taking? Econometrica, 82(2):463-505, 2014.

[92] BERGER, A. N.; HASAN, I. ; ZHOU, M.. Bank ownership and efficiency in china: What will happen in the world's largest nation? Journal of Banking \& Finance, 33(1):113-130, 2009. 
[93] BIKHCHANDANI, S.; HIRSHLEIFER, D. ; WELCH, I.. A theory of fads, fashion, custom, and cultural change as informational cascades. Journal of political Economy, 100(5):992-1026, 1992.

[94] JAMES, C.. Some evidence on the uniqueness of bank loans. Journal of financial economics, 19.

[95] LUMMER, S. L.; MCCONNELL, J. J.. Further evidence on the bank lending process and the capital-market response to bank loan agreements. Journal of Financial Economics, 25(1):99-122, 1989. 
A

\section{Appendix to Chapter 1}

A.1

Figures

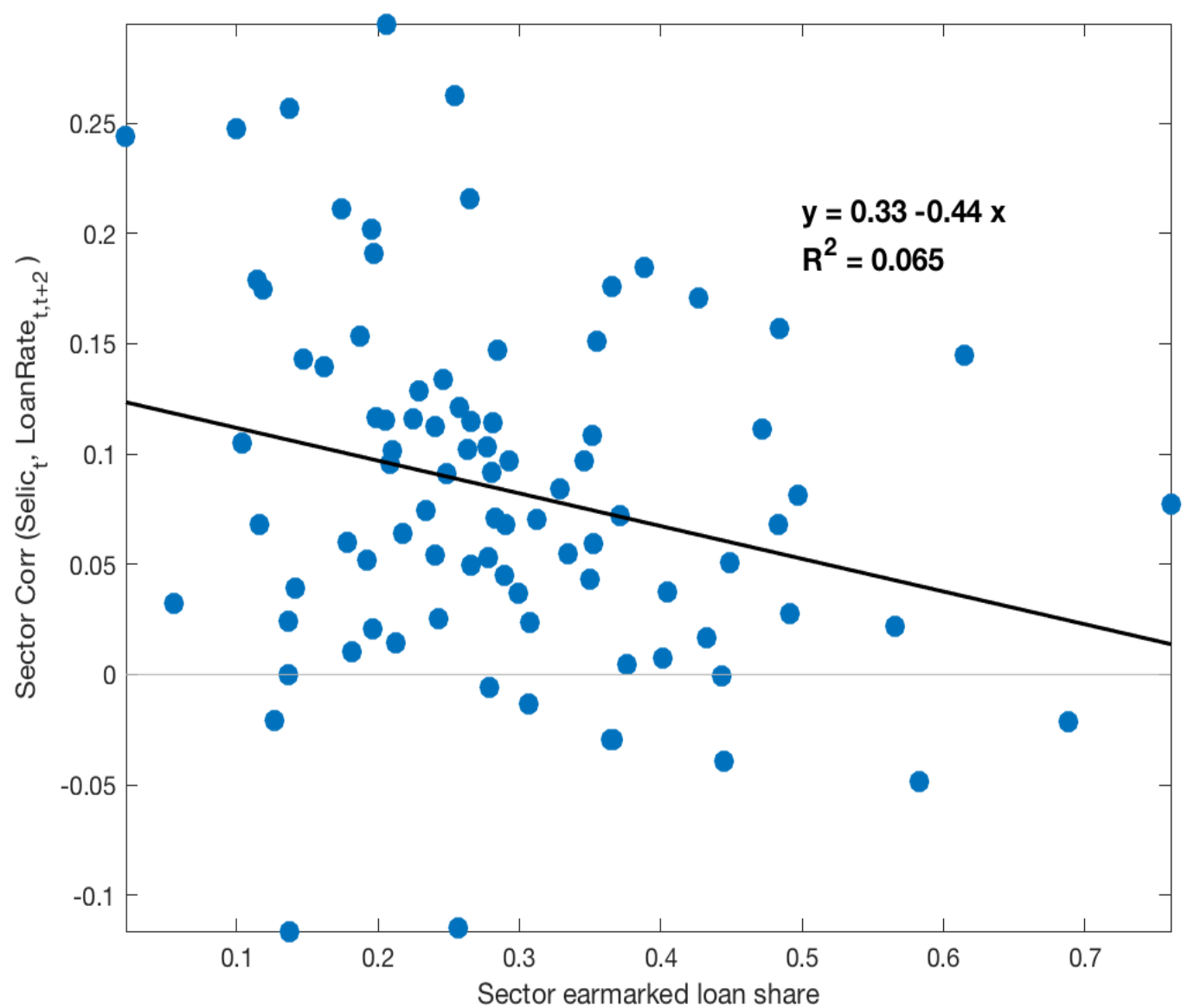

Figure A.1.1: Correlation between 3-month ahead moving averages of changes in loans rates and changes in the Selic rate against the time average share of earmarked loans among bank debt for each manufacturing industry sector. Slope is statistically significant at $5 \%$. 

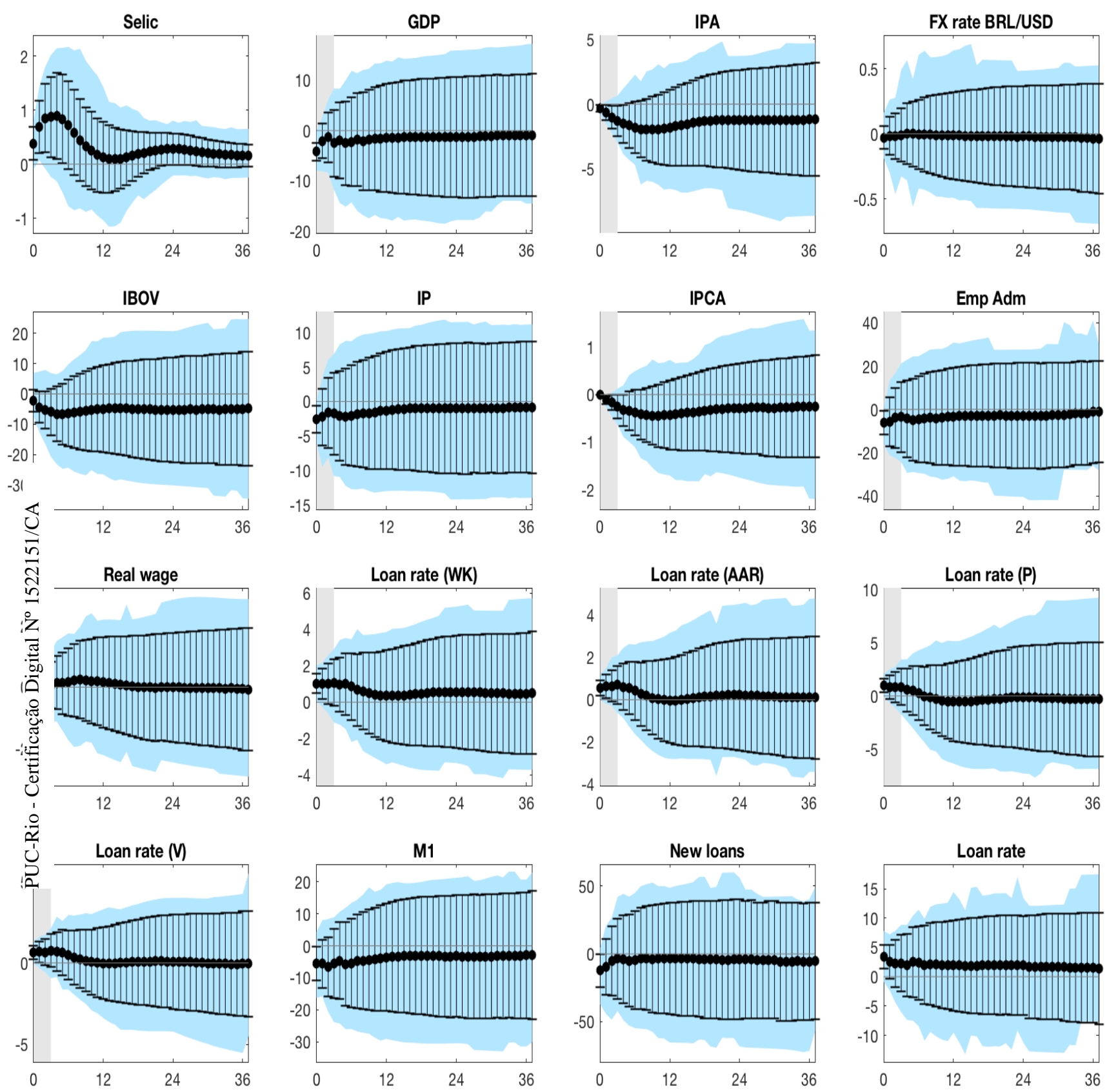

Figure A.1.2: Posterior mean bounds interval (black lines) and 68\% credibility region (blue shaded region) for macro variables responses after a 50bps contractionary monetary shock. The gray vertical region indicates sign restricted variables and the restricted horizon. IRF values are in percent and defined on level variables. 
A. 2

Control estimates in OLS regressions 
Table A.2.1: Percentiles on the parameter associated to working capital share on OLS regressions in equation 1-11.

\begin{tabular}{|c|c|c|c|c|c|c|c|}
\hline $\begin{array}{l}\text { IRF } \\
\text { horizon }\end{array}$ & $\begin{array}{c}\text { Per- } \\
\text { centile }\end{array}$ & IPA & IP & $\begin{array}{l}\text { New } \\
\text { loans }\end{array}$ & $\begin{array}{l}\text { Loan } \\
\text { rates }\end{array}$ & $\begin{array}{l}\text { Emp } \\
\text { adm. }\end{array}$ & $\begin{array}{l}\text { Real } \\
\text { wage }\end{array}$ \\
\hline \multirow[t]{3}{*}{$\mathrm{h}=\mathbf{0}$} & $\mathrm{p} 16$ & 0.57 & -5.16 & -1.22 & -3.18 & -40.92 & -10.11 \\
\hline & $\mathrm{p} 50$ & 1.20 & 3.15 & 13.81 & 0.56 & -21.50 & -1.65 \\
\hline & p84 & 2.84 & 14.32 & 31.09 & 5.53 & -12.65 & 2.71 \\
\hline \multirow[t]{3}{*}{$\mathrm{h}=1$} & p16 & 0.51 & -3.31 & -0.70 & -6.42 & -43.44 & -10.24 \\
\hline & $\mathrm{p} 50$ & 1.44 & 3.92 & 20.16 & 0.57 & -20.76 & -2.13 \\
\hline & $\mathrm{p} 84$ & 3.28 & 11.44 & 39.50 & 6.05 & -13.19 & 4.10 \\
\hline \multirow[t]{3}{*}{$\mathrm{h}=\mathbf{2}$} & p16 & 0.41 & -2.65 & -9.12 & -7.45 & -41.98 & -10.71 \\
\hline & $\mathrm{p} 50$ & 1.38 & 6.83 & 16.06 & 0.27 & -25.00 & -1.54 \\
\hline & $\mathrm{p} 84$ & 4.16 & 14.90 & 43.26 & 6.71 & -16.79 & 5.18 \\
\hline \multirow{3}{*}{ 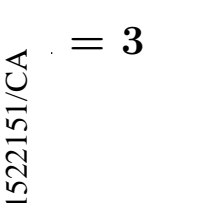 } & p16 & 0.50 & -3.07 & -17.52 & -8.99 & -44.83 & -14.97 \\
\hline & $\mathrm{p} 50$ & 1.91 & 3.99 & 11.82 & 1.98 & -24.36 & -6.56 \\
\hline & $\mathrm{p} 84$ & 4.30 & 16.53 & 42.62 & 7.87 & -12.97 & 3.66 \\
\hline \multirow{3}{*}{ 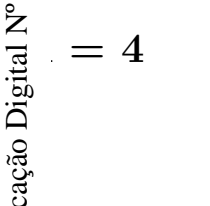 } & p16 & 0.14 & -4.87 & -25.30 & -9.53 & -46.44 & -17.63 \\
\hline & $\mathrm{p} 50$ & 1.59 & 1.87 & 12.82 & 2.11 & -23.96 & -8.42 \\
\hline & p84 & 4.25 & 15.53 & 41.96 & 8.79 & -14.96 & 1.00 \\
\hline \multirow{3}{*}{ 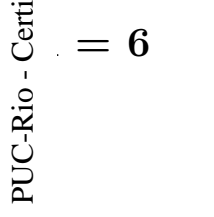 } & p16 & 0.04 & -5.54 & -32.79 & -7.96 & -51.14 & -20.64 \\
\hline & $\mathrm{p} 50$ & 1.63 & 1.71 & 9.81 & 1.50 & -25.26 & -10.61 \\
\hline & $\mathrm{p} 84$ & 4.82 & 16.01 & 44.02 & 9.45 & -16.24 & 5.42 \\
\hline \multirow[t]{3}{*}{$\mathrm{h}=8$} & p16 & -0.11 & -6.02 & -35.15 & -6.69 & -51.69 & -24.02 \\
\hline & $\mathrm{p} 50$ & 1.63 & 0.77 & -3.24 & 0.78 & -22.80 & -11.16 \\
\hline & $\mathrm{p} 84$ & 4.33 & 18.74 & 38.24 & 10.79 & -9.72 & 4.69 \\
\hline \multirow[t]{3}{*}{$h=10$} & p16 & -0.42 & -6.92 & -41.63 & -6.83 & -47.35 & -25.18 \\
\hline & $\mathrm{p} 50$ & 1.20 & -0.62 & -7.54 & -0.58 & -19.22 & -11.79 \\
\hline & p84 & 3.80 & 19.68 & 35.47 & 9.86 & -3.81 & 2.83 \\
\hline \multirow[t]{3}{*}{$h=12$} & p16 & -0.49 & -6.38 & -34.46 & -7.07 & -45.88 & -26.75 \\
\hline & $\mathrm{p} 50$ & 1.27 & 0.01 & -6.72 & 0.29 & -15.24 & -12.11 \\
\hline & p84 & 3.36 & 18.99 & 33.46 & 8.71 & -0.99 & 0.85 \\
\hline $\begin{array}{l}\text { observa- } \\
\text { tions }\end{array}$ & & 74 & 74 & 99 & 89 & 99 & 99 \\
\hline
\end{tabular}

Note: dependent variables are the mean of the identified set for industrial production (IP), producer price index (IPA), new loans, loan rates, new employment admissions, real wages. Distribution is calculated across iterations of the algorithm (ie: for different values of $\phi$ ). 
Table A.2.2: Percentiles on the parameter associated to the log of campaign contributions in 2014 on OLS regressions in equation 1-11.

\begin{tabular}{|c|c|c|c|c|c|c|c|}
\hline $\begin{array}{l}\text { IRF } \\
\text { horizon }\end{array}$ & $\begin{array}{c}\text { Per- } \\
\text { centile }\end{array}$ & IPA & IP & $\begin{array}{l}\text { New } \\
\text { loans }\end{array}$ & $\begin{array}{l}\text { Loan } \\
\text { rates }\end{array}$ & $\begin{array}{l}\text { Emp } \\
\text { adm. }\end{array}$ & $\begin{array}{l}\text { Real } \\
\text { wage }\end{array}$ \\
\hline \multirow[t]{3}{*}{$\mathrm{h}=\mathbf{0}$} & $\mathrm{p} 16$ & -0.02 & -0.34 & -0.16 & -0.09 & -0.03 & -0.01 \\
\hline & $\mathrm{p} 50$ & 0.00 & -0.14 & 0.31 & 0.03 & 0.21 & 0.11 \\
\hline & p84 & 0.03 & 0.04 & 1.09 & 0.20 & 0.42 & 0.21 \\
\hline \multirow[t]{3}{*}{$\mathrm{h}=1$} & p16 & -0.01 & -0.60 & -0.45 & -0.11 & 0.09 & -0.04 \\
\hline & $\mathrm{p} 50$ & 0.02 & -0.35 & 0.26 & 0.04 & 0.23 & 0.06 \\
\hline & $\mathrm{p} 84$ & 0.07 & -0.09 & 0.93 & 0.33 & 0.50 & 0.14 \\
\hline \multirow[t]{3}{*}{$\mathrm{h}=\mathbf{2}$} & p16 & -0.01 & -0.74 & -0.19 & -0.13 & 0.17 & -0.08 \\
\hline & $\mathrm{p} 50$ & 0.03 & -0.37 & 0.42 & 0.07 & 0.36 & 0.02 \\
\hline & $\mathrm{p} 84$ & 0.11 & -0.10 & 1.26 & 0.33 & 0.65 & 0.13 \\
\hline \multirow{3}{*}{ 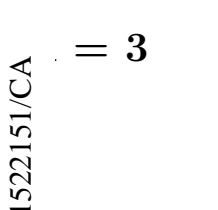 } & p16 & 0.01 & -0.50 & 0.00 & -0.22 & 0.17 & -0.09 \\
\hline & $\mathrm{p} 50$ & 0.05 & -0.08 & 0.64 & 0.01 & 0.44 & 0.05 \\
\hline & p84 & 0.13 & 0.32 & 1.62 & 0.30 & 0.77 & 0.17 \\
\hline \multirow{3}{*}{ 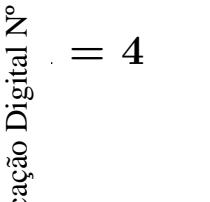 } & p16 & 0.03 & -0.41 & -0.11 & -0.20 & 0.15 & -0.09 \\
\hline & $\mathrm{p} 50$ & 0.06 & -0.12 & 0.60 & 0.01 & 0.44 & 0.04 \\
\hline & p84 & 0.16 & 0.38 & 1.56 & 0.28 & 0.80 & 0.20 \\
\hline \multirow{3}{*}{ 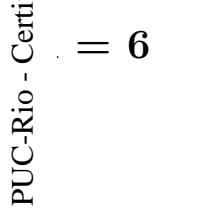 } & p16 & 0.02 & -0.55 & 0.11 & -0.16 & 0.20 & -0.11 \\
\hline & p50 & 0.05 & -0.16 & 0.73 & 0.07 & 0.45 & 0.05 \\
\hline & p84 & 0.13 & 0.40 & 1.79 & 0.33 & 0.94 & 0.17 \\
\hline \multirow[t]{3}{*}{$\mathrm{h}=8$} & p16 & 0.01 & -0.62 & 0.20 & -0.21 & 0.20 & -0.11 \\
\hline & $\mathrm{p} 50$ & 0.06 & -0.10 & 0.89 & 0.06 & 0.44 & 0.05 \\
\hline & $\mathrm{p} 84$ & 0.14 & 0.55 & 2.00 & 0.34 & 0.96 & 0.20 \\
\hline \multirow[t]{3}{*}{$h=10$} & p16 & 0.01 & -0.56 & -0.19 & -0.16 & 0.13 & -0.14 \\
\hline & $\mathrm{p} 50$ & 0.05 & -0.19 & 0.74 & 0.11 & 0.39 & 0.06 \\
\hline & p84 & 0.13 & 0.47 & 2.04 & 0.36 & 0.89 & 0.30 \\
\hline \multirow[t]{3}{*}{$\mathrm{h}=12$} & p16 & 0.01 & -0.59 & -0.23 & -0.16 & 0.08 & -0.17 \\
\hline & $\mathrm{p} 50$ & 0.04 & -0.14 & 0.72 & 0.12 & 0.32 & 0.05 \\
\hline & p84 & 0.13 & 0.40 & 1.91 & 0.38 & 0.83 & 0.29 \\
\hline $\begin{array}{l}\text { observa- } \\
\text { tions }\end{array}$ & & 74 & 74 & 99 & 89 & 99 & 99 \\
\hline
\end{tabular}

Note: dependent variables are the mean of the identified set for industrial production (IP), producer price index (IPA), new loans, loan rates, new employment admissions, real wages. Distribution is calculated across iterations of the algorithm (ie: for different values of $\phi$ ). 
Table A.2.3: Percentiles on the parameter associated to the average firm size on OLS regressions in equation 1-11.

\begin{tabular}{|c|c|c|c|c|c|c|c|}
\hline $\begin{array}{l}\text { IRF } \\
\text { horizon }\end{array}$ & $\begin{array}{c}\text { Per- } \\
\text { centile }\end{array}$ & IPA & IP & $\begin{array}{l}\text { New } \\
\text { loans }\end{array}$ & $\begin{array}{l}\text { Loan } \\
\text { rates }\end{array}$ & $\begin{array}{l}\text { Emp } \\
\text { adm. }\end{array}$ & $\begin{array}{l}\text { Real } \\
\text { wage }\end{array}$ \\
\hline \multirow[t]{3}{*}{$\mathbf{h}=\mathbf{0}$} & $\mathrm{p} 16$ & -0.15 & 0.38 & -3.47 & -1.68 & -0.11 & -0.83 \\
\hline & $\mathrm{p} 50$ & -0.06 & 1.00 & -1.36 & -1.11 & 0.66 & -0.34 \\
\hline & p84 & -0.02 & 1.66 & -0.33 & -0.51 & 1.77 & -0.17 \\
\hline \multirow[t]{3}{*}{$h=1$} & p16 & -0.31 & -0.00 & -2.17 & -1.27 & -0.25 & -0.58 \\
\hline & $\mathrm{p} 50$ & -0.17 & 0.74 & -0.66 & -0.75 & 0.28 & -0.12 \\
\hline & p84 & -0.06 & 1.57 & 0.70 & -0.38 & 0.93 & 0.16 \\
\hline \multirow[t]{3}{*}{$\mathrm{h}=\mathbf{2}$} & p16 & -0.37 & -0.25 & -2.82 & -1.08 & -1.04 & -0.40 \\
\hline & $\mathrm{p} 50$ & -0.20 & 0.75 & -1.07 & -0.58 & -0.07 & -0.00 \\
\hline & p84 & -0.08 & 1.49 & 0.47 & -0.11 & 0.69 & 0.30 \\
\hline \multirow{3}{*}{ 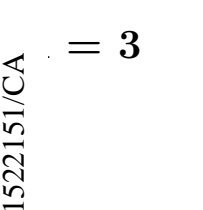 } & p16 & -0.37 & -0.43 & -2.85 & -1.15 & -1.31 & -0.28 \\
\hline & $\mathrm{p} 50$ & -0.20 & 0.46 & -0.97 & -0.49 & -0.47 & 0.24 \\
\hline & $\mathrm{p} 84$ & -0.06 & 1.49 & 1.65 & -0.03 & 0.53 & 0.75 \\
\hline \multirow{3}{*}{ 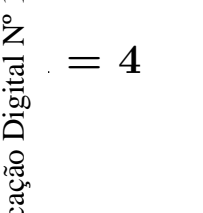 } & p16 & -0.39 & -0.75 & -2.05 & -1.07 & -1.53 & -0.12 \\
\hline & $\mathrm{p} 50$ & -0.18 & 0.10 & -0.19 & -0.41 & -0.52 & 0.40 \\
\hline & p84 & -0.04 & 0.95 & 2.84 & 0.27 & 0.48 & 1.10 \\
\hline \multirow{3}{*}{ 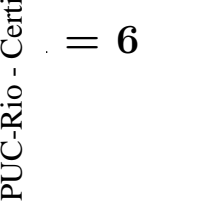 } & p16 & -0.37 & -0.79 & -3.25 & -1.13 & -1.58 & -0.03 \\
\hline & $\mathrm{p} 50$ & -0.14 & 0.05 & -0.38 & -0.49 & -0.28 & 0.55 \\
\hline & $\mathrm{p} 84$ & 0.06 & 1.03 & 2.36 & 0.26 & 0.43 & 1.23 \\
\hline \multirow[t]{3}{*}{$\mathrm{h}=8$} & p16 & -0.30 & -1.17 & -3.84 & -1.01 & -1.85 & 0.06 \\
\hline & $\mathrm{p} 50$ & -0.12 & -0.12 & -0.22 & -0.44 & -0.38 & 0.85 \\
\hline & $\mathrm{p} 84$ & 0.15 & 0.69 & 3.00 & 0.45 & 0.61 & 1.56 \\
\hline \multirow[t]{3}{*}{$\mathrm{h}=10$} & p16 & -0.31 & -1.36 & -2.31 & -0.95 & -1.61 & 0.01 \\
\hline & $\mathrm{p} 50$ & -0.07 & -0.16 & 0.05 & -0.37 & -0.28 & 0.87 \\
\hline & p84 & 0.13 & 0.58 & 2.92 & 0.44 & 0.84 & 1.68 \\
\hline \multirow[t]{3}{*}{$\mathrm{h}=12$} & p16 & -0.32 & -1.30 & -2.04 & -1.01 & -1.51 & 0.05 \\
\hline & $\mathrm{p} 50$ & -0.07 & -0.12 & 0.42 & -0.44 & -0.27 & 0.88 \\
\hline & p84 & 0.12 & 0.49 & 2.68 & 0.40 & 0.95 & 1.67 \\
\hline $\begin{array}{l}\text { observa- } \\
\text { tions }\end{array}$ & & 74 & 74 & 99 & 89 & 99 & 99 \\
\hline
\end{tabular}

Note: dependent variables are the mean of the identified set for industrial production (IP), producer price index (IPA), new loans, loan rates, new employment admissions, real wages. Distribution is calculated across iterations of the algorithm (ie: for different values of $\phi$ ). 


\section{A.3}

\section{Robust $\beta$ estimates}

In table A.3.1 we try as dependent variables points in the identified set of IRF's other then the mean. We do it replacing step 5 in the algorithm to compute identified sets for the following step.

5. Consider $l_{i, j, h}(\phi)$ and $u_{i, j, h}(\phi)$ the lower and upper bounds of the identified set of IRF's associated to a standard deviation shock of variable $j$ on variable $i, h$ periods after the shock. Draw a uniform random number $k$ between 0 and 1 . For every $i, j, h$, compute the dependent variable as:

$$
I R F_{j}^{i, h}=l_{i, j, h}(\phi)+k\left(u_{i, j, h}(\phi)-l_{i, j, h}(\phi)\right) .
$$

Run OLS regressions for the dependent variables calculated above:

$$
I R F_{j}^{i, h}=\alpha^{i, h}+\beta^{i, h} e m l_{j}+\theta^{\mathbf{i}, \mathbf{h}} \mathbf{Z}_{\mathbf{j}}+v_{j}^{i, h} .
$$

For each draw of $\phi$, repeat the above regressions 10 times for different values of $k$. 
Table A.3.1: $\beta$ percentiles for OLS regressions in equation 1-11. Robust parameters estimates for different points in the identified set of IRF's.

\begin{tabular}{|c|c|c|c|c|c|c|c|}
\hline $\begin{array}{l}\text { IRF } \\
\text { horizon }\end{array}$ & $\begin{array}{c}\text { Per- } \\
\text { centile }\end{array}$ & IPA & IP & $\begin{array}{l}\text { New } \\
\text { loans }\end{array}$ & $\begin{array}{l}\text { Loan } \\
\text { rates }\end{array}$ & $\begin{array}{l}\text { Emp } \\
\text { adm. }\end{array}$ & $\begin{array}{l}\text { Real } \\
\text { wage }\end{array}$ \\
\hline \multirow[t]{3}{*}{$\mathbf{h}=\mathbf{0}$} & p16 & -0.51 & -1.24 & -27.55 & -3.82 & 0.85 & -1.40 \\
\hline & $\mathrm{p} 50$ & 0.11 & 1.33 & -10.97 & -0.12 & 5.69 & 0.27 \\
\hline & p84 & 1.12 & 6.11 & 7.15 & 2.77 & 14.82 & 1.91 \\
\hline \multirow[t]{3}{*}{$h=1$} & p16 & -0.23 & -1.32 & -28.02 & -5.48 & 1.69 & -2.02 \\
\hline & p50 & 0.55 & 2.65 & -6.48 & -0.57 & 9.47 & 0.40 \\
\hline & p84 & 2.03 & 9.17 & 19.60 & 2.80 & 17.37 & 2.97 \\
\hline \multirow[t]{3}{*}{$\mathrm{h}=2$} & p16 & -0.05 & -1.42 & -33.00 & -7.82 & 1.59 & -2.02 \\
\hline & $\mathrm{p} 50$ & 1.04 & 3.81 & -5.30 & -1.91 & 10.82 & 0.64 \\
\hline & $\mathrm{p} 84$ & 3.28 & 11.75 & 26.47 & 2.24 & 21.22 & 3.51 \\
\hline \multirow{3}{*}{ 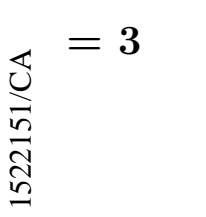 } & p16 & 0.43 & -1.07 & -34.57 & -9.54 & -1.10 & -1.45 \\
\hline & p50 & 1.43 & 4.72 & -3.10 & -2.73 & 10.23 & 1.61 \\
\hline & p84 & 3.72 & 13.66 & 35.84 & 2.25 & 22.13 & 5.43 \\
\hline \multirow{3}{*}{ 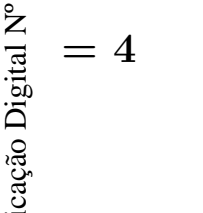 } & p16 & 0.60 & -2.00 & -34.55 & -10.86 & -3.11 & -1.67 \\
\hline & p50 & 1.55 & 4.83 & 0.73 & -3.29 & 10.64 & 1.87 \\
\hline & p84 & 3.88 & 14.53 & 44.09 & 2.31 & 21.10 & 6.29 \\
\hline \multirow{3}{*}{ 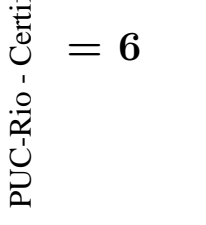 } & p16 & 0.77 & -3.33 & -41.13 & -13.56 & -3.92 & -2.36 \\
\hline & p50 & 1.61 & 4.46 & -0.86 & -4.48 & 11.94 & 2.19 \\
\hline & p84 & 3.97 & 15.46 & 48.96 & 1.90 & 23.73 & 6.75 \\
\hline \multirow[t]{3}{*}{$\mathrm{h}=8$} & p16 & 0.70 & -4.50 & -44.76 & -14.67 & -4.74 & -2.66 \\
\hline & $\mathrm{p} 50$ & 1.83 & 4.23 & -0.82 & -5.30 & 12.14 & 2.47 \\
\hline & $\mathrm{p} 84$ & 3.73 & 16.22 & 49.90 & 1.57 & 24.70 & 7.53 \\
\hline \multirow[t]{3}{*}{$h=10$} & p16 & 0.52 & -6.07 & -47.82 & -14.59 & -4.93 & -2.94 \\
\hline & $\mathrm{p} 50$ & 1.68 & 3.55 & -2.69 & -5.10 & 12.93 & 2.48 \\
\hline & $\mathrm{p} 84$ & 3.51 & 15.30 & 53.64 & 2.33 & 25.79 & 7.66 \\
\hline \multirow[t]{3}{*}{$h=12$} & p16 & 0.36 & -6.98 & -50.07 & -14.57 & -4.73 & -3.54 \\
\hline & $\mathrm{p} 50$ & 1.59 & 2.87 & -1.58 & -4.71 & 12.99 & 2.35 \\
\hline & p84 & 3.34 & 15.39 & 56.65 & 3.04 & 25.90 & 7.70 \\
\hline $\begin{array}{l}\text { observa- } \\
\text { tions }\end{array}$ & & 74 & 74 & 99 & 89 & 99 & 99 \\
\hline
\end{tabular}

Note: dependent variables are random points in identified set for industrial production (IP), producer price index (IPA), new loans, loan rates, new employment admissions, real wages. Distribution is calculated across iterations of the algorithm (ie: for different values of $\phi$ and $k$ ). 
B

\section{Appendix to Chapter 2}

\section{B.1}

3-equation model

Table B.1.1: Calibrated parameters: 3-equation model

\begin{tabular}{ccc}
\hline \hline Parameter & Parameter interpretation & Value \\
\hline$\beta$ & discount factor & 0.99 \\
$\sigma$ & inverse of IES & 1 \\
$\varphi$ & inverse Frisch elasticity & 1 \\
$\epsilon$ & demand elasticity & 6 \\
$\theta$ & Calvo parameter & 0.66 \\
$\phi_{\pi}$ & inflation coefficient (T. rule) & 1.5 \\
$\phi_{y}$ & output coefficient (T. rule) & 0.1 \\
$\rho_{s}$ & cost-push shock persistence & 0.8 \\
$\rho_{d}$ & demand shock persistence & 0.9 \\
$\rho_{r}$ & monetary shock persistence & 0.6 \\
$\sigma_{r}$ & std monetary shock & 0.5 \\
$\sigma_{s}$ & std cost-push shock & 0.5 \\
$\sigma_{d}$ & std demand shock & 0.5 \\
\hline \hline
\end{tabular}




\section{B.2 \\ Smets and Wouters (2007) model}

Table B.2.1: Proportion of negative responses for different IRF horizons monetary neutrality in 8 years

\begin{tabular}{lccccccc}
\hline \hline Variables & $\mathbf{h}=\mathbf{0}$ & $\mathbf{h}=\mathbf{2}$ & $\mathbf{h}=\mathbf{4}$ & $\mathbf{h}=\mathbf{6}$ & $\mathbf{h}=\mathbf{8}$ & $\mathbf{h}=\mathbf{1 0}$ & $\mathbf{h}=\mathbf{1 2}$ \\
\hline $\mathbf{y}$ & $64 \%$ & $83 \%$ & $95 \%$ & $100 \%$ & $100 \%$ & $100 \%$ & $100 \%$ \\
lab & $63 \%$ & $82 \%$ & $95 \%$ & $100 \%$ & $100 \%$ & $100 \%$ & $100 \%$ \\
$\mathbf{w}$ & $77 \%$ & $90 \%$ & $96 \%$ & $100 \%$ & $100 \%$ & $100 \%$ & $100 \%$ \\
$\mathbf{c}$ & $65 \%$ & $83 \%$ & $94 \%$ & $100 \%$ & $100 \%$ & $100 \%$ & $100 \%$ \\
inv & $56 \%$ & $78 \%$ & $100 \%$ & $100 \%$ & $100 \%$ & $98 \%$ & $85 \%$ \\
\hline \hline
\end{tabular}

Table B.2.2: Proportion of negative responses for different IRF horizons monetary neutrality in 9 years

\begin{tabular}{|c|c|c|c|c|c|c|c|}
\hline Variables & $\mathrm{h}=\mathbf{0}$ & $\mathrm{h}=2$ & $\mathrm{~h}=4$ & $\mathrm{~h}=6$ & $\mathrm{~h}=8$ & $\mathrm{~h}=10$ & $\mathrm{~h}=12$ \\
\hline $\mathbf{y}$ & $64 \%$ & $84 \%$ & $97 \%$ & $100 \%$ & $100 \%$ & $100 \%$ & $100 \%$ \\
\hline lab & $64 \%$ & $83 \%$ & $97 \%$ & $100 \%$ & $100 \%$ & $100 \%$ & $100 \%$ \\
\hline w & $80 \%$ & $93 \%$ & $98 \%$ & $100 \%$ & $100 \%$ & $100 \%$ & $100 \%$ \\
\hline c & $65 \%$ & $83 \%$ & $95 \%$ & $100 \%$ & $100 \%$ & $100 \%$ & $100 \%$ \\
\hline inv & $58 \%$ & $80 \%$ & $100 \%$ & $100 \%$ & $100 \%$ & $100 \%$ & $89 \%$ \\
\hline
\end{tabular}

Table B.2.3: Proportion of negative responses for different IRF horizons monetary neutrality in 11 years

\begin{tabular}{lccccccc}
\hline \hline Variables & $\mathbf{h}=\mathbf{0}$ & $\mathbf{h}=\mathbf{2}$ & $\mathbf{h}=\mathbf{4}$ & $\mathbf{h}=\mathbf{6}$ & $\mathbf{h}=\mathbf{8}$ & $\mathbf{h}=\mathbf{1 0}$ & $\mathbf{h}=\mathbf{1 2}$ \\
\hline $\mathbf{y}$ & $65 \%$ & $85 \%$ & $98 \%$ & $100 \%$ & $100 \%$ & $100 \%$ & $100 \%$ \\
lab & $65 \%$ & $85 \%$ & $98 \%$ & $100 \%$ & $100 \%$ & $100 \%$ & $100 \%$ \\
$\mathbf{w}$ & $82 \%$ & $94 \%$ & $100 \%$ & $100 \%$ & $100 \%$ & $100 \%$ & $100 \%$ \\
$\mathbf{c}$ & $66 \%$ & $84 \%$ & $96 \%$ & $100 \%$ & $100 \%$ & $100 \%$ & $100 \%$ \\
inv & $60 \%$ & $83 \%$ & $100 \%$ & $100 \%$ & $100 \%$ & $100 \%$ & $92 \%$ \\
\hline \hline
\end{tabular}


Table B.2.4: Proportion of negative responses for different IRF horizons monetary neutrality in 12 years

\begin{tabular}{lccccccc}
\hline \hline Variables & $\mathbf{h}=\mathbf{0}$ & $\mathbf{h}=\mathbf{2}$ & $\mathbf{h}=\mathbf{4}$ & $\mathbf{h}=\mathbf{6}$ & $\mathbf{h}=\mathbf{8}$ & $\mathbf{h}=\mathbf{1 0}$ & $\mathbf{h}=\mathbf{1 2}$ \\
\hline $\mathbf{y}$ & $65 \%$ & $85 \%$ & $98 \%$ & $100 \%$ & $100 \%$ & $100 \%$ & $100 \%$ \\
lab & $65 \%$ & $85 \%$ & $98 \%$ & $100 \%$ & $100 \%$ & $100 \%$ & $100 \%$ \\
$\mathbf{w}$ & $82 \%$ & $94 \%$ & $100 \%$ & $100 \%$ & $100 \%$ & $100 \%$ & $100 \%$ \\
$\mathbf{c}$ & $66 \%$ & $84 \%$ & $96 \%$ & $100 \%$ & $100 \%$ & $100 \%$ & $100 \%$ \\
inv & $61 \%$ & $84 \%$ & $100 \%$ & $100 \%$ & $100 \%$ & $100 \%$ & $92 \%$ \\
\hline \hline
\end{tabular}

Table B.2.5: Mean identified shock weights for sign and zero restrictions identification

\begin{tabular}{|c|c|c|c|c|c|c|c|}
\hline Sign and zero restrictions & $\epsilon_{r}$ & $\epsilon_{a}$ & $\epsilon_{p}$ & $\epsilon_{b}$ & $\epsilon_{g}$ & $\epsilon_{I}$ & $\epsilon_{w}$ \\
\hline $\begin{array}{l}\mathrm{M}_{\text {Onetary neutrality in } \mathbf{8}} \\
\text { ars }\end{array}$ & 0.81 & -0.00 & 0.01 & 0.04 & 0.00 & 0.12 & 0.00 \\
\hline 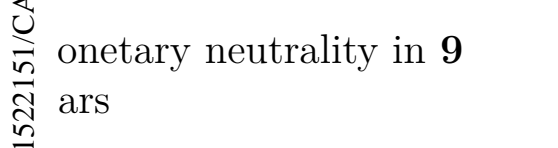 & 0.82 & -0.00 & 0.02 & 0.04 & 0.00 & 0.11 & 0.00 \\
\hline 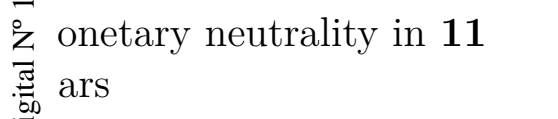 & 0.82 & -0.00 & 0.02 & 0.03 & 0.00 & 0.11 & 0.00 \\
\hline 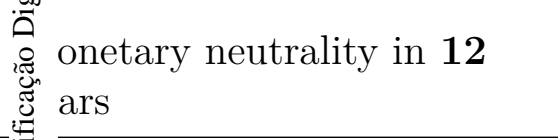 & 0.82 & -0.00 & 0.02 & 0.03 & 0.00 & 0.11 & 0.00 \\
\hline
\end{tabular}




\section{B.3}

\section{Empirical application with US data}
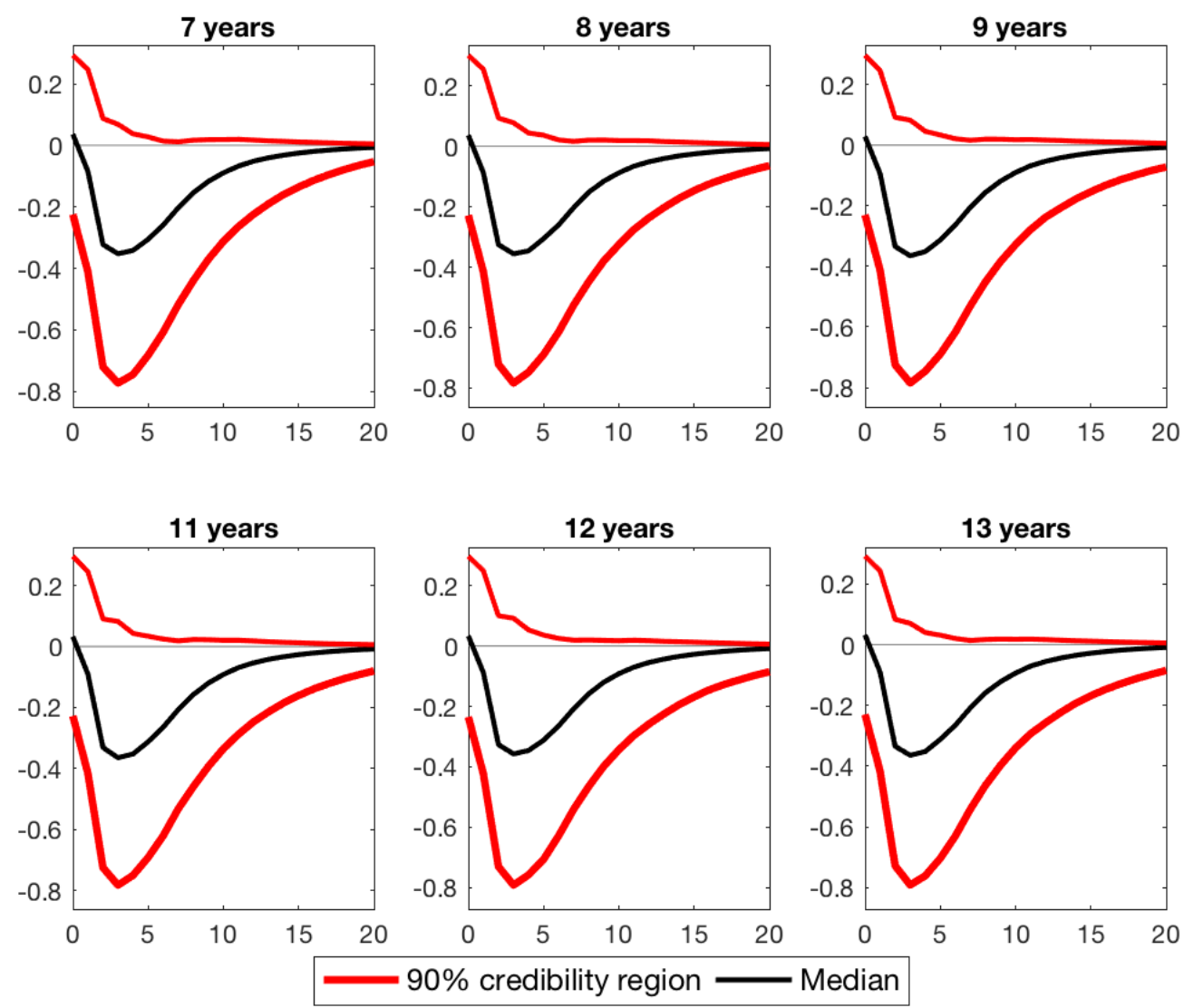

Figure B.3.1: Identified output responses of a $\sigma_{i}$ contractionary monetary shock imposing the neutrality restrictions in different time lengths. Estimated 3variable VAR with US data. Sample: 1956Q1 - 2004 Q4. 

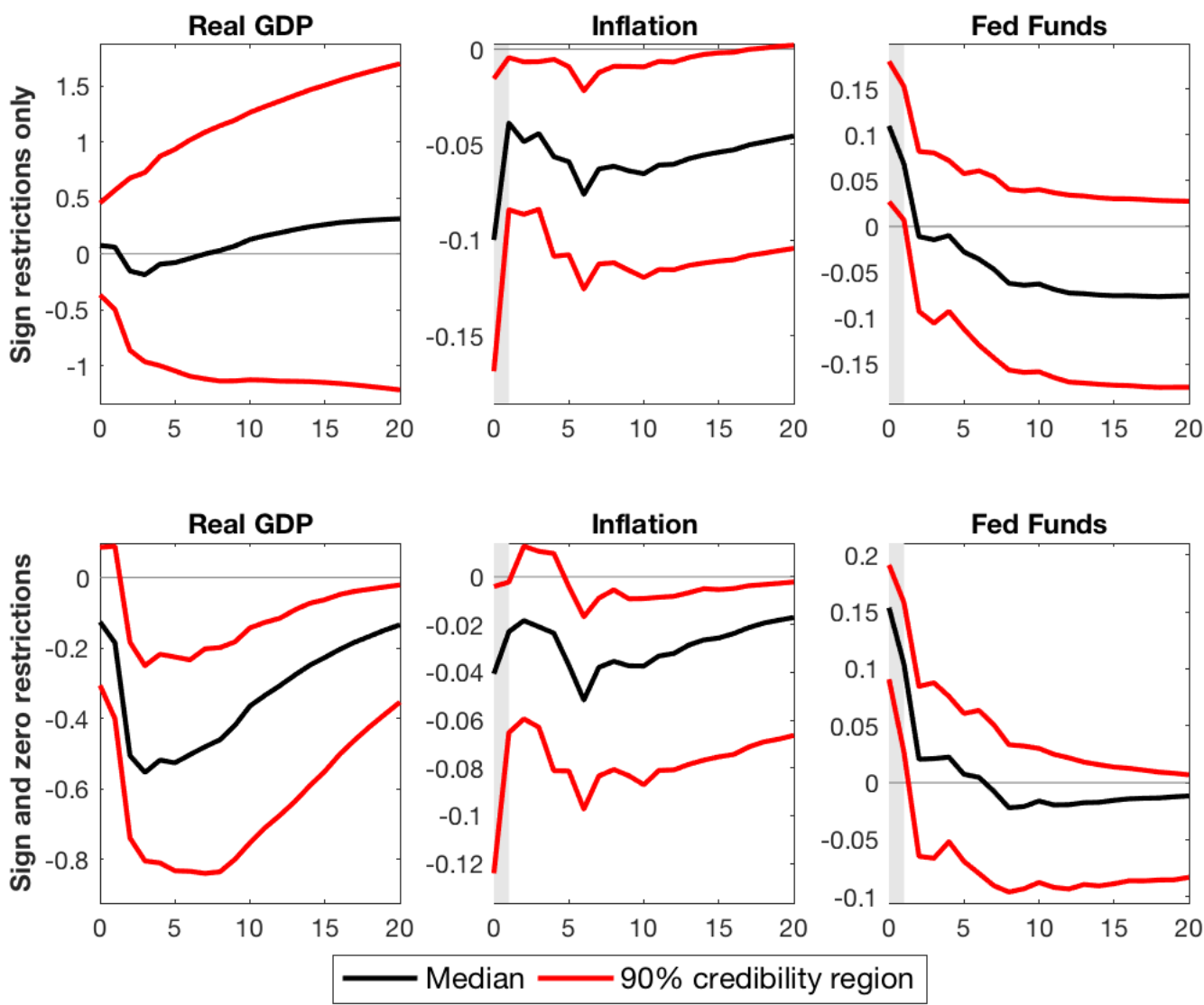

Figure B.3.2: Identified IRF's of a $\sigma_{i}$ contractionary monetary shock for the "sign restriction only" approach (first row) and the identification setup incorporating the neutrality restrictions (second row). Estimated 3-variable VAR with US data. Sample: 1978Q1 - 2004 Q4. 
C

\section{Appendix to Chapter 3}

\section{C.1 \\ Placebo regressions}

Table C.1.1: Linear probability model estimates of equation 3-1. Dependent

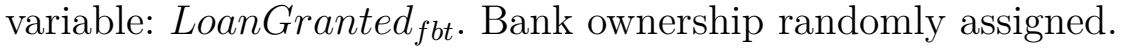

\begin{tabular}{|c|c|c|c|c|}
\hline Variables & $(1)$ & $(2)$ & $(3)$ & $(4)$ \\
\hline $\mathcal{F}_{b t}$ & 0.001 & & & \\
\hline \multirow{3}{*}{$\frac{\mathcal{F}_{b t}}{\widehat{N}} \cdot S M E_{f}$} & $(0.002)$ & & & \\
\hline & 0.001 & 0.002 & 0.003 & 0.002 \\
\hline & $(0.002)$ & $(0.001)$ & $(0.002)$ & $(0.002)$ \\
\hline PreviousLoan $_{f t}$ & 0.003 & 0.003 & & \\
\hline & $(0.002)$ & $(0.002)$ & & \\
\hline PreviousLoan $_{f t} \bullet S M E_{f}$ & $-0.035^{* * *}$ & $-0.031^{* * *}$ & & \\
\hline & $(0.003)$ & $(0.003)$ & & \\
\hline $\mathcal{F}_{b t} \bullet$ PreviousLoan $_{f t}$ & -0.004 & -0.003 & 0.003 & 0.000 \\
\hline & $(0.004)$ & $(0.003)$ & $(0.004)$ & $(0.004)$ \\
\hline $\mathcal{F}_{b t} \bullet$ PreviousLoan $_{f t} \bullet S M E_{f}$ & 0.006 & 0.004 & 0.000 & 0.003 \\
\hline & $(0.004)$ & $(0.004)$ & $(0.007)$ & $(0.007)$ \\
\hline Bank controls: & Yes & Yes & Yes & - \\
\hline \multicolumn{5}{|l|}{ Fixed effects: } \\
\hline Month & Yes & Yes & - & - \\
\hline Bank & No & Yes & Yes & - \\
\hline Firm & Yes & Yes & - & - \\
\hline Firm-month & No & No & Yes & Yes \\
\hline Bank-month & No & No & No & Yes \\
\hline Observations & 378,558 & 378,558 & 101,067 & 101,067 \\
\hline
\end{tabular}

Note: Standard errors in parentheses, clustered at the bank-month level. ${ }^{*} p<0.1,{ }^{* *} p<0.05$, *** $p<0.01$. Columns (1) and (2) present 53,497 firm fixed effects. Columns (3) and (4) present 42,082 firm-month fixed effects. 
Table C.1.2: Linear probability model estimates of equation 3-2. Dependent variable: LoanGranted Lbt $_{\text {f }}$ Bank ownership randomly assigned.

\begin{tabular}{|c|c|c|c|c|}
\hline Variables & $(1)$ & $(2)$ & $(3)$ & (4) \\
\hline \multirow[t]{2}{*}{$\mathcal{F}_{b t}$} & 0.001 & & & \\
\hline & $(0.002)$ & & & \\
\hline \multirow[t]{2}{*}{$\mathcal{F}_{b t} \bullet S M E_{f}$} & 0.001 & 0.002 & 0.002 & 0.001 \\
\hline & $(0.002)$ & $(0.001)$ & $(0.002)$ & $(0.002)$ \\
\hline \multirow[t]{2}{*}{ PreviousLoan_PDft } & $0.005^{* *}$ & $0.005^{* *}$ & & \\
\hline & $(0.003)$ & $(0.003)$ & & \\
\hline \multirow[t]{2}{*}{$\mathcal{F}_{b t} \bullet$ PreviousLoan_PD $D_{f t}$} & $-0.008^{* *}$ & $-0.007^{*}$ & 0.000 & -0.004 \\
\hline & $(0.004)$ & $(0.004)$ & $(0.005)$ & $(0.005)$ \\
\hline \multirow[t]{2}{*}{ PreviousLoan_F $F_{f t}$} & -0.003 & -0.002 & & \\
\hline & $(0.004)$ & $(0.004)$ & & \\
\hline \multirow[t]{2}{*}{$\mathcal{F}_{b t} \bullet$ PreviousLoan_F $F_{f t}$} & 0.007 & 0.006 & 0.005 & 0.007 \\
\hline & $(0.005)$ & $(0.005)$ & $(0.006)$ & $(0.006)$ \\
\hline \multirow[t]{2}{*}{ PreviousLoan_PD $D_{f t} \bullet S M E_{f}$} & $-0.035^{* * *}$ & $-0.030^{* * *}$ & & \\
\hline & $(0.004)$ & $(0.004)$ & & \\
\hline \multirow[t]{2}{*}{ PreviousLoan_F $F_{f t} \bullet S M E_{f}$} & $-0.019^{* * *}$ & $-0.021^{* * *}$ & & \\
\hline & $(0.005)$ & $(0.005)$ & & \\
\hline \multirow[t]{2}{*}{$\mathcal{F}_{b t} \bullet$ PreviousLoan_PD $f t \bullet S M E_{f}$} & $0.010^{* *}$ & $0.008^{*}$ & 0.004 & 0.009 \\
\hline & $(0.005)$ & $(0.005)$ & $(0.007)$ & $(0.007)$ \\
\hline \multirow[t]{2}{*}{$\mathcal{F}_{b t} \bullet$ PreviousLoan_F $F_{f t} \bullet S M E_{f}$} & -0.005 & -0.005 & 0.005 & -0.001 \\
\hline & $(0.007)$ & $(0.007)$ & $(0.010)$ & $(0.011)$ \\
\hline Bank controls: & Yes & Yes & Yes & - \\
\hline \multicolumn{5}{|l|}{ Fixed effects: } \\
\hline Month & Yes & Yes & - & - \\
\hline Bank & No & Yes & Yes & - \\
\hline Firm & Yes & Yes & - & - \\
\hline Firm-month & No & No & Yes & Yes \\
\hline Bank-month & No & No & No & Yes \\
\hline Observations & 378,558 & 378,558 & 101,067 & 101,067 \\
\hline
\end{tabular}

Note: Standard errors in parentheses, clustered at the bank-month level. ${ }^{*} p<0.1,{ }^{* *} p<0.05$, ${ }^{* * *} p<0.01$. Columns (1) and (2) present 53,497 firm fixed effects. Columns (3) and (4) present 42,082 firm-month fixed effects. 


\section{2}

\section{Investigating the importance of loan type complementarities with simu- lated data}

In what follows, we give an example with simulated data that shows our findings aren't necessarily a consequence of intricate relations between market shares of loan types by bank ownership and complementarities among loan types. For that, we define a Data Generating Process (DGP) that replicates important moments of the true data and condition loan approvals only on bank ownership types. This DGP is built to mimic important features of our data. All data moments are calculated following loan applications. To simplify the exercise, we don't discriminate between different types of firm size.

Tables C.2.3 to C.2.5 present true data moments, along moments calculated with a single artificial sample of 600,000 loan applications. Every quarter, one out of 40,000 firms applies for a loan in a foreign or a domestic bank. Roughly one fourth of loan applications are made to foreign banks, as shown in table C.2.3. Loan approval probabilities are conditional only on bank ownership type. Table ?? presents theses probabilities. Conditional on a loan being approved, for firms that borrowed in the last quarter, loan type is defined to replicate the unconditional transition matrix presented in table C.2.4. This matrix is similar to the ones presented in table 3.6, but in this case probabilities are unconditional to bank ownership, firm size and previous lenders ownership type. For firms that didn't borrow in the last quarter, loan type is defined to replicate market shares of loan types by bank ownership, displayed in table C.2.5. The schematic representation of the DGP is given in figure C.2.1. ${ }^{1}$

Table C.2.3: Loan application share by bank ownership

\begin{tabular}{lccccc}
\hline \hline & \multicolumn{2}{c}{ True data } & & \multicolumn{2}{c}{ Artificial sample } \\
\cline { 2 - 3 } \cline { 5 - 6 } & Foreign & $\begin{array}{c}\text { Private } \\
\text { Domestic }\end{array}$ & & Foreign & $\begin{array}{c}\text { Private } \\
\text { Domestic }\end{array}$ \\
$\begin{array}{l}\text { Loan application } \\
\text { share }\end{array}$ & 0.272 & 0.728 & & 0.272 & 0.728 \\
\hline \hline
\end{tabular}

\footnotetext{
${ }^{1}$ In real data, firms differ in size, firms can apply for more than one loan within the same period and more than two different types of loans exist. Nevertheless, since loan applications are independent in the DGP used for our simulation, introducing these complications wouldn't change our conclusions.
} 


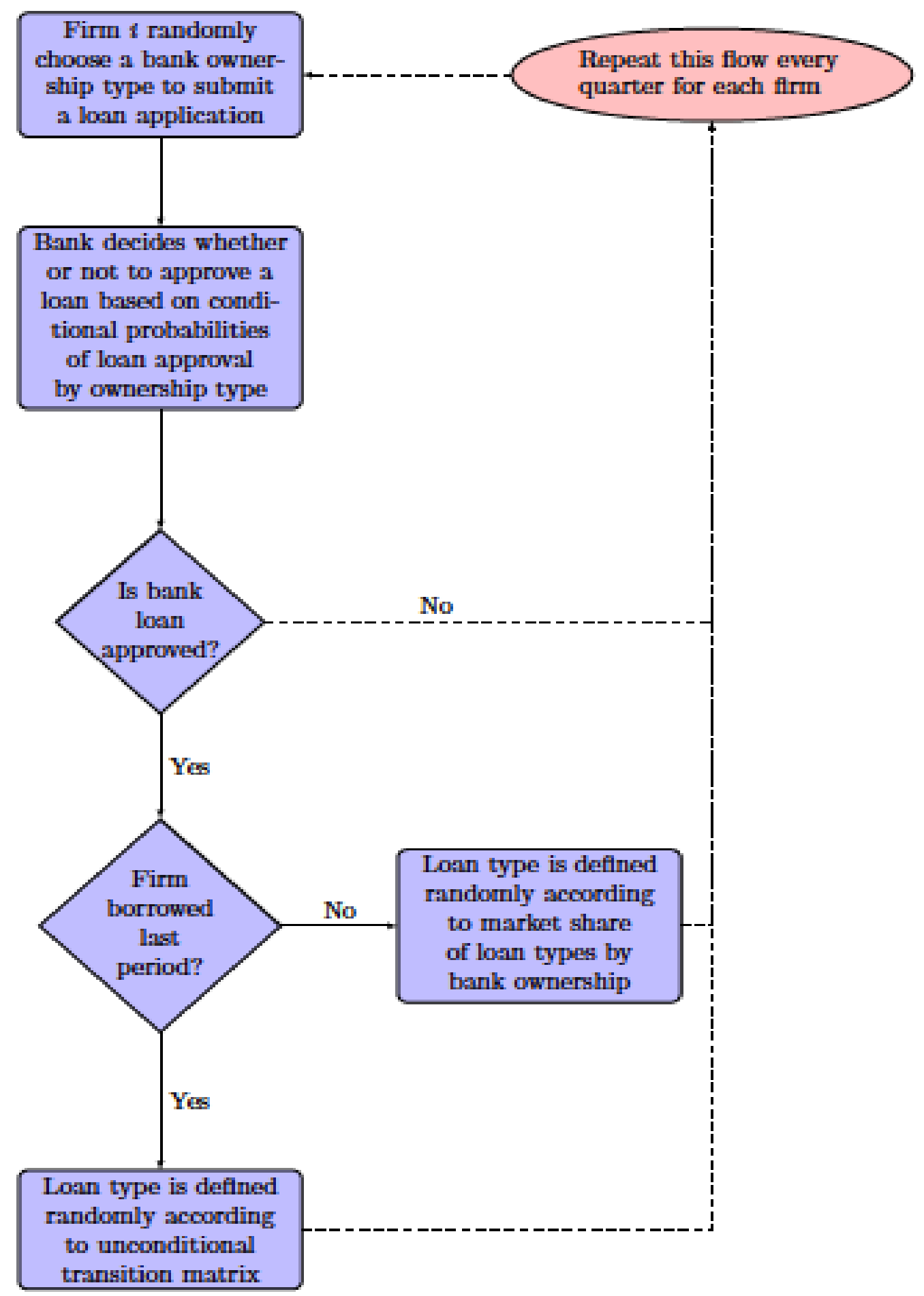

Figure C.2.1: Schematic representation of DGP. 
Table C.2.4: Transition matrices across loan types calculated for all loans granted up to 3 months after information requests for firms that borrowed previously from other lenders. Matrix entry $(i, j)$ identifies the share of firms that took loans of type $i$ in $[t-1, t-3]$ that moved to loan type $j$ in $[t, t+3]$.

\begin{tabular}{|c|c|c|c|c|c|}
\hline \multicolumn{3}{|c|}{ True data } & \multicolumn{3}{|c|}{ Artificial data } \\
\hline & $\begin{array}{l}\text { short- } \\
\text { term }\end{array}$ & other & & $\begin{array}{l}\text { short- } \\
\text { term }\end{array}$ & other \\
\hline $\begin{array}{l}\text { short } \\
\text { term }\end{array}$ & $83 \%$ & $17 \%$ & $\begin{array}{l}\text { short- } \\
\text { term }\end{array}$ & $82 \%$ & $18 \%$ \\
\hline other & $52 \%$ & $48 \%$ & other & $53 \%$ & $47 \%$ \\
\hline
\end{tabular}

Table C.2.5: Market share of operations by bank ownership and loan type

\begin{tabular}{lccccc}
\hline \hline & \multicolumn{2}{c}{ True data } & & \multicolumn{2}{c}{ Artificial data } \\
\cline { 2 - 3 } \cline { 5 - 6 } & $\begin{array}{c}\text { short- } \\
\text { term }\end{array}$ & Other & & $\begin{array}{c}\text { Short } \\
\text { term }\end{array}$ & Other \\
Foreign & $59 \%$ & $41 \%$ & & $60 \%$ & $40 \%$ \\
$\begin{array}{l}\text { Private } \\
\text { Domestic }\end{array}$ & $89 \%$ & $11 \%$ & & $88 \%$ & $12 \%$ \\
\hline \hline
\end{tabular}

As can be seen, the artificial sample replicates data moments quiet well. Also, as expected, OLS regressions of equations 3-1 and 3-2 using the artificial sample don't result in statistically significant coefficients for the interaction between $\mathcal{F}$ and (PreviousLoan, PreviousLoan_PD,PreviousLoan_F). These estimates are presented in table C.2.6, together with real data estimates. The take out from this exercise is that the combination of different market shares of loan types by bank ownership and the existence of a transition matrix seem in the real data don't necessarily result in the findings of this paper. Our exercise is an example of that. 
Table C.2.6: Regression estimates with real and artificial data. Dependent variable: LoanGranted fbt $_{\text {f }}$

\begin{tabular}{|c|c|c|c|c|}
\hline & \multicolumn{2}{|c|}{ True data } & \multicolumn{2}{|c|}{ Artificial data } \\
\hline & (1) & $(2)$ & $(3)$ & (4) \\
\hline \multirow[t]{2}{*}{$\mathcal{F}_{b t}$} & 0.004 & 0.004 & $0.019^{* * *}$ & $0.019^{* * *}$ \\
\hline & $(0.003)$ & $(0.003)$ & $(0.001)$ & $(0.001)$ \\
\hline \multirow[t]{2}{*}{ PreviousLoan $_{f t}$} & $-0.027^{* * *}$ & & -0.001 & \\
\hline & $(0.002)$ & & $(0.002)$ & \\
\hline \multirow{2}{*}{$\mathcal{F}_{b t} \bullet$ PreviousLoan $_{f t}$} & $0.007^{* * *}$ & & -0.001 & \\
\hline & $(0.003)$ & & $(0.003)$ & \\
\hline \multirow[t]{2}{*}{ PreviousLoan_PD $f t$} & & $-0.024^{* * *}$ & & -0.001 \\
\hline & & $(0.002)$ & & $(0.002)$ \\
\hline \multirow[t]{2}{*}{$\mathcal{F}_{b t} \bullet$ PreviousLoan_PD $f t$} & & $0.005^{*}$ & & -0.000 \\
\hline & & $(0.003)$ & & $(0.003)$ \\
\hline \multirow[t]{2}{*}{ PreviousLoan_F $F_{f t}$} & & $-0.017^{* * *}$ & & -0.002 \\
\hline & & $(0.003)$ & & $(0.003)$ \\
\hline \multirow{2}{*}{$\mathcal{F}_{b t} \bullet$ PreviousLoan_ $F_{f t}$} & & $0.010^{* *}$ & & -0.002 \\
\hline & & $(0.004)$ & & $(0.005)$ \\
\hline \multirow[t]{2}{*}{ Constant } & & & $0.099^{* * *}$ & $0.099^{* * *}$ \\
\hline & & & $(0.000)$ & $(0.000)$ \\
\hline Bank controls: & Yes & Yes & - & - \\
\hline \multicolumn{5}{|l|}{ Fixed effects: } \\
\hline Month & Yes & Yes & - & - \\
\hline Bank & No & No & - & - \\
\hline Firm & Yes & Yes & - & - \\
\hline Firm-month & No & No & - & - \\
\hline Bank-month & No & No & - & - \\
\hline Observations & 378,558 & 378,558 & 600,000 & 600,000 \\
\hline
\end{tabular}

Note:

${ }^{*} \mathrm{p}<0.1 ;{ }^{* *} \mathrm{p}<0.05 ;{ }^{* * *} \mathrm{p}<0.01$ 